Aus der Klinik für Kardiologie und Pneumologie

(Prof. Dr. med. G. Hasenfuß)

der Medizinischen Fakultät der Universität Göttingen

\title{
Rekrutierung von Immunzellen in das perivaskuläre Fettgewebe bei Adipositas - Bedeutung von Leptin
}

\author{
INAUGURAL - DISSERTATION \\ zur Erlangung des Doktorgrades \\ der Medizinischen Fakultät der \\ Georg-August-Universität zu Göttingen
}

vorgelegt von

Sebastian Herzberg

aus

Duderstadt

Göttingen 2017 
Dekan:

Referent/in:

Ko-Referent/in:
Prof. Dr. rer. nat. H. K. Kroemer

Prof. Dr. med. K. Schäfer

Prof. Dr. med. J. Wilting

Datum der mündlichen Prüfung: 14. Juni 2018 
Publiziert in Clinical Research Cardiology April 2011:

Schroeter M, Herzberg S, Jerchel I, Schäfer K (2011): Bedeutung von Integrin $\alpha 4$ für die Rekrutierung von Immunzellen in das perivaskuläre Fettgewebe bei Adipositas. Clin Res Cardiol 100, Suppl 1, V781

Publiziert in Arteriosclerosis Thrombosis Vascular Biology März 2013:

Schroeter MR, Eschholz N, Herzberg S, Jerchel I, Leifheit-Nestler M, Czepluch FS, Chalikias G, Konstantinides S, Schäfer K (2013): Leptin-Dependent and Leptin-Independent Paracrine Effects of Perivascular Adipose Tissue on Neointima Formation. Arterioscler Thromb Vasc Biol $\underline{33}$, 980- 


\section{INHALTSVERZEICHNIS}

Abkürzungsverzeichnis .............................................................................................................................V

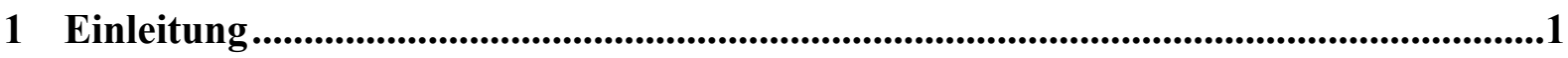

1.1 Atherosklerose .......................................................................................................................... 1

1.2 Adipositas als kardiovaskulärer Risikofaktor ................................................................................ 2

1.2.1 Ausbildung eines präinflammatorischen Status durch Fettgewebshypertrophie und

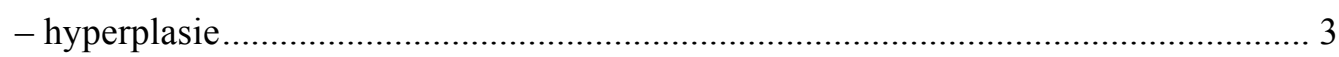

1.3 Bedeutung des perivaskulären Fettgewebes für die Atherosklerose .................................... 4

1.4 Mechanismen der Immunzellrekrutierung und Fettgewebsinflammation ............................... 5

1.4.1 Gesteigerte Expression von Zelladhäsionsmolekülen auf aktiviertem Endothel .......... 5

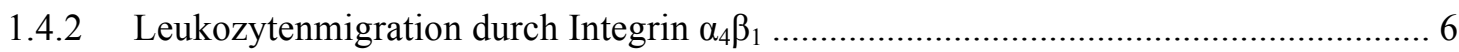

1.4.3 Leptin-Einfluss auf die angeborene und erworbene Immunantwort ............................ 6

1.4.4 Leptinabhängige integrinvermittelte Rekrutierung von Endothelvorläuferzellen in

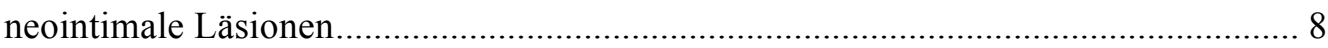

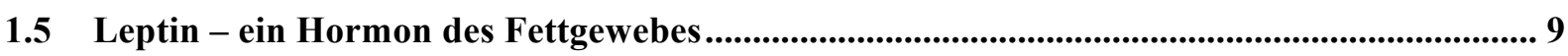

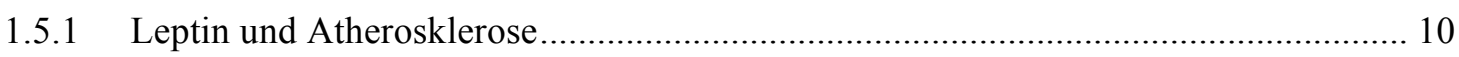

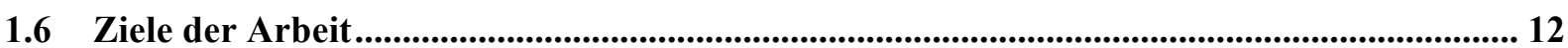

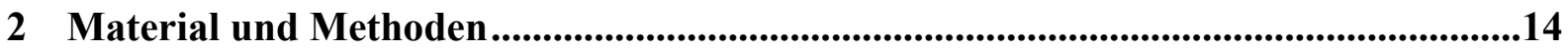

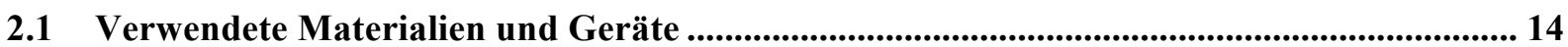

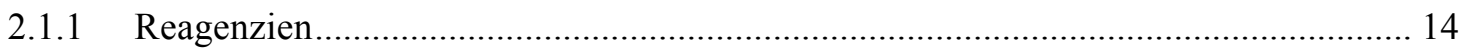

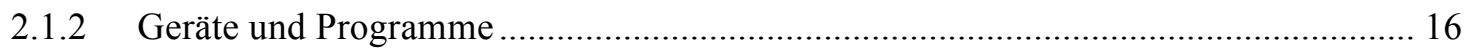

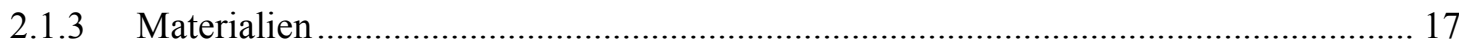

2.1.4 Puffer und Lösungen für Gewebefärbungen........................................................... 18

2.2 Untersuchungen im Tiermodell.................................................................................................... 19

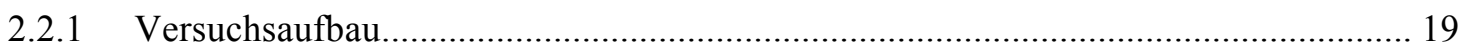

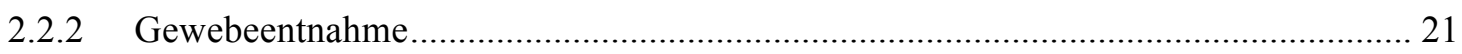

2.2.3 Histologische Analyse der Mausaorten ………................................................... 21

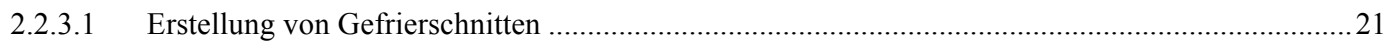

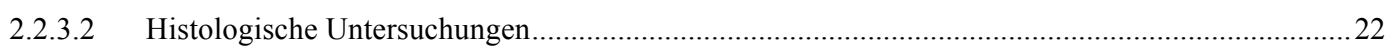

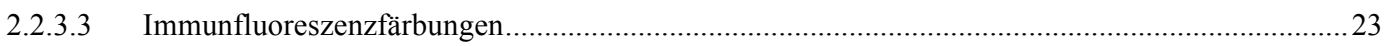

2.2.4 Genehmigung der im Rahmen der Studie durchgeführten Tierversuche ..................... 26

2.3 Untersuchungen an humanem Probenmaterial..................................................................... 27

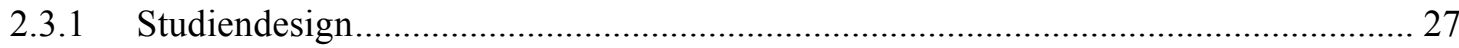

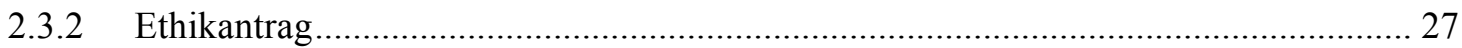

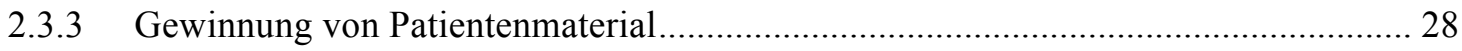

2.3.4 Erfassung demografischer und laborchemischer Parameter ........................................ 29 
2.4 Durchflusszytometrie von Blut und Fettgewebe........................................................................ 29

2.4.1 Allgemeines Protokoll zur Aufbereitung des Fettgewebes ......................................... 29

2.4.2 Verwendete Lösungen und Puffer …………............................................................. 30

2.4.3 Inkubation und Analyse der Proben ....................................................................... 30 31

2.4.4 Verwendete Antikörper im murinen Modell ................................................................ 31 32

2.4.5 Verwendete Antikörper im humanen Modell ......................................................... 32

2.5 RNA-Isolierung und Analyse mittels Reverser Transkriptase PCR ....................................... 33

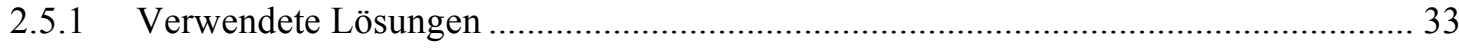

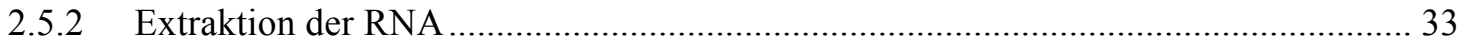

2.5.3 Konzentrationsbestimmung der RNA-Proben.............................................................. 34

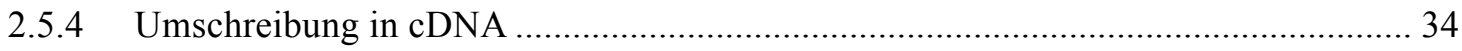

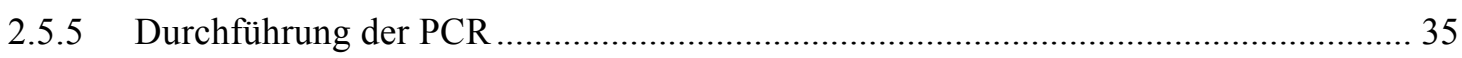

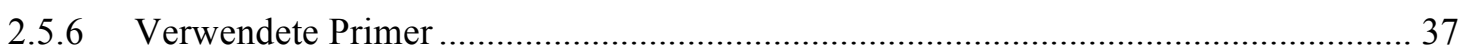

2.6 Isolation und Analyse von Proteinen - Western Blot ........................................................... 37

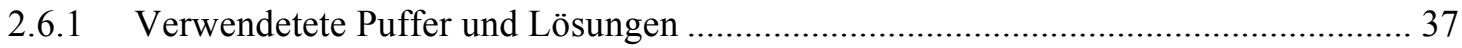

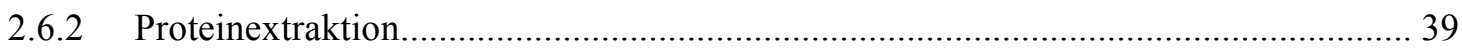

2.6.3 Bestimmung der Proteinkonzentration ................................................................... 39

2.6.4 SDS-Polyacrylamid-Gelektrophorese und Western Blot .............................................. 40

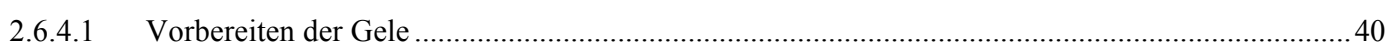

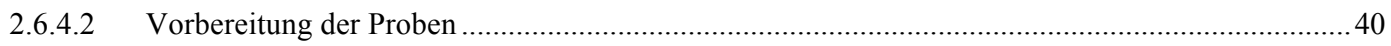

2.6.4.3 Auftragen der Proben auf die Gele und Elektrophorese .............................................................. 41

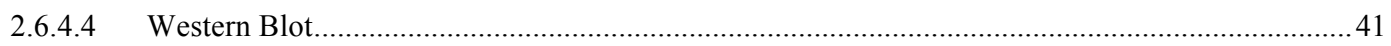

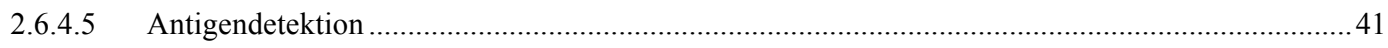

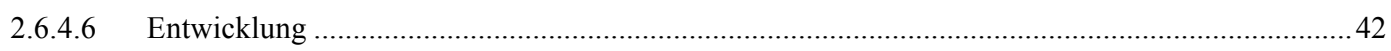

2.6.4.7 Verwendete Antikörper und Verdünnungen ........................................................................... 42

2.6.5 Enzyme-linked Immunosorbent Assay (ELISA) - Nachweis von Leptin im Serum

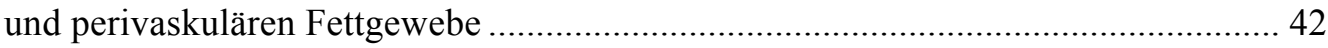

2.6.5.1 Verwendete Lösungen und Verdünnungen muriner ELISA …......................................................43

2.6.5.2 Verwendete Lösungen und Verdünnungen humaner ELISA ........................................................ 43

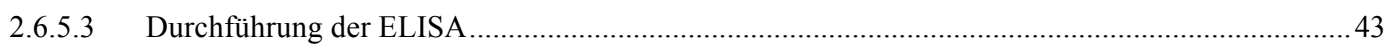

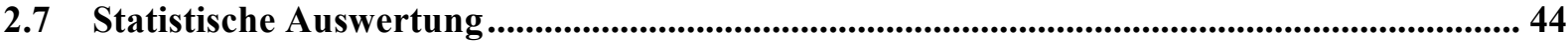

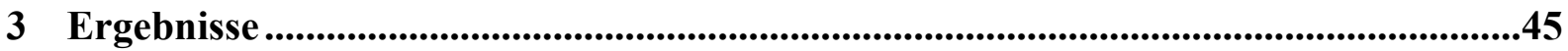

\subsection{Auswirkungen von Übergewicht auf die perivaskuläre Fettgewebs-inflammation im}

Tiermodell ..................................................................................................................................................... 45

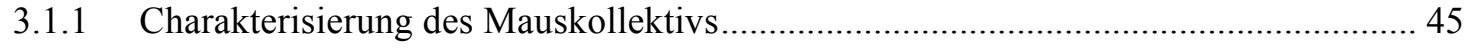

3.1.1.1 Körpergewicht und Gewicht des viszeralen Fettdepots .................................................................45

3.1.1.2 Messungen der Leptinspiegel im Serum .................................................................................. 46 
3.1.2 Zunahme des perivaskulären Fettgewebe und der perivaskulären Leptinexpression

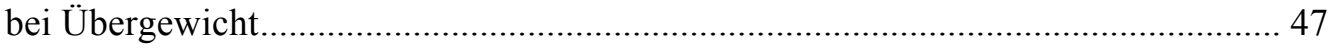

3.1.3 Einfluß von Übergewicht auf die Zahl zirkulierender Integrin $\alpha_{4}$-positiver Zellen .... 48

3.1.4 Anstieg der Integrin $\alpha_{4}$ - und Integrin $\alpha_{4} /$ Leptinrezeptor-doppeltpositiven Zellen im perivaskulären Fettgewebe bei Übergewicht

3.1.5 Untersuchung der Expression potentieller Liganden von Integrin $\alpha_{4}$ im perivaskulären Fettgewebe: VCAM-1 und Fibronektin

3.1.6 Untersuchungen zur Anzahl und Differenzierung der Leukozyten im perivaskulären Fettgewebe unter Einfluss von Hochfettdiät...................................... 52

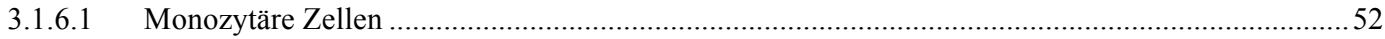

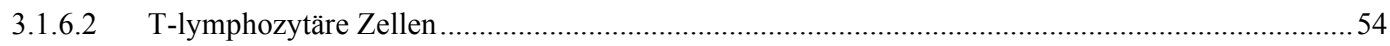

3.1.7 Untersuchung der Abhängigkeit der perivaskulären Inflammation von Übergewicht

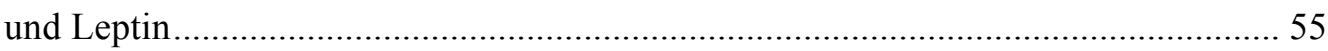

3.1.7.1 Wirkung von Übergewicht auf die viszerale Fettgewebsinflammation mit und ohne Leptin .........56

3.2 Humane Studie 62

3.2.1 Klinische und laborchemische Charakterisierung des Patientenkollektivs ................. 62

3.2.2 Charakterisierung der zirkulierenden Leukozyten....................................................... 65

3.2.3 Charakterisierung der Leukozyten im perikardialen Fettgewebe ................................ 67

3.2.4 Untersuchng von Integrin $\alpha_{4}$-positiven Leukozyten im perikardialen Fettgewebe ..... 69

4 Diskussion ...............................................................................................................................71

4.1 Einfluss von Adipositas auf die perivaskuläre Fettgewebsinflammation.............................. 74

4.1.1 Zunahme der Leptinexpression sowohl im Serum als auch im perivaskulären

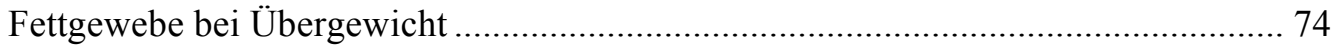

4.1.2 Rückgang der zirkulierenden Integrin $\alpha_{4}$-positiven Leukozyten bei gleich-zeitigem Anstieg der Integrin $\alpha_{4}$ - und ObR-Expression der residenten Fettgewebsleukozyten

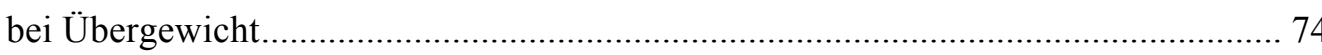

4.1.3 Hochregulierung der Adhäsionsmoleküle für Integrin $\alpha_{4}$ in der Gefäßwand bei Übergewicht

4.1.4 Gesteigerte perivaskuläre Inflammation bei Übergewicht durch Einwanderung mononukleärer Leukozyten .

4.1.5 Perivaskuläre Inflammation unabhängig vom Leptinspiegel bei Übergewicht............ 78

4.1.6 Leptin-abhängige viszerale Fettgewebsinflammation bei übergewichtigen Mäusen.. 79

4.2 Einfluss von Adipositas und KHK auf die perivaskuläre Inflammation beim Menschen... 81

4.2.1 Vermehrte Rekrutierung Integrin $\alpha_{4}$-positiver Immunzellen ins perivaskuläre

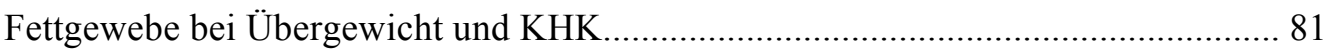

4.2.2 Keine Unterschiede in der Fettgewebsinflammation bei humaner Adipositas............ 82

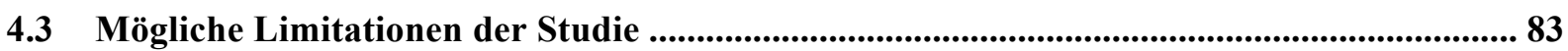

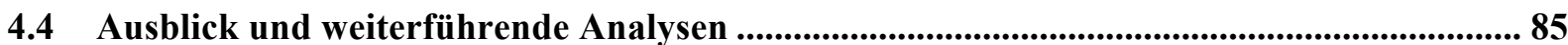




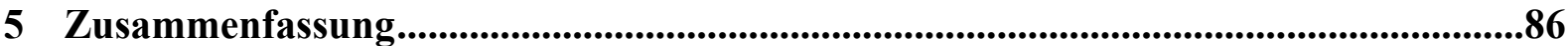

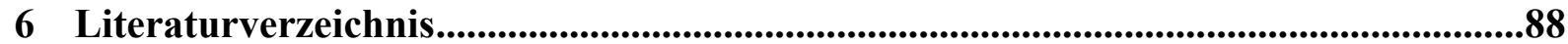




\section{ABKÜRZUNGSVERZEICHNIS}

\begin{tabular}{|c|c|}
\hline $\mathrm{ACE}$ & Angiotensin converting enzyme \\
\hline Aqua dest. & destilliertes Wasser \\
\hline APC & Allophycocyanin \\
\hline ApoE & Apolipoprotein E \\
\hline ASS & Acetylsalicylsäure \\
\hline AT1 & Angiotensin-II-Rezeptor Subtyp 1 \\
\hline $\mathrm{BCA}$ & bicinchoninic acid \\
\hline BMI & Body-Mass-Index \\
\hline BSA & bovines Serumalbumin \\
\hline $\mathrm{CD}$ & cluster of differentiation \\
\hline cDNA & copy Desoxyribonukleinsäure \\
\hline cGMP & zyklisches Guanosinmonophosphat \\
\hline CRP & C-reaktives Protein \\
\hline DAPI & 4',6-Diamidino-2-phenylindol \\
\hline DEGS & Studie zur Gesundheit Erwachsener in Deutschland \\
\hline DEPC & Diethylpyrocarbonat \\
\hline DNA & Desoxyribonukleinsäure \\
\hline $\mathrm{EF}$ & Ejektionsfraktion \\
\hline EKG & Elektrokardiogramm \\
\hline ELAM-1 & endotheliales Leukozyten-Zelladhäsionsmolekül-1 \\
\hline ELISA & enzymgekoppelter Immunadsorptionstest \\
\hline EPC & endotheliale Progenitorzellen \\
\hline E-Selektin & endotheliales Selektin \\
\hline EtOH & Ethanol \\
\hline FACS & fluorescence activated cell sorting \\
\hline FITC & fluorescein isothiocyanat \\
\hline FSC & forward scatter \\
\hline GAPDH & Glyzerinaldehyd-3-Phosphat-Dehydrogenase \\
\hline GFP & green fluorescent protein \\
\hline GFR & glomeruläre Filtrationsrate \\
\hline $\mathrm{Hb}$ & Hämoglobin \\
\hline HCAEC & humane koronar-arterielle Endothelzellen \\
\hline $\mathrm{HF}$ & Herzfrequenz \\
\hline HFD & Hochfettdiät \\
\hline HRP & Horseraddish Peroxidase \\
\hline hsCRP & high-sensitive CRP \\
\hline HUVEC & humane Nabelschnurvenen-Endothelzellen \\
\hline ICAM-1 & intercellular adhesion molecule 1 \\
\hline
\end{tabular}




\begin{tabular}{|c|c|}
\hline IFN- $\gamma$ & Interferon $\gamma$ \\
\hline IL & Interleukin \\
\hline iNOS & induzierbare NO-Synthase \\
\hline KHK & koronare Herzkrankheit \\
\hline LDL & low density lipoprotein \\
\hline LPS & Lipopolysaccharid \\
\hline MCP-1 & macrophage chemoattractant protein 1 \\
\hline mRNA & Messenger RNA \\
\hline MTC & Masson-Trichrom-Färbung \\
\hline $\mathrm{NaOH}$ & Natronlauge \\
\hline $\mathrm{NC}$ & Normalfutter \\
\hline NGS & normales Ziegenserum \\
\hline $\mathrm{NF} \kappa \mathrm{B}$ & nuclear factor $\kappa B$ \\
\hline NK-Zellen & natürliche Killerzellen \\
\hline NO & Stickstoffmonoxid \\
\hline ns & nicht signifikant \\
\hline $\mathrm{n} / \mathrm{v}$ & nicht verfügbar \\
\hline ObR & Leptin-Rezeptor \\
\hline pAVK & periphere arterielle Verschlusskrankheit \\
\hline PBS & phosphatgepufferte Salzlösung, $1 \mathrm{X}$ in Aqua dest. \\
\hline PCR & Polymerasekettenreaktion \\
\hline PE & Phycoerythrin \\
\hline PerCP/Cy5.5 & Peridinin-Chlorophyll-Protein Complex/Cyanin 5.5 \\
\hline PFA & Paraformaldehyd \\
\hline PVAT & perivaskuläres Fettgewebe \\
\hline RNA & Ribonukleinsäure \\
\hline RT & Raumtemperatur \\
\hline SDS & Natriumdodecylsulfat \\
\hline SEM & Standardfehler \\
\hline $\mathrm{SSC}$ & sideward scatter \\
\hline STAT & signal transducers and activators of transcription \\
\hline TAH & Thrombozytenaggregationshemmer \\
\hline TBS & Tris-gepufferte Kochsalzlösung \\
\hline TEMED & Tetramethylethylendiamin \\
\hline TG & Triglyzeride \\
\hline TNF- $\alpha$ & Tumornekrosefaktor-alpha \\
\hline UMG & Universitätsmedizin Göttingen \\
\hline VAT & viszerales Fettgewebe \\
\hline VCAM-1 & vascular cell adhesion molecule 1 \\
\hline VEGF & vascular endothelial growth factor \\
\hline
\end{tabular}




\begin{tabular}{ll}
\hline VLA-4 & very late antigen 4 \\
\hline vWF & von-Willebrand-Faktor \\
\hline WHO & Weltgesundheitsorganisation \\
\hline WT & Wildtyp \\
\hline ZTE & Zentrale Tierexperimentelle Einrichtung \\
\hline
\end{tabular}




\section{Einleitung}

Kardiovaskuläre Erkrankungen haben eine weltweit sehr hohe Prävalenz und sind nach Angaben der Weltgesundheitsorganisation (WHO) die häufigste Todesursache. Eine aktuelle Studie zur Gesundheit Erwachsener in Deutschland (DEGS) ergab eine Lebenszeitprävalenz bei den 40- bis 79-Jährigen von 9,3 \% (Gosswald et al. 2013) und stimmt hierin überein mit den Daten der American Heart Association aus dem Jahre 2012 (Go et al. 2014). 2012 verstarben laut Statistischem Bundesamt in Deutschland 349.217 Menschen (40,2 \% aller Todesfälle) an den Folgen einer Erkrankung des Herz-Kreislauf-Systems (Statistisches Bundesamt 2013), davon 14,2\% an einer durch Atherosklerose bedingten chronischischämischen Herzerkrankung oder einem akuten Myokardinfarkt und weitere 2,2 \% an den Folgen einer Atherosklerose der peripheren Gefäße.

\subsection{Atherosklerose}

Die Atherosklerose ist ein inflammatorischer Prozess der Gefäßintima, der einen progressiven Verlauf zeigt und die Ursache von koronaren sowie zerebralen Gefäßverengungen bzw. verschlüssen ist (Fuster et al. 1992). Ein erster wichtiger Schritt in der Entstehung der (peri-) vaskulären Inflammation ist die Transmigration von Leukozyten aus dem Blut in die Gefäßwand (Libby et al. 2009).

Hierzu werden die Endothelzellen von leicht oxidiertem LDL dazu angeregt, zum einen Adhäsionsmoleküle auszubilden und zum anderen chemotaktische Proteine und Wachstumsfaktoren auszuschütten, um Monozyten in die Gefäßwand zu rekrutieren.

Die wichtigsten Zelladhäsionsmoleküle für die Rektrutierung von Leukozyten sind ICAM-1, P-Selektin, E-Selektin, PCAM-1 und auch VCAM-1.

Die Transmigration der Leukozyten erfolgt dann über Adhäsionsmoleküle auf der Zelloberfläche, darunter Integrin $\alpha_{4} \beta_{1}$, welches über Bindung an das auf aktivierten Endothelzellen vermehrt exprimierte Adhäsionsmolekül VCAM-1 zu einer Anheftung der Leukozyten an die Gefäßwand führt (Lusis 2000; Shih et al. 1999) Abb. 1.1). In frühen Läsionen finden sich subendothelial Makrophagen, die durch Aufnahme von LDLCholesterin zu so genannten Schaumzellen transformieren. Diese Läsionen können bereits im 
ersten Lebensjahrzehnt in der Aorta, im zweiten in den Koronargefäßen sowie in der dritten oder vierten Lebensdekade in den Karotiden als fatty streaks nachgeweisen werden (Lusis 2000; Stary et al. 1995). In der Folge kommt es zu einem Fortschreiten der Läsionen durch Anhäufung von nekrotischem Material, welches aus dem Untergang der Schaumzellen stammt, sowie zur vermehrten Einwanderung von glatten Muskelzellen aus der Gefäßmedia. Es entsteht eine fibröse Plaque, die in der Folge zu einem akuten Gefäßverschluss durch Bildung eines Thrombus führen und je nach Lokalisation einen Myokardinfarkt oder einen Apoplex zur Folge haben kann (Stary et al. 1995).

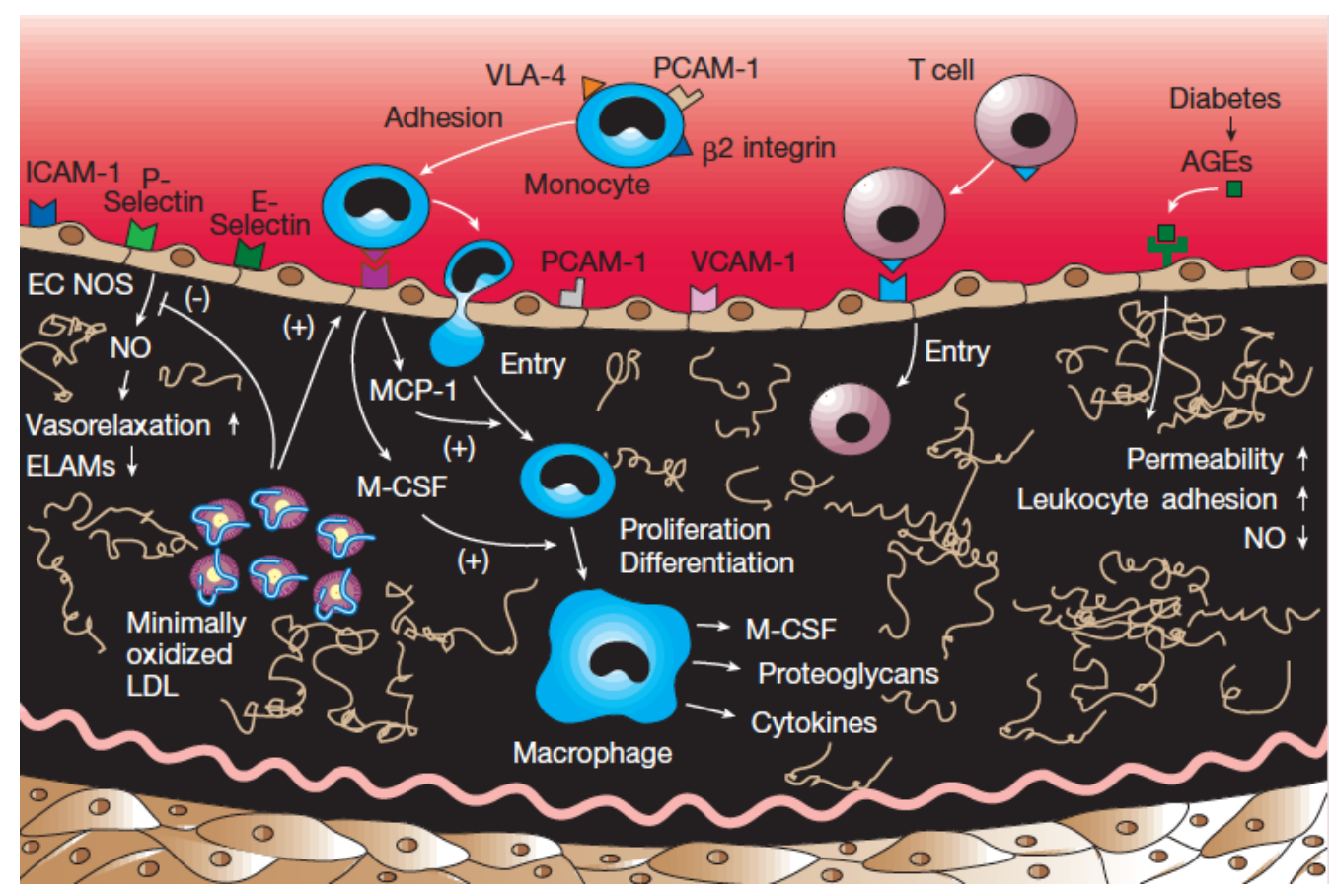

Abb. 1.1 Mechanismus der Leukozytenadhäsion und -transmigration. Abbildung aus Lusis (2000)

\subsection{Adipositas als kardiovaskulärer Risikofaktor}

Adipositas und Übergewicht zählen in den Industrienationen $\mathrm{zu}$ den wichtigsten Gesundheitsproblemen, und auch in den Schwellen- und Entwicklungsländern nimmt die Prävalenz von Übergewicht zu. Krankhafte Störungen des Körpergewichts sind über den Body-Mass-Index (BMI) definiert: Untergewicht (BMI $<17,5 \mathrm{~kg} / \mathrm{m}^{2}$ ), Normalgewicht (BMI $\left.18-25 \mathrm{~kg} / \mathrm{m}^{2}\right)$, Übergewicht $\left(25-30 \mathrm{~kg} / \mathrm{m}^{2}\right)$ und Adipositas (BMI $\left.>30 \mathrm{~kg} / \mathrm{m}^{2}\right)$. Nach der DEGS des Robert Koch-Instituts aus den Jahren 2008-2011 sind 67,1 \% der Männer und $53 \%$ der Frauen in Deutschland übergewichtig. Von diesen hatten 23,3\% der Männer und 
23,9 \% der Frauen definitionsgemäß eine Adipositas. Im Verlauf der vergangenen 15 Jahre verhielt sich die Prävalenz von Übergewicht in der Altersgruppe der 18- bis 79-Jährigen konstant. Es besteht jedoch eine Zunahme in der Zahl adipöser Menschen sowie des Anteils der Personen, die bereits im jungen Alter unter schwerem Übergewicht leiden und damit lebenslang ein erhöhtes Risiko tragen, an mit Adipositas assoziierten Krankheiten zu erkranken (Mensink et al. 2013). Neben den ökonomischen Folgen des zunehmenden Anteils übergewichtiger Personen in der Gesellschaft stehen die Folgeerkrankungen, die zu den häufigsten Todesursachen zählen, im Mittelpunkt des wissenschaftlichen Interesses.

\subsubsection{Ausbildung eines präinflammatorischen Status durch Fettgewebshypertrophie und-hyperplasie}

Das viszerale Fettgewebe ist nicht nur ein Speicherort für Triacylglyceride, sondern ein sekretorisches Organ, welches über Ausschüttung von verschiedenen Hormonen und Zytokinen an der Regulation unter anderem von Energiehomöostase, Entzündungsprozessen und Blutdruck beteiligt ist (Gustafson et al. 2007; Hajer et al. 2008; Skurk et al. 2007). Bei Übergewicht ist der Gehalt an Makrophagen im Fettgewebe erhöht und mehrere Untersuchungen konnten zeigen, dass die Wechselwirkung zwischen Adipozyten und Makrophagen eine wichtige Rolle spielt in der Entwicklung einer Fettgewebsdysfunktion und Insulinresistenz (Rega-Kaun et al. 2013). Die genauen Mechanismen der Immunzellrekrutierung sind kaum bekannt. Jedoch scheint es eine deutliche Korrelation zwischen der Anzahl von F4/80 $0^{+}$-Makrophagen im Fettgewebe und der Adipozytengröße sowie auch des Körpergewichts zu geben. Zudem kodieren etwa 30\% der im Fettgewebe vorhandenen Gene für Proteine, die makrophagenspezifisch sind. Zusätzlich konnte nachgewiesen werden, dass nahezu alle im Fettgewebe vorhandenen proinflammatorischen Zytokine - im Speziellen TNF $\alpha$, iNOS und IL6 - von den Markophagen sezerniert werden (Weisberg et al. 2003). Es konnte ferner gezeigt werden, dass in murinen Modellen mit insulinresistenzbedingtem Übergewicht eine verminderte Anzahl regulatorischer T-Zellen im viszeralen Fettgewebe vorhanden war. Über eine veränderte Differenzierung der Zytokine kommt es zu einer direkten Veränderung der Insulinresistenz und damit zu erhöhter Glukoseaufnahme. Gleichzeitig zeigte sich eine erhöhte inflammatorische Aktivität (Feuerer et al. 2009). Ergänzend kommt es durch erhöhte Konzentration von CD8 ${ }^{+}$-Effektor-TLymphozyten im Fettgewebe zu einer Migration von Makrophagen dort hin. Dies führt zu 
einer gesteigerten Fettgewebsinflammation sowie ebenfalls $\mathrm{zu}$ vermehrter systemischer Insulinresistzenz (Nishimura et al. 2009).

Da Übergewicht durch ein Ungleichgewicht zwischen Energiebedarf und Nahrungsaufnahme $\mathrm{zu}$ einer vermehrten Akkumulation von Triacylglyceriden führt, kommt es im viszeralen und perivaskulären Fettgewebe zur einer Hypertrophie und gleichzeitig zu einer Hyperplasie der Adipozyten (de Ferranti und Mozaffarian 2008). Die vom Fettgewebe freigesetzten Fettsäuren führen über Bildung von TNF $\alpha$ zu verstärkter Lipolyse und durch Freisetzung von MCP-1 zu einer vermehrten Rekrutierung von Monozyten ins Fettgewebe und deren Transformation zu Makrophagen (Permana et al. 2006). Hierdurch kommt es zu einer parakrinen Kettenreaktion, die lokal eine chronische niedriggradige Entzündungsreaktion hervorruft (Hajer et al. 2008).

\subsection{Bedeutung des perivaskulären Fettgewebes für die Atherosklerose}

Es ist bekannt, dass die Masse an viszeralem Fettgewebe mit einem erhöhten Risiko für kardiovaskuläre Erkrankungen assoziiert ist und einen besseren Vorhersagewert für das Auftreten kardiovaskulärer Ereignisse besitzt als ein erhöhter BMI (Janssen et al. 2004). Deshalb rückt das epikardiale perivaskuläre Fettgewebe (PVAT) als eine Schicht viszeralen Fettgewebes, das zwischen Myokard und Perikard liegend ein Gewebe reich an bioaktiven Substanzen in direkter Nachbarschaft zu den Koronararterien darstellt (Mazurek et al. 2003), in den Fokus neuerer Untersuchungen. Es ist jedoch wenig über die Funktion und den Beitrag perivaskulärer Inflammation an der Entstehung von Atherosklerose bekannt.

Bereits Iacobellis et al. (2003) und de Vos et al. (2008) untersuchten in klinischen Studien den Zusammenhang zwischen metabolischem Syndrom und der Masse des epikardialen Fettgewebes mittels transthorakalen Echokardiographie und Computertomografie. Sie stellten eine signifikante Korrelation zwischen dem epikardialen Fettgewebe und den mit dem metabolischen Syndrom assoziierten Parametern Hüftumfang, diastolischer Blutdruck, Nüchtern-Insulinspiegel und LDL-Cholesterin fest.

Payne et al. (2010) sowie Gormez et al. (2011) konnten zeigen, dass die bei Übergewicht vermehrte Konzentration von Leptin im PVAT mit einer signifikant verstärkten endothelialen Dysfunktion in den Koronarien und erhöhten Expression des ObR assoziiert war. 
Ein weiterer Effekt der durch das perivaskuläre Fettgewebe hervorgerufen wird, ist eine Induktion der Expression von VCAM-1 auf Endothelzellen. Hierdurch kann es zu einer gesteigerten Integrin-abhängigen Rekrutierung von Monozyten in die Gefäßwand kommen (DeVerse et al. 2013; Kralisch et al. 2008). Weiterhin kommt es im perivaskulären Fett zu einer gesteigerten glatten Gefäßmuskelproliferation und einer Veränderung der synthetisierten Extrazellularmatrix-Proteine und dadurch $\mathrm{zu}$ einer vermehrten LDL-Retention und Oxidation in der Gefäßintima, was zur Bildung der fibrösen Plaquekappe beiträgt (Badimon et al. 2013). In Vorarbeiten der Gruppe konnte gezeigt werden, dass Übergewicht mit einer vermehrten Expression von Leptin im perivaskulären Fettgewebe assoziiert ist (Schroeter et al. 2013) und dass Leptin in vitro zum parakrinen Effekt viszeralen Fettgewebes auf die verstärkte Proliferation glatter Gefäßmuskelzellen beiträgt (Schroeter et al. 2013).

\subsection{Mechanismen der Immunzellrekrutierung und Fettgewebsinflammation}

\subsubsection{Gesteigerte Expression von Zelladhäsionsmolekülen auf aktiviertem Endothel}

Das vaskuläre Zelladhäsionsmolekül VCAM-1 ist ein Oberflächenantigen, welches auf aktivierten Endothelzellen der Gefäßintima exprimiert wird und gemeinsam mit anderen Adhäsionsmolekülen wie ELAM-1 (endotheliales Leukozytenadhäsionsmolekül) und ICAM1 (interzelluläres Zelladhäsionsmolekül) für die Interaktion des Endothels mit zirkulierenden Leukozyten verantwortlich ist (Carlos et al. 1990). Die Anhaftung zirkulierender Leukozyten, speziell Monozyten, ist ein essentieller Bestandteil der Rekrutierung von Immunzellen in die Gefäßwand, inklusive des perivaskulären Fettgewebes, und damit wichtig bei der Entwicklung der Atherosklerose. Risikopatienten für kardiovaskuläre Erkrankungen können chronisch einen systemisch niedriggradigen Inflammationsstatus aufweisen (Berg und Scherer 2005; Saito et al. 2003). Durch den erhöhten systemischen Spiegel an proinflammatorischen und Akute-Phase-Proteinen, wie CRP und vor allem TNF $\alpha$ und IL-1, kommt es zu einer vermehrten Expression des vaskulären Zelladhäsionsmoleküls VCAM-1 auf Endothelzellen, welches über Integrine eine Leukozytenadhäsion vermittelt und damit eine wichtige Schnittstelle in der Entstehung atherosklerotischer Läsionen bei Übergewicht darstellt (Elices et al. 1990). 


\subsubsection{Leukozytenmigration durch Integrin $\alpha_{4} \beta_{1}$}

Integrine stelle eine Gruppe Proteine dar, die in der Zell-Zell- und Zell-Matrix-Interaktion eine zentrale Rolle spielen. Sie zeigen eine heterodimere $\alpha / \beta$-Struktur und besitzen eine weite Verteilung auf fast allen Zellen (Hynes 1987). Diese Struktur erlaubt eine Einteilung in drei Subgruppen: $\beta_{2}$-Integrine spielen in der Zell-Zell-Interaktion innerhalb des Immunsystems eine wichtige Rolle (Kishimoto et al. 1989), wohingegen $\beta_{1}$ - und $\beta_{3}$-Integrine hauptsächlich an der Kommunikation von Immunzellen mit der Extrazellulärmatrix beteiligt sind (Ruoslahti 1988). Die $\beta_{1}$-Integrine, auch very-Late antigens (VLA) genannt, interagieren insbesondere mit Kollagen, Fibronektin und Laminin (Hemler 1990). Integrin $\alpha_{4} \beta_{1}$ (VLA-4) besitzt eine Sonderstellung, da er zum Einen nur von lymphoiden und myeloiden Zellen exprimiert wird (Hemler et al. 1987) und zum Anderen untypischerweise auch an der Zell-Zell-Interaktion beteiligt ist (Bednarczyk und McIntyre 1990). Das Integrin $\alpha_{4} \beta_{1}$ stellt den wichtigsten leukozytären Liganden für eine feste Bindung der mononukleären Zellen an die Gefäßintima dar, während VCAM-1 den endothelständigen Mediator der Leukozytendiapedese bildet. Daher wird der Interaktion von Integrin $\alpha_{4} \beta_{1}$ mit VCAM-1 auf aktiviertem Endothel eine bedeutende Rolle in der Pathogenese der Atherosklerose zugeschrieben (Elices et al. 1990). Dieser Einfluss der Integrin-Endothel-Interaktion auf die Entstehung vaskulärer Läsionen konnte durch in vivo Mausstudien belegt werden: Da Integrin $\alpha_{4} \beta_{1}$-Knockout-Mäuse nicht lebensfähig sind, wurde mittels eines synthetischen Fibronektin-ähnlichen Liganden die Rekrutierung von Leukozyten über den Integrin/VCAM-Mechanismus in WT- und LDLRezeptor-defizienten (LDLR ${ }^{-/}$) Mäusen verhindert. Die C57BL/6 (WT)-Mäuse zeigen eine langsamere Entwicklung atherosklerotischer Läsionen unter HFD, wohingegen die LDLR ${ }^{-/}$ Mäuse ausgedehnte Läsionen in relativ kurzen Zeiträumen entwickeln. Dadurch konnte gezeigt werden, dass durch Blockade der VLA4-vermittelten Immunzellrekrutierung sowohl die Leukzytenextravasation als auch die Bildung früher atherosklerotischer Läsionen signifikant reduziert wird (Shih et al. 1999).

\subsubsection{Leptin-Einfluss auf die angeborene und erworbene Immunantwort}

Leptin ist neben Energiehomöostase und Gewichtsregulation auch an der Aktivierung und Modulation der humoralen und zellulären Immunantwort beteiligt (Fernandez-Riejos et al. 2010). Es wird vermutet, dass die bei Übergewicht zu beobachtende Beeinträchtigung der 
Immunantwort auf die Hyperleptinämie und begleitende Leptinresistenz zurückzuführen ist. B- und T-Lymphozyten zeigen eine hohe Expression des Leptinrezeptors, was darauf schließen lässt, dass ihre Funktion durch Leptin moduliert werden kann (Busso et al. 2002). Es konnte weiterhin gezeigt werden, dass zusätzlich zur Immunantwort auch Hämato- und Lymphopoese unter dem Einfluss von Leptin stehen. Durch hohe Leptinspiegel kommt es zu einer Hochregulierung vor allem der Lymphopoese (Claycombe et al. 2008). Auch auf Monozyten und Neutrophilen konnte der ObR nachgewiesen werden (Claycombe et al. 2008). Insgesamt scheint der Einfluss von Leptin einen proinflammatorischen Effekt darzustellen, der über die Aktivierung von Immunzellen und Induktion der monozytären Produktion proinflammatorischer Zytokine wie TNF $\alpha$, IL-6 und IL-12 vermittelt wird (Loffreda et al. 1998). Leptin besitzt eine Aminosäuresequenz, die jener der Zytokinfamilie ähnelt (Madej et al. 1995) und ObR zeigt eine Grundstruktur, über die er - analog zur Signaltransduktion des IL-6-Rezeptors- über eine rezeptor-assoziierte Janus-Kinase agiert (Sanchez-Margalet et al. 2003) Daher ist anzunehmen, dass auch Leptin durch sein „Zytokin-ähnliches“ Verhalten an der Regulation der angeboren Immunität beteiligt ist (Lord et al. 1998). Nach einem inflammatorischen Stimulus, z.B. Stimulation mit Lipopolysaccharid (LPS) und Zytokinen im Speziellen IL-1 $\beta$-, zeigt sich ein Anstieg des zirkulierenden Leptins (Faggioni et al. 1998). Leptin hat einen Einfluss auf die Phagozytoseaktivität und Zytokinproduktion von Monozyten (Loffreda et al. 1998) und verändert ihre Empfindlichkeit auf inflammatorische Stimuli (Faggioni et al. 2001). Eine Hyperleptinämie fördert die Reifung und Aktivierung von zirkulierenden Monozyten (Santos-Alvarez et al. 1999) und die Produktion von IL-6 und TNFa (Kiguchi et al. 2009). In Makrophagen stimuliert eine Leptinbindung die Expression der Lipoproteinlipase (Maingrette und Renier 2003). Auch natural killer cells (NK-Zellen) exprimieren den ObR. Hierüber wird STAT3-vermittelt die Produktion von IL-2 und Perforin reguliert und somit neben der Reifung auch die Aktivierung und Zytotoxizität beeinflusst (Matarese et al. 2005; Tian et al. 2002; Zhao et al. 2003).

Neben der Aktivierung der angeborenen findet man ebenfalls eine leptinabhängige Regulation der erworbenen Immunität. Leptindefiziente $o b / o b$-Mäuse zeigen eine herabgesetzte Empfindlichkeit ihrer T-Lymphozyten auf spezifische Stimuli sowie eine Atrophie der lymphatischen Organe und reduzierte Gesamtzahl zirkulierender T-Zellen auf (Fantuzzi und Faggioni 2000; Howard et al. 1999; Lord et al. 1998). Durch einen antiapoptotischen Effekt von Leptin auf T-Lymphozyten (Howard et al. 1999) kommt es bei gesunden Tieren nicht zu einer Atrophie des Thymus, sondern zu einer Aufrechterhaltung eines funktionierenden 
Thymusepithels und Thymopoese durch verstärkte negative Selektion der Thymozyten (Gruver et al. 2009).

\subsubsection{Leptinabhängige integrinvermittelte Rekrutierung von Endothelvorläuferzellen in neointimale Läsionen}

Endotheliale Vorläuferzellen (EPC) sind charakterisiert als CD34-positive Zellen des peripheren Blutes und damit Bestandteil der hämatopoetischen Stammzellreihe (Asahara et al. 1997). Sie sind also Leukozyten-ähnliche Zellen und zeigen somit auch ein vergleichbares Migrationsverhalten.

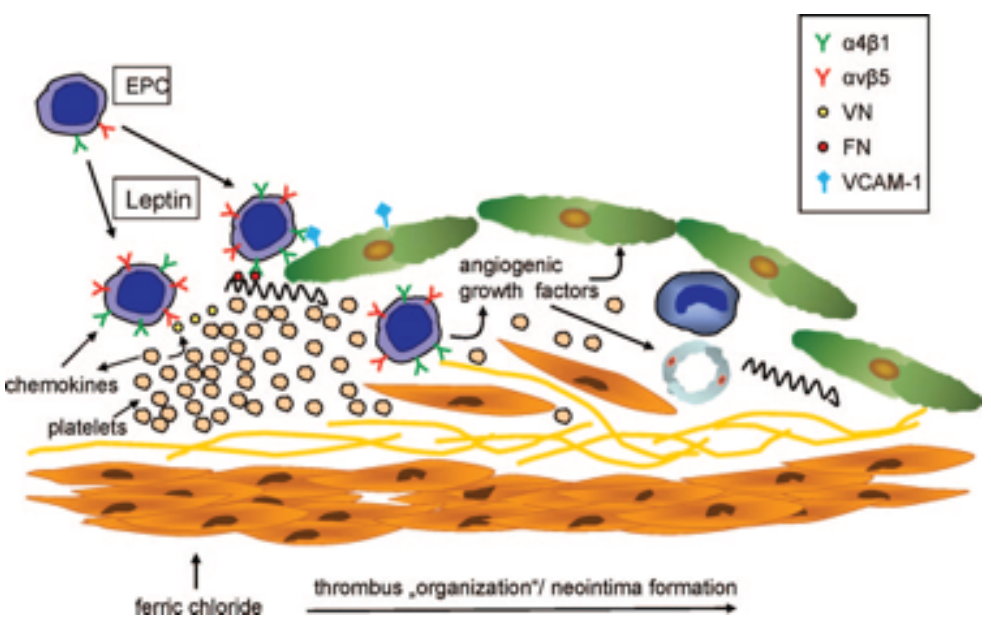

In Vorarbeiten der Arbeitsgruppe konnte gezeigt werden, Schroeter et al. (2008), dass humane EPC in vitro den Leptinrezeptor exprimieren und unter Stimulation mit rekombinantem Leptin eine vermehrte Bindungsfähigkeit an Vitronektin und Fibronektin entwickelten. Zudem konnte

Abb. 1.2 Einfluss von Leptin auf die Leukozytenmigration in atherosklerotische Läsionen. Abbildung aus Schober und Weber (2008)

gezeigt werden, dass durch die Leptin-Stimulation die Fähigkeit der EPC auf einem Monolayer humaner Endothelzellen sowie an aktivierte Thrombozyten zu binden, anstieg. Interessanterweise konnte ebenso nachgewiesen werden, dass durch Leptinstimulation die Expression der Integrine $\alpha_{4} \beta_{1}$ und $\alpha_{v} \beta_{5}$ signifikant zunahm. Die Verwendung von Leptinblockierenden Antikörpern konnte diese Effekte reduzieren, was den möglichen Einfluss von Leptin auf die Integrin-vermittelte Einwanderung von zirkulierenden Zellen in die Gefäßwand bestärkt. Durch In-vivo-Experimente in athymen Nacktmäusen konnte gezeigt werden, dass injizierte Fluoreszenz-markierte EPC nach vorheriger Leptinstimulation Integrin-abhängig vermehrt in Intimaverletzungen einwanderten, was mit einer verbesserten ReEndothelialisierung und einem Rückgang der Neointimabildung assoziiert war. Bereits in einer Vorarbeit konnten Schroeter et al. (2007) zeigen, dass Leptinrezeptoren nicht nur auf 
Endothelzellen, sondern auch auf Monozyten und Makrophagen innerhalb der atherosklerotischen Plaques exprimiert werden, was vermuten lässt, dass Leptin Integrine auf Immunzellen aktivieren könnte.

\subsection{Leptin - ein Hormon des Fettgewebes}

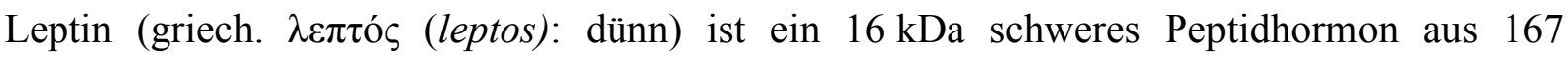
Aminosäuren, welches von den Adipozyten des weißen Fettgewebes gebildet wird. Das Protein wird durch das obese-Gen kodiert (Zhang et al. 1994) und ist an der Regulation des Fettstoffwechsels sowie an der Appetitregulation beteiligt (Ahima 2005). Die fehlende Expression von Leptin führt, wie der Phänotyp leptindefizienter ob/ob-Mäuse zeigt, zu massivem Übergewicht begleitet von Insulinresistenz, Diabetes mellitus sowie Infertilität. Wird diesen Mäusen Leptin zugeführt, normalisieren sich sowohl ihr Körpergewicht als auch die metabolischen Störungen (Zhang et al. 1994). Die Signalvermittlung erfolgt über einen membranständigen Rezeptor (Leptinrezeptor, $\mathrm{ObR})$, der in sechs Isoformen $\left(\mathrm{ObR}_{\mathrm{a}-\mathrm{f}}\right)$ vorliegt, welche durch alternatives Spleißen aus einer gemeinsamen mRNA entstehen (Ahima und Osei 2004). ObR $\mathrm{b}_{\mathrm{b}}$, die lange Isoform, wird hauptsächlich von den Neuronen im Hypothalamus exprimiert und vermittelt den appetitregulierenden Effekt von Leptin. Er aktiviert in Zellen den Janus-Kinase (Jak2)-Signalweg und führt über eine Translokation von phosphorylierten STAT3-Proteinen in den Zellkern zur Regulation der Zielgene (Bjorbaek 1997). Die kurzen Isoformen des ObR konnten auf Zellen sowohl des vaskulären als auch des Immunsystems identifiziert werden. In immunhistochemischen Analysen von Gefäßwandpräparaten konnte in allen Wandschichten die Expression des ObR nachgewisen werden (Schroeter et al. 2007): In Präparaten mit neointimalen oder atherosklerotischen Läsionen war ObR vorwiegend am Gefäßlumen und in der Subintima lokalisiert. Mittels Doppelfärbungen mit Antikörpern gegen vascular endothelial growth factor-receptor 2 (VEGF-R2) und dem VE-Cadherin konnten die Zellen als Endothelzellen identifiziert werden. Innerhalb der Läsionen zeigten sich vor allem CD14-positive Monozyten/Makrophagen als ObR-positive Zellen.

Weiterhin wird angenommen, dass Leptin proatherogene Effekte besitzt und damit bei Übergewichtigen mit Hyperleptinämie $\mathrm{zu}$ einer erhöhten Atherosklerose- sowie Thromboseneigung beitragen könnte. Untersuchungen an leptindefizienten $o b / o b$-Mäusen konnten zeigen, dass diese Mäuse - trotz Übergewicht - signifikant weniger Thromben und 
eine geringere Neointima nach arterieller Verletzung ausbilden als WT-Mäuse (Konstantinides et al. 2004; Schroeter et al. 2013).

\subsubsection{Leptin und Atherosklerose}

In einer klinischen Studie stellten Wolk et al. (2004) Hyperleptinämie als eigenständigen Risikofaktor für das Eintreten kardiovaskulärer Komplikationen wie Herztod, Herzinfarkt sowie Apoplex heraus. Leptin steht damit prognostisch in einer Reihe mit Risikofaktoren wie Stadium der KHK, Inflammation, Insulinresistenz, Übergewicht, Dyslipidämie sowie Hypertonie. Jedoch einzig Leptin und das KHK-Stadium zeigten signifikante Korrelation mit dem Eintreten kardiovaskulärer Komplikationen. Dies unterstreicht die herausragende Bedeutung von Leptin für die Prognose kardiovaskulärer Erkrankungen.

Simonds et al. (2014) konnten im murinen Modell einen eindeutigen Zusammenhang zwischen Übergewicht mit begleitendem Anstieg des Leptinserumspiegels und signifikant erhöhter Herzfrequenz und Blutdruck herausstellen. Das Übergewicht scheint jedoch nicht ursächlich für diese Effekte zu sein. Leptin- und leptinrezeptordefiziente Mäuse zeigten normalen Blutdruck und Herzfrequenz trotz signifikant höherem Gewicht. Ebenfalls konnten die eingetretenen Anstiege von Blutdruck und Herzfrequenz in gesunden übergewichtigen Mäusen durch Applikation von Antikörpern gegen Leptin oder den Leptinrezeptor wieder vollständig normalisiert werden. Zudem konnten sie in vivo und in vitro die Wirkung von Leptin auf Neurone des dorsomedialen Hypothalamus zeigen, welche eine direkte kreislaufmodulierende Funktion besitzen.

Die proatherogenen Effekte des Leptins könnten sich aus einer Verstärkung der endothelialen Dysfunktion ergeben, die zum einen auf einer gestörten Relaxationsfähigkeit als Antwort auf Vasodilatatoren beruht, zum anderen mit dem Verlust NO-abhängiger Endotheleigenschaften wie Plättchenhemmung, Fibrinolyse sowie antiinflammatorischer und antiproliferativer Eigenschaften (Boger et al. 1996). Tierexperimentelle In-vitro-Studien konnten zeigen, dass Endothelzellen funktionelle Leptinrezeptoren exprimieren und dass die Applikation hoher Leptindosen eine Endothel-abhängige Vasorelaxation auslösen (Lembo et al. 2000). In-vivoUntersuchungen konnten zeigen, dass Applikation von Leptin zu einer erhöhten Konzentraion von cGMP - einem second messenger des NO-Pathways - im Plasma führt (Beltowski et al. 2002), jedoch konnte der genaue Mechanismus noch nicht geklärt werden. Es wird 
angenommen, dass Leptin die iNOS stimuliert und dadurch verstärkt NO produziert wird, die die Endothelfunktion stören und zu oxidativem Stress führen (Naseem 2005). Des Weiteren konnte gezeigt werden, dass unter Einfluss von Adipositas der Leptinspiegel unabhängig von BMI, CRP und Insulinsensitivität positiv mit den Plasmaspiegeln zweier Marker für Endothelaktivierung und -schädigung korrelierte: VCAM-1 und lösliches Thrombomodulin (Porreca et al. 2004).

Der prothrombotische Effekt von Leptin konnte in früheren Arbeiten der Arbeitsgruppe um Frau Prof. Schäfer und Prof. Konstantinides nachgewiesen werden. Hierzu wurde in murinen In-vivo-Studien mit Hilfe eines $\mathrm{FeCl}_{3}$-Modells eine chemische Verletzung an der A. carotis und damit eine Thrombusbildung induziert. Es zeigte sich, dass leptin- und leptinrezeptordefiziente Mäuse im Vergleich zur Kontrollgruppe der Wildtyp (WT)-Mäuse eine gestörte Thrombusbildung vorwiesen. Durch intraperitoneale Injektion von Leptin vor der Arterienverletzung konnte sowohl bei WT- als auch bei ob/ob-Mäusen, nicht aber bei $d b / d b$-Mäusen eine verstärkte Thrombusbildung beobachtet werden, was dafürspricht, dass Leptin über seinen Rezeptor die Thrombusbildung fördert. Die Tatsache, dass mit leptinneutralisierenden Antikörpern in WT-Mäusen die arterielle und venöse Thrombusbildung vermindert werden konnte, bestätigt die Rolle des Leptins an der Thrombogenese (Konstantinides et al. 2001; Konstantinides et al. 2004).

Eine weitere wichtige Rolle bei der Entwicklung von atherosklerotischen Plaques und deren Ruptur spielt die Entzündungsreaktion der Gefäßwand (Yudkin et al. 2000). Daher sind systemische Entzündungsmarker, wie das in der Leber gebildete C-reaktive Protein (CRP) wichtige Risikomarker für kardiovaskuläre Erkrankungen. Weiterführende Analysen konnten zeigen, dass CRP direkt wichtige proatherogene Prozesse, wie die Aktivierung von glatten Gefäßmuskelzellen oder die Monozyten-Adhäsion an Endothelzellen stimuliert (Venugopal et al. 2005). Untersuchungen in normalgewichtigen und adipösen Personen zeigten, dass bei den Übergewichtigen eine positive Korrelation der Leptinspiegel mit den Plasmaspiegeln von Akute-Phase-Proteinen - speziell CRP - vorliegt. Diese Korrelation scheint BMI-unabhängig zu sein, da im Plasma normalgewichtiger Personen der CRP-Spiegel lediglich mit dem Leptinspiegel, jedoch nicht mit dem BMI korrelierte (Shamsuzzaman et al. 2004). Gleichzeitig konnte gezeigt werden, dass bei Normalgewichtigen eine Applikation von Leptin zu einem Anstieg der CRP-Konzentration führte (Hukshorn et al. 2002). Außerdem zeigte sich, dass der Abfall des Leptinspiegels beim Fasten bereits vor signifikanter Gewichtsabnahme mit einem Abfall des CRP korrelierte (Monzillo et al. 2003) und dass 
ebenso eine niedrigdosierte Gabe von Leptin in der Fasten-Phase zu einem signifikanten Anstieg der CRP-Konzentrationen bei Übergewichtigen führte (Canavan et al. 2005).

Zusammenfassend lässt sich sagen, dass Leptin im Rahmen der Adipositas einen proinflammatorischen Status fördert. Über die Aktivierung Atherosklerose-fördernder Prozesse an der Gefäßwand könnte eine Hyperleptinämie im Rahmen des metabolischen Syndroms als Risikofaktor bei kardiovaskulären Erkrankungen gelten.

\subsection{Ziele der Arbeit}

Adipositas stellt einen wichtigen Risikofaktor für Atherosklerose und kardiovaskuläre Erkrankungen dar und geht mit einer Hyperleptinämie und einem proinflammatorischen Status einher. Neben dem Einfluss des viszeralen Fettgewebes weisen neuere klinische und experimentelle Studien auf einen Einfluss der perivaskulären Fettgewebsinflammation auf den Fortschritt atherosklerotischer Läsionen hin. Bislang ist wenig bekannt über die genauen Mechanismen der Entstehung einer perivaskulären Inflammation sowie die Spezifikationen der Immunzellen, die an diesem Prozess beteiligt sind. Ein zentraler Faktor für die Entstehung der Fettgewebsinflammation ist die Interaktion von Integrin $\alpha_{4} \beta_{1}$ (VLA-4) mit VCAM-1 und die Vermittlung der Adhäsion von Leukozyten an aktivierte Endothelzellen. Eine vermehrte Endothelaktivierung wird durch Adipositas begünstigst, da ein proinflammatorischer Zustand vorliegt. Zudem konnte gezeigt werden, dass es zu einer signifikanten Erhöhung der Leptinkonzentration im perivaskulären Fettgewebe kommt. Vorarbeiten der Gruppe konnten zeigen, dass Leptin die Expression von Integrin $\alpha_{4} \beta_{1}$ auf Endothelvorläuferzellen und dadurch deren Bindung an VCAM-1 auf aktiviertem Endothel fördert. Ob dieser Effekt auf Immunzellen übertragbar ist und eine Rolle für die vermehrte Rekrutierung von Leukozyten in das perivaskuläre Fettgewebe und die Gefäßwand bei Übergewicht und Hyperleptinämie spielt, ist nicht bekannt.

Die vorliegende Arbeit untersucht den Zusammenhang zwischen Adipositas und der Rekrutierung von Immunzellen in die Gefäßwand, insbesondere die Bedeutung von Leptin für die Rekrutierung Integrin $\alpha_{4} \beta_{1}$-positiver Immunzellen in das perivaskuläre Fettgewebe. Hierzu wurden zunächst Wildtyp-Mäuse 8 Wochen auf fettreiche Diät gesetzt, um eine Gewichtszunahme und Übergewicht zu induzieren. Anschließend wurde sowohl viszerales als auch perivaskuläres Fettgewebe histologisch, molekularbiologisch und durchflusszyto- 
metrisch auf den Anteil spezifischer Immunzellpopulationen untersucht und mit Geweben normalgewichtiger Kontrollen verglichen. Um die Abhängigkeit der Prozesse von Leptin zu untersuchen, wurden die Analysen zusätzlich auf leptindefiziente, übergewichtige ob/obMäuse ausgeweitet.

In einem zweiten Schritt wurden, in Kooperation mit der Abteilung Thorax-, Herz- und Gefäßchirurgie der Universitätsmedizin Göttingen, peri- und epikardiale Fettgewebsproben von Patienten mit manifester KHK sowie von Kontrollpatienten mit Ausschluss einer KHK, die einen Aortenklappenersatz erhielten, analog zu den Untersuchungen im murinen Modell durchflusszytometrisch auf den Gehalt an spezifischen Immunzellen und die Zusammensetzung des Fettgewebes untersucht. Ziel dieser Untersuchungen war, die zelluläre Zusammensetzung des perivaskulären Fettgewebes im Mausmodell zu analysieren und mit möglichen Veränderungen bei Patienten mit fortgeschrittenen atherosklerotischen Läsionen $\mathrm{zu}$ vergleichen, um daraus einen Leptin-abhängigen Zusammenhang zwischen perikardialer Inflammation und Schwere der Koronaren Herzerkrankung herstellen zu können. 


\section{MATERIAL UND MeTHODEN}

\subsection{Verwendete Materialien und Geräte}

\subsubsection{Reagenzien}

\begin{tabular}{|c|c|c|}
\hline Artikel & Art.-Nummer & Firma \\
\hline 100 bp DNA Ladder & N3231L & New England Biolabs, Ipswich, MA, USA \\
\hline Aceton & 8222511000 & Merck KGaA, Darmstadt, D \\
\hline AEC & $00-2007$ & Invitrogen by Life Technologies, Carlsbad, CA, USA \\
\hline Agarose & 840004 & Biozym, Hameln, D \\
\hline Albumin Standard & 23209 & Thermo Fisher Scientific, Waltham, MA, USA \\
\hline Antibody-Diluent & S3022 & Dako Denmark A/S, Glostrup, DK \\
\hline Antikörper Immunfluoreszenz & & s. Immunfluoreszenz, Kap. 2.2.3.3 \\
\hline Antikörper Immunhistochemie & & s. Immunhistochemie, Kap. 2.3.4.3 \\
\hline Antikörper Western Blot & & s. Western Blot, Kap. 2.6.4.7 \\
\hline Antikörper Durchflusszytometrie & & s. Durchflusszytometrie, Kap. 2.4.3, 2.4.4 \\
\hline Aprotinin & A6279 & Sigma-Aldrich, St. Louis, MO, USA \\
\hline APS (Ammoniumpersulfat) & A3678 & Sigma-Aldrich, St. Louis, MO, USA \\
\hline Ethanol & 1009831000 & Merck KGaA, Darmstadt, D \\
\hline BCA Protein Assay & 23227 & Thermo Fisher Scientific, Waltham, MA, USA \\
\hline Biebrich-Scharlachrot & B6008 & Sigma-Aldrich, St. Louis, MO, USA \\
\hline Bromphenolblau & B0126 & Sigma-Aldrich, St. Louis, MO, USA \\
\hline BSA (Bovines Serum Albumin) & A7906 & Sigma-Aldrich, St. Louis, MO, USA \\
\hline Chloroform & 102445250 & Merck KGaA, Darmstadt, D \\
\hline dNTPs & $\mathrm{C} 114 \mathrm{H}$ & Promega, Fitchburg, WI, USA \\
\hline DEPC- $\mathrm{H}_{2} \mathrm{O}$ & & eigene Herstellung \\
\hline Eisenchlorid (29\%, in Aqua dest.) & 236489 & Sigma-Aldrich, St. Louis, MO, USA \\
\hline Eisessig & 1000631000 & Merck KGaA, Darmstadt, D \\
\hline Ethanol & $603-002-0-05$ & Chemie-Vertrieb Hannover, Hannover, D \\
\hline Eosin & HAT110216 & Sigma-Aldrich, St. Louis, MO, USA \\
\hline Entellan & 1079610100 & Merck KGaA, Darmstadt, D \\
\hline FACS ${ }^{\text {TM }}$ Lysing Solution & 349202 & BD Biosciences, San Jose, CA, USA \\
\hline Formalin & 252549 & Sigma-Aldrich, St. Louis, MO, USA \\
\hline Gelatine & G1890 & Sigma-Aldrich, St. Louis, MO, USA \\
\hline Gill's Hämatoxylin & 6765007 & Thermo Fisher Scientific, Waltham, MA, USA \\
\hline
\end{tabular}




\begin{tabular}{|c|c|c|}
\hline Glycerol & G6251 & Sigma-Aldrich, St. Louis, MO, USA \\
\hline Glycerol Reagent Plus & G7757 & Sigma-Aldrich, St. Louis, MO, USA \\
\hline Glyzin (Pufferan) & 3908.3 & Carl Roth GmbH + Co.KG, Karlsruhe, D \\
\hline GoTaq & BIO-21083 & Bioline, London, UK \\
\hline Hämatoxylin & 1043020100 & Merck KGaA, Darmstadt, D \\
\hline Harris Hämatoxylin & 6765001 & Thermo Shandon, Runcorn, UK \\
\hline HistoMount & 9999122 & Thermo Fisher Scientific, Waltham, MA, USA \\
\hline Human Leptin Quantikine ELISA Kit & DLP00 & R\&D Sygstems, Minneapolis, MN, USA \\
\hline Hydrochlorid & 109057 & Merck KGaA, Darmstadt, D \\
\hline ImmuMount & 9990402 & Thermo Fisher Scientific, Waltham, MA, USA \\
\hline Isofluran & B506 & Abbott, North Chicago, IL, USA \\
\hline Isopropanol (2-Propanol) & 278475 & Sigma-Aldrich, St. Louis, MO, USA \\
\hline Kaliumaluminiumsulfat & 31242 & Sigma-Aldrich, St. Louis, MO, USA \\
\hline Kaliumchlorid & 05433 & Sigma-Aldrich, St. Louis, MO, USA \\
\hline Kaliumhexacyanoferrat (II) & P-0387 & Sigma-Aldrich, St. Louis, MO, USA \\
\hline Kernechtrot & N-8002 & Sigma-Aldrich, St. Louis, MO, USA \\
\hline Kollagenase A & 10103586001 & Roche Applied Science, Penzberg, D \\
\hline Leupeptin & L2884 & Sigma-Aldrich, St. Louis, MO, USA \\
\hline Mayer's Hämatoxylin & MHS32 & Sigma-Aldrich, St. Louis, MO, USA \\
\hline Mercaptoethanol & M7154 & Sigma-Aldrich, St. Louis, MO, USA \\
\hline Methanol & 106009 & Merck KGaA, Darmstadt, D \\
\hline Methylbutan & 106056 & Merck KGaA, Darmstadt, D \\
\hline Maus Leptin Quantikine ELISA Kit & MOB00 & R\&D Systems, Minneapolis, MN, USA \\
\hline $\mathrm{MgCl}_{2}$ & $\mathrm{~A} 351 \mathrm{H}$ & Promega, Fitchburg, WI, USA \\
\hline M-MLV RT 5X Puffer & M531A & Promega, Fitchburg, WI, USA \\
\hline M-MLV Reverse Transkriptase & M170B & Promega, Fitchburg, WI, USA \\
\hline $\mathrm{NaOH}, 2 \mathrm{M}$ & 109136 & Merck KGaA, Darmstadt, D \\
\hline $\mathrm{NaCl}, 0,9 \%$ & $387028 \mathrm{R}$ & B.Braun Melsungen AG, Melsungen, D \\
\hline Natriumthiosulfat & 1065161000 & Merck KGaA, Darmstadt, D \\
\hline NGS (Normales Ziegenserum) & X0907 & Dako Denmark A/S, Glostrup, DK \\
\hline Ö1-Rot-O & O-0625 & Sigma-Aldrich, St. Louis, MO, USA \\
\hline PBS, $10 \%$ & 70011-036 & Invitrogen by Life Technologies, Carlsbad, CA, USA \\
\hline Pepstatin & P5318 & Sigma-Aldrich, St. Louis, MO, USA \\
\hline Phenol & P1037 & Sigma-Aldrich, St. Louis, MO, USA \\
\hline Phosphomolybdänsäure & P7390 & Sigma-Aldrich, St. Louis, MO, USA \\
\hline Phosphotungstensäure & P6395 & Sigma-Aldrich, St. Louis, MO, USA \\
\hline Pikrinsäure, gesättigt & P6744-1GA & Sigma-Aldrich, St. Louis, MO, USA \\
\hline PMSF & 6367.1 & Carl Roth $\mathrm{GmbH}+$ Co.KG, Karlsruhe, D \\
\hline
\end{tabular}




\begin{tabular}{|c|c|c|}
\hline Ponceau S & P7170 & Sigma-Aldrich, St. Louis, MO, USA \\
\hline Precision Plus Protein Standard & $161-0374$ & Bio Rad Laboratories GmbH, München, D \\
\hline Primer Forward & & s. Primerliste, Kap. 2.5.5 \\
\hline Primer Reverse & & s. Primerliste, Kap. 2.5.5 \\
\hline Propylen-Glycerol & 398039 & Sigma-Aldrich, St. Louis, MO, USA \\
\hline Random Hexamere & C118A & Promega, Fitchburg, WI, USA \\
\hline RNase Inhibitor & BIO-65028 & Bioline, London, UK \\
\hline Rotiphorese Gel 40 & T802.1 & Carl Roth GmbH + Co.KG, Karlsruhe, D \\
\hline Salzsäure, konzentriert & 1099110001 & Merck KgaA, Darmstadt, D \\
\hline Säurefuchsin & F8129 & Sigma-Aldrich, St. Louis, MO, USA \\
\hline Silbernitrat & S-6506 & Sigma-Aldrich, St. Louis, MO, USA \\
\hline Sodium Dodecyl Sulfat (SDS) & L4509 & Sigma-Aldrich, St. Louis, MO, USA \\
\hline Solvent Blue 43 & 531251 & Sigma-Aldrich, St. Louis, MO, USA \\
\hline Stickstoff, flüssig & & hausintern \\
\hline $\begin{array}{l}\text { SuperSignal WestPico } \\
\text { Chemiluminescent Substrate }\end{array}$ & 34080 & Thermo Fisher Scientific, Waltham, MA, USA \\
\hline TEMED & 2367.3 & Carl Roth GmbH + Co.KG, Karlsruhe, D \\
\hline Tissue Tec O.C.T. Compound & 4583 & Sakura Finetek Europe B.V.; Zoeterwoude, NL \\
\hline Trinatriumcitrat & S4641 & Sigma-Aldrich, St. Louis, MO, USA \\
\hline TRI Reagenz & AM9738 & Ambion by Life Technologies, Carlsbad, CA, USA \\
\hline Triton $\mathrm{X}-100$ & 93426 & Sigma-Aldrich, St. Louis, MO, USA \\
\hline Trizma-Base & T6066 & Sigma-Aldrich, St. Louis, MO, USA \\
\hline Tween 20 & P1379 & Sigma-Aldrich, St. Louis, MO, USA \\
\hline Tysabri ${ }^{\circledR}$ (Natalizumab) & PZN 4971976 & Elan Pharma International Ltd., Dublin, IRL \\
\hline VectaShield Mounting Medium & H-1000 & Vector, Burlingame, CA, USA \\
\hline VectaStain Elite ABC Kit (Standard) & PK-6100 & Vector, Burlingame, CA, USA \\
\hline Wasserstoffperoxid, 30\% & 55760 & Otto Fischar GmbH \& Co. KG, Saarbrücken, D \\
\hline Xylol & 9713.3 & Carl Roth $\mathrm{GmbH}+\mathrm{Co.KG}$, Karlsruhe, D \\
\hline Xylolersatz / HistoClear & 9990505 & Thermo Fisher Scientific, Waltham, MA, USA \\
\hline Zinkformalin & 6764255 & Thermo Fisher Scientific, Waltham, MA, USA \\
\hline
\end{tabular}

\subsubsection{Geräte und Programme}

\begin{tabular}{ll}
\hline Artikel & Firma \\
\hline AlphaEase FC TM & Genetic Technologies Inc., Miami, FL, USA \\
\hline Axio Vision 3.0 (Graphikprogramm) & Carl Zeiss AG, Oberkochen, D \\
\hline BD FACSCanto $^{\text {TM }}$ II & BD Biosciences, San Jose, CA, USA \\
\hline BD FACSDiva $^{\text {TM }}$ Software & BD Biosciences, San Jose, CA, USA \\
\hline Entwicklungsmaschine (SRX-101A) $^{\text {En }}$ & Konica Minolta, Langenhagen, D \\
\hline
\end{tabular}




\begin{tabular}{ll}
\hline Fluoreszenzmikroskop (Zeiss Axiovert 200) & Carl Zeiss AG, Oberkochen, D \\
\hline GraphPad Prism 5 (Statistikprogramm) & GraphPad Software, Inc., La Jolla, CA, USA \\
\hline Image Pro Plus (Grafikprogramm) & Media Cybernetics, Inc.; Bethesda, MD, USA \\
\hline Kryostat (Jung Frigocut 2800N) & Leica Mikrosysteme GmbH, Wetzlar, D \\
\hline Mikroskop (Olympus BX51) & Olympus Deutschland GmbH, Hamburg, D \\
\hline Mikrotom (RM2125 RTS) & Leica Mikrosysteme GmbH, Wetzlar, D \\
\hline Plattenfotometer & BIO-TEK Instruments GmbH, Bad Friedrichshall, D \\
\hline Spektrofotometer (utrospec 3000) & Pharmacia Biotech, jetzt GE Healthcare, München, D \\
\hline SPSS Statistics 20.0 & IBM Corporation, New York, NY, USA \\
\hline Sterilisierung (Steri 250) & Simon Kelter AG, Burgdorf, CH \\
\hline Thermomixer comfort & Eppendorf AG, Hamburg, D \\
\hline Vortexmixer (Vortex-Genie 2) & Scientific Industries Inc., Bohemia, NY, USA \\
\hline Waage (Extend) & Sartorius AG, Göttingen, D \\
\hline Wasserbad (D8) & Haake, Karlsruhe, D \\
\hline Western-Blot-Apparatur (Mini Protean III) & Bio Rad Laboratories GmbH, München, D \\
\hline Wippschüttler & SSL4, Stuart über Roth, Karlsruhe, D \\
\hline Zentrifuge (5702R) & Eppendorf AG, Hamburg, D \\
\hline Zentrifuge (5415D) & Eppendorf AG, Hamburg, D \\
\hline Zentrifuge (Rotanta/S) & Andreas Hettich GmbH \& Co.KG, Tuttlingen, D \\
\hline
\end{tabular}

\subsubsection{Materialien}

\begin{tabular}{lll}
\hline Artikel & Art.-Nummer & Firma \\
\hline Deckgläschen 24x60mm & BB024060A1 & Gerhard Menzel GmbH, Braunschweig, D \\
\hline Eppendorfgefäß & 0030120.094 & Eppendorf AG, Hamburg, D \\
\hline Filterpapier & D3701 & GE Healthcare, München, D \\
\hline Insulinspritzen, 1 ml & $9161309 \mathrm{~V}$ & B. Braun Melsungen AG, Melsungen, D \\
\hline Kryoröhrchen & 368632 & Thermo Fisher Scientific, Waltham, MA, USA \\
\hline MACS Separation Filter & $130-041-407$ & Miltenyi Biotech, Bergisch Gladbach, D \\
\hline Mikrowellplatten & 269620 & Thermo Fisher Scientific, Waltham, MA, USA \\
\hline Nitrozellulosemembran & Protran & Whatman, Dassel, D \\
\hline Objektträger Superfrost Plus & J1800AMNZ & Gerhard Menzel GmbH, Braunschweig, D \\
\hline PAP PEN Mini & LP0002 & Zytomed Systems, Berlin, D \\
\hline PCR-Tubes & 72.991 .002 & Sarstedt, Nümbrecht, D \\
\hline Pipetten & & Eppendorf AG, Hamburg, D \\
\hline Pipettenspitzen & Biosphere & Sarstedt, Nümbrecht, D \\
\hline Polystyreneröhrchen & 352052 & BD Biosciences, San Jose, CA, USA \\
\hline Röntgenfilme & Super RX & Fuji Foto Film GmbH, Düsseldorf, D \\
\hline Serologische Pipetten & & Sarstedt, Nümbrecht, D \\
\hline Skalpell & 5205052 & Feather Safety Razor Co. LTD, Osaka, JP \\
\hline
\end{tabular}




\subsubsection{Puffer und Lösungen für Gewebefärbungen}

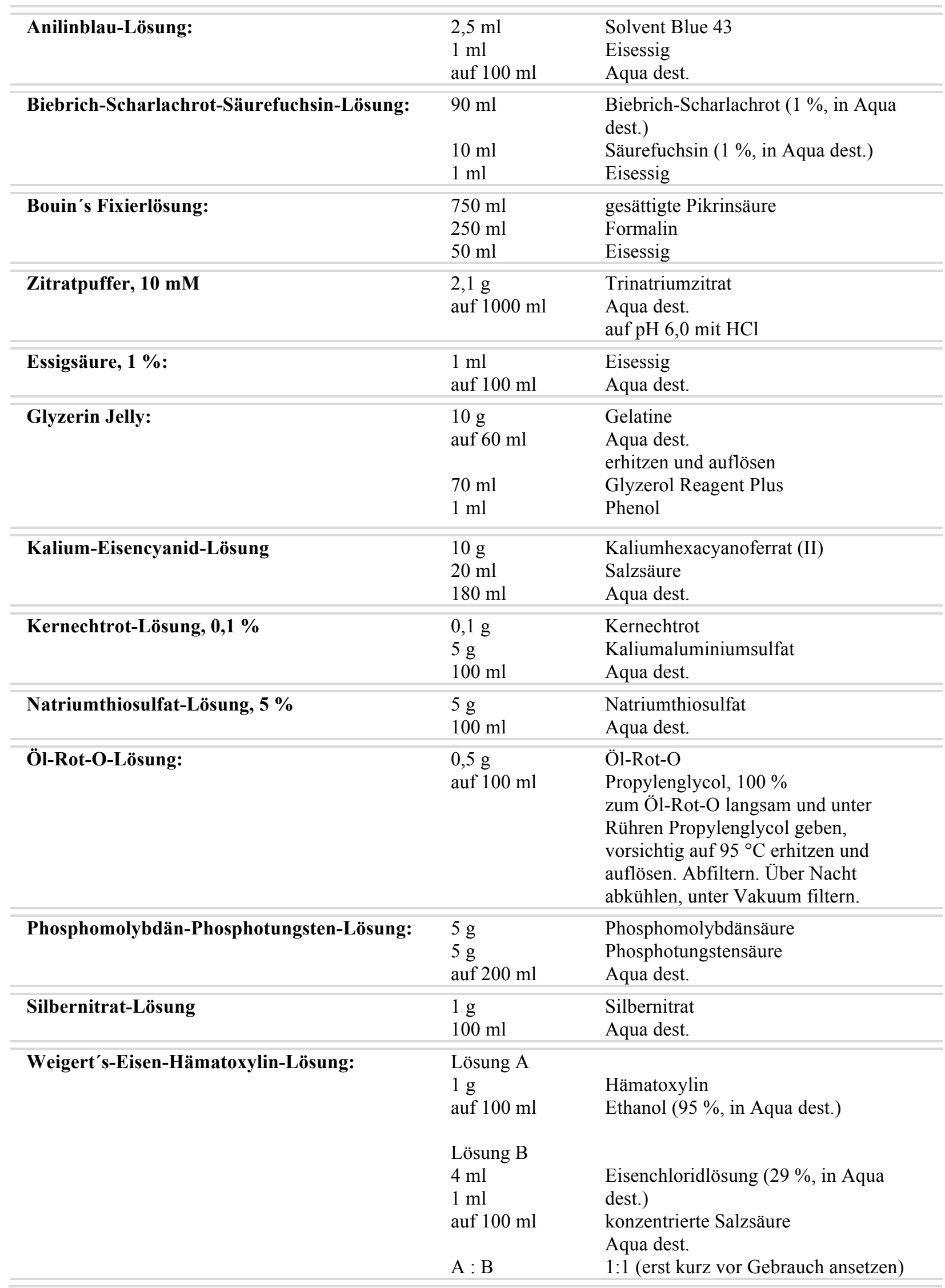




\subsection{Untersuchungen im Tiermodell}

\subsubsection{Versuchsaufbau}

Zur Untersuchung des Einflusses von Übergewicht mit und ohne Hyperleptinämie auf die perivaskuläre Inflammation wurden insgesamt 145 männliche C57BL6/J (WT) WildtypMäuse sowie 15 leptin-defiziente C57BL6/J-Lep ${ }^{\text {ob }}$ (ob/ob) Mäuse im Alter von 6-7 Wochen bei Jackson Laboratories (Bar Harbor, ME, USA) bezogen. Die Tiere wurden dann in der Zentralen Tierexperimentellen Einrichtung (ZTE) der Universitätsmedizin Göttingen (UMG) gehalten. Wasser und Futter standen in ausreichendem Maß zur freien Verfügung.

Die Tiere wurden nach ihrer Ankunft gewogen und in zwei Gruppen aufgeteilt. Jeweils die Hälfte der Tiere wurde mit hochkalorischer Hochfettdiät (HFD; 45 \% der Kalorien aus Fett; D12451 Research Diets Inc., New Brunswick, NJ, USA), die andere Hälfte mit Normalfutter (NC; $10 \%$ der Kalorien aus Fett; D12450B Research Diets Inc.) bis zur Gewebeentnahme gefüttert (s. Tab. 2.1). Die Mäuse wurden unter der Diät wöchentlich gewogen.

\begin{tabular}{lcc}
\hline Kalorienanteil (\%) & HFD: D12451 & NC: D12450B \\
\hline Protein & 20 & 20 \\
\hline Kohlenhydrate & 35 & 70 \\
\hline Fett & 45 & 10 \\
\hline $\mathrm{kcal} / \mathrm{g}$ & 4,73 & 3,85 \\
\hline
\end{tabular}

Tab. 2.1. Verwendetes Mausfutter. Zusammensetzung des Kaloriengehaltes. Auszug aus dem Datenblatt der Firma. 
Zur Bestimmung einer ausreichenden Dauer der Hochfettdiät hinsichtlich einer perivaskulären Akkumulation von Fettgewebe wurden zunächst jeweils 15 WT-Mäuse mit NC sowie nach Gabe von 2, 4 sowie 8 Wochen HFD untersucht. Die entnommenen Gewebe wurden nach folgendem Schema analysiert:

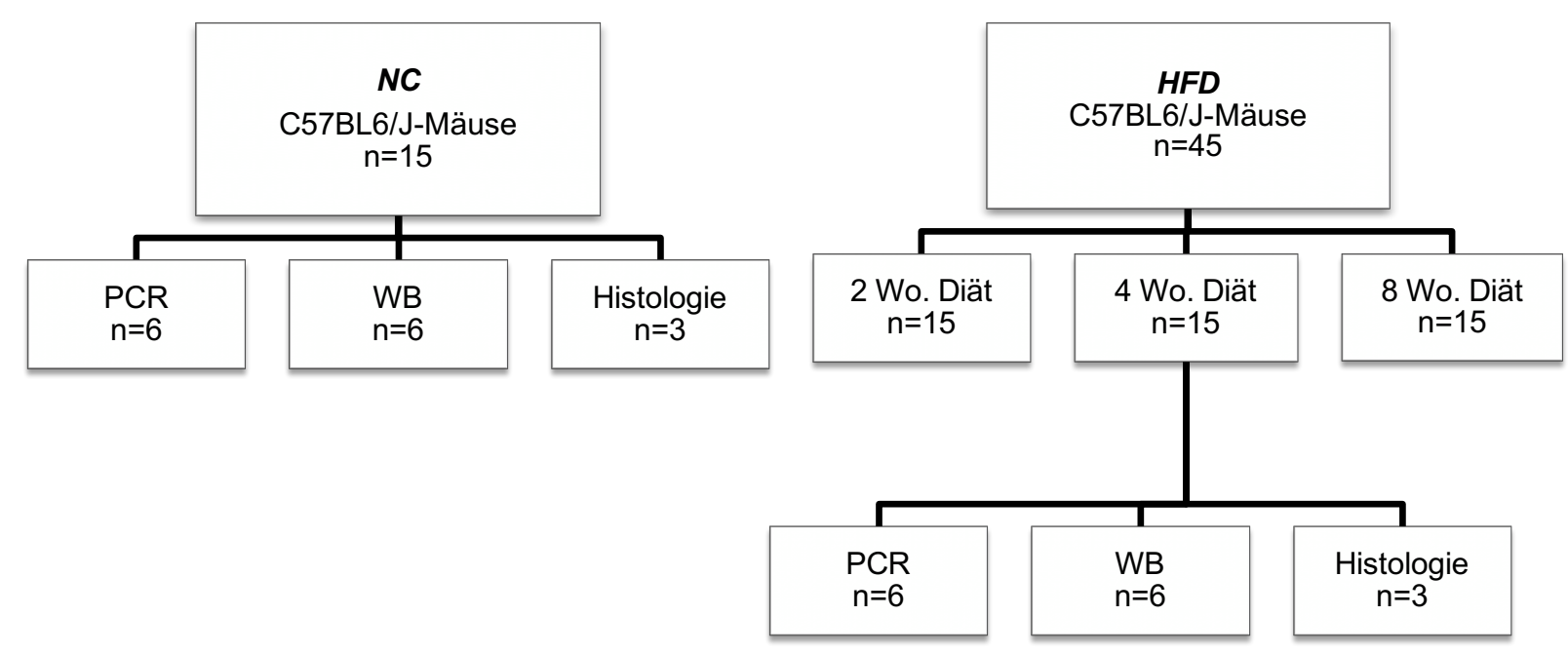

Zur weiteren Differenzierung des Einflusses von Übergewicht wurde nach Protein- und RNAAnalysen der ersten vier Gruppen die optimale Dauer der Diät auf 8 Wochen festgesetzt und erneut 60 WT- sowie 10 Leptin-defiziente $o b / o b$-Mäuse untersucht. Zur Untersuchung des Einflusses von Übergewicht auf der Basis eine genetischen Leptinmangels wurden zusätzlich die Gewebe von 5 ob/ob-Mäusen untersucht (0 Wochen HFD). Somit wurden insgesamt 15 $o b / o b$-Mäuse eingesetzt.

Außerdem wurde zur Simulation einer Langzeit-Adipositas eine Untersuchung mit WTMäusen initiiert, die jeweils 6 Monate auf NC $(n=5)$ sowie HFD $(n=5)$ gesetzt wurden.

Die Bedeutung von Integrin $\alpha_{4}$ für die Rekrutierung von Immunzellen in das Fettgewebe bei Adipositas wurde an 15 WT-Mäusen nach intrakardialer Injektion des monoklonalen Integrin$\alpha_{4}$-Antikörpers Natalizumab (Tysabri®) an Tag 0 und Tag 28 einer 8-wöchigen HFD untersucht.

Alle Gewebe wurden jeweils zur Hälfte für PCR- und FACS-Analysen verwendet. 


\subsubsection{Gewebeentnahme}

Nach entsprechender Dauer der Diät wurde allen Tieren das viszerale und perikardiale Fettgewebe, die abdominale Aorta sowie venöses Blut zur Bestimmung der Leptin-Spiegel entnommen. Neben dem Körpergewicht wurde auch das Gewicht des viszeralen Fettdepots erfasst, um einen weiteren Parameter zur Evaluation der Adipositas zu haben.

Die Mäuse wurden vor der Tötung durch zervikale Dislokation mittels inhalativer IsofluranNarkose tief betäubt und gewogen. Außerdem wurde von den Versuchstieren Blut durch kardiale Punktion in mit EDTA (Verdünnung 1:10) vorbeladenen Insulinspritzen abgenommen. Nach Tötung erfolgte die Eröffnung des Bauchraums mittels medianer Laparatomie und die epididymalen, viszeralen Fettdepots (VAT) wurden entnommen und gewogen. Nach Eröffnung des Thorax wurde das Herz mitsamt perivaskulärem Fettgewebe (PVAT) entfernt, vom PVAT separiert und dann gewogen. Des Weiteren wurde die abdominale Aorta unter einem Operationsmikroskop freipräpariert und dann entnommen. Die Gewebe für Western-Blot- und PCR-Analysen wurden in flüssigem Stickstoff schockgefroren und dann bei $-80^{\circ} \mathrm{C}$ gelagert. Die Gewebe, welche für FACS-Analysen verwendet wurden, sowie die Aortenpräparate wurden in physiologischer Kochsalzlösung auf Eis gelagert.

Das Blut wurde in ein Eppendorfgefäß überführt und anschließend bei $3000 \mathrm{rpm}$ für 10 Minuten zentrifugiert. Das Serum wurde in einem frischen Eppendorfgefäß bei $-80{ }^{\circ} \mathrm{C}$ für weitere Analysen weggefroren.

Die für die Histologie vorgesehenen Aortenpräparate wurden mit Hilfe von Tissue Tek ${ }^{\mathrm{TM}}$ auf einem vorbereiteten beschrifteten Korkplättchen eingebettet. Hierzu wurde der Korken in einen mit Methylbutan gefüllten Behälter eingetaucht, der in flüssigem Stickstoff gekühlt wurde. Nach Einbettung wurden die Gewebe bei $-20^{\circ} \mathrm{C}$ bis zum Erstellen der Gewebequerschnitte gelagert.

\subsubsection{Histologische Analyse der Mausaorten}

\subsubsection{Erstellung von Gefrierschnitten}

Die eingebetteten Gewebe wurden an einem vorgekühlten Kryotom auf eine Dicke von $5 \mu \mathrm{m}$ geschnitten und jeweils 3 bis 4 Serienschnitte auf einen Objektträger überführt. Für jedes 
Präparat wurden 20 Objektträger angefertigt, welche mit der Nummer des Präparates beschriftet und in Objektträgerkästen bei $-20^{\circ} \mathrm{C}$ gelagert wurden.

\subsubsection{Histologische Untersuchungen}

\subsection{Nachfixierung}

Die Gefrierschnitte wurden 5 Minuten bei RT aufgetaut und danach 5 Minuten in PBS gewässert. Danach erfolgte die Nachfixierung für 10 Minuten in vorgekühltem Aceton bei $20^{\circ} \mathrm{C}$. Vor der Weiterverarbeitung wurden die Objektträger unter dem Abzug getrocknet.

\subsection{Hämatoxylin-Eosin-Färbung}

Zur Übersicht über die Gewebestruktur wurde zunächst eine Hämatoxylin-Eosin-Färbung durchgeführt.

Die Kernfärbung lief für 5 Minuten in Hämalaun nach Harris, gefolgt von einer kurzen Spülung in destilliertem Wasser. Die Differenzierung erfolgte durch dreimaliges kurzes Eintauchen in $\mathrm{HCl}$-Alkohol, anschließend wurde unter fließendem Leitungswasser 15 Minuten lang gebläut. Die Gegenfärbung schloss sich für 2 Minuten in 0,5 \%igem Eosin an, gefolgt von mehrmaligem Spülen in destilliertem Wasser. Daran schloss sich eine weitere Differenzierung durch kurzes Eintauchen in 80 \%igen EtOH sowie die Entwässerung durch eine aufsteigende Alkoholreihe mit jeweils zweimalig 2 Minuten in $95 \%$ und $100 \% \mathrm{EtOH}$ und zweimalig 5 Minuten in Xylolersatzmittel an. Abschließend wurden die Objektträger mit dem Eindeckmittel Entellan versiegelt.

\subsection{Masson-Trichrom-Färbung}

Zur Darstellung einer perivaskulären Fibrose wurde die Bindegewebsfärbung nach MassonTrichrom durchgeführt.

Nach durchgeführter Nachfixierung (siehe oben) standen die Schnitte über Nacht unter dem Abzug in Bouin's-Fixierlösung und wurden am nächsten Morgen unter fließendem Leitungswasser gespült. Die Kernfärbung erfolgte in Weigert's-Eisen-Hämatoxylin-Lösung, in welcher die Schnitte für 10 Minuten inkubiert wurden gefolgt von 10-minütigem Waschen in Leitungswasser. Die Muskelfärbung in Biebrich-Scharlachrot-Säurefuchsin schloss sich für 
15 Minuten nach kurzem Spülen in Aqua dest. an. Danach folgte die Kollagenfärbung in Phosphomolybdän-Phosphotungsten-Lösung für 15 Minuten und in Anilinblau-Lösung für 8 Minuten, gefolgt von 5-minütiger Differenzierung in $1 \%$ iger Essigsäure sowie der Entwässerung durch eine aufsteigende Alkoholreihe mit jeweils zweimalig 2 Minuten in $95 \%$ und $100 \%$ EtOH und Histoclear. Das Eindecken erfolgte mit Hilfe von Histomount.

\subsubsection{4 ÖI-Rot-O-Färbung}

Zur Beurteilung des perivaskulären Fettgewebes wurde eine Öl-Rot-O-Färbung durchgeführt. Hierbei erfolgte die Nachfixierung der Schnitte nach 20-minütiger Trocknung bei RT für 5 Minuten in eisgekühltem Formalin mit anschließendem 3-mal 2-minütigem Waschen in Aqua dest. Danach erfolgte die Inkubation in $100 \%$ Propylen-Glyzerol für 5 Minuten bei RT und die Färbung in Öl-Rot-O-Lösung für 8 Minuten bei $60^{\circ} \mathrm{C}$ im Wasserbad. Im Anschluss daran wurden die Schnitte für 5 Minuten bei RT in $85 \%$ igem Propylen-Glyzerol inkubiert und danach 3-malig für je 2 Minuten in Aqua dest. gewaschen. Die Kernfärbung erfolgte durch 10-maliges kurzes Eintauchen in Gill's Hämatoxylin, anschließend wurden die Schnitte etwa 30 Sekunden unter fließendem Leitungswasser gebläut. Das Eindecken erfolgte mittels bei $60{ }^{\circ} \mathrm{C}$ im Wasserbad verflüssigter Glyzerin-Jelly.

\subsubsection{Immunfluoreszenzfärbungen}

\subsection{Allgemeines Protokoll für das Anfertigen von Immunfluoreszenzfärbungen}

Nach dem Auftauen der Schnitte wurden diese für 5 Minuten in PBS gewässert, gefolgt von einer 10-minütigen Fixierung in vorgekühltem Aceton bei $-20{ }^{\circ} \mathrm{C}$. Nach dem Trocknen unter dem Abzug wurden die Schnitte erneut in PBS gewässert, bevor die Inkubation mit dem 1. Antikörper folgte. Zum Einsparen von Antikörper wurden die Schnitte auf dem Objektträger mit einem hydrophoben Wachsstift umrandet. Danach wurden - je nach Größe des Schnittes - zwischen 50 und $100 \mu 1$ des in Antibody-Diluent verdünnten Primärantikörpers aufgetragen. Zur Inkubation wurden die Objektträger in einer feuchten Kammer gelagert, alle übrigen Schritte wurden in Glasküvetten mit Objektträgerhaltern durchgeführt. Nach der Inkubation erfolgte ein erneutes Waschen in PBS für 3-malig 5 Minuten. Darauf folgte die Inkubation des zweiten, mit einem Fluoreszenzfarbstoff gekoppelten Sekundärantikörpers. Nach erneutem Waschen in PBS für 3 mal 5 Minuten wurden die Schnitte zur Kernfärbung mit 
DAPI, welches 1:500 in PBS verdünnt wurde, für 30 Minuten bei Raumtemperatur inkubiert. Nach abschließendem Waschen erfolgte das Eindecken mit VectaShield und die Lagerung der Schnitte in völliger Dunkelheit bei $4{ }^{\circ} \mathrm{C}$ bis zur Begutachtung unter dem Fluoreszenzmikroskop Zeiss Axiovert 200 und Fotodokumentation mit Hilfe von Zeiss AxioVision.

\subsection{Nachweis des CD3-Oberflächenantigens auf T-Lymphozyten}

Zur Untersuchung der Verteilung und Häufigkeit der T-Lymphozyten in der Gefäßwand und im perivaskulären Fettgewebe wurden die angefertigten Schnitte auf das Oberflächen-Antigen CD3 angefärbt. Es handelt sich hierbei um einen Proteinkomplex, der aus 4 Ketten besteht. In Interaktion mit dem T-Zell-Rezeptor und der $\zeta$-Kette bildet CD3 den T-Zell-RezeptorKomplex und dient der Aktivierung von T-Lymphozyten.

Die Färbung wurde gemäß o. a. allgemeinem Protokoll durchgeführt.

Die Inkubation des ersten Antikörpers wurde über Nacht bei $4{ }^{\circ} \mathrm{C}$ gefolgt von 45 Minuten bei RT durchgeführt. Der zweite Antikörper wurde zunächst für 120 Minuten bei $4{ }^{\circ} \mathrm{C}$ und danach bei Raumtemperatur für zusätzliche 20 Minuten inkubiert.

Verwendete Antikörper und Verdünnungen:

\begin{tabular}{llll}
\hline & Antikörper & Verdünnung & Best.-Nr. \\
\hline 1. AK & CD 3 & $1: 20$ & sc-101422, SantaCruz Biotechnology Inc., Santa Cruz, CA, USA \\
\hline 2. AK & goat anti-rat 555 & $1: 400$ & MFP-A2434, MoBiTec GmbH, Göttingen, D \\
\hline Kerne & DAPI & $1: 500$ & D9542, Sigma-Aldrich, St. Louis, MO, USA \\
\hline
\end{tabular}

Tab. 2.2. Antikörper für die CD3-Immunfluoreszenzfärbung

\subsection{Nachweis des F4/80-Oberflächen-Antigens auf Makrophagen}

Um die Verteilung und das Vorkommen von Makrophagen und dendritischen Zellen in der Gefäßwand und dem perivaskulären Gewebe zu erfassen, wurden die Schnitte auf den Immunmarker F4/80, der spezifisch von murinen Monozyten exprimiert wird, angefärbt. F4/80 ist ein Transmembranrezeptor aus der Klasse der G-Protein-gekoppelten Adhäsionsrezeptoren. Es kommt auf der Oberfläche reifer Makrophagen vor.

Die Färbung wurde gemäß o. a. allgemeinem Protokoll durchgeführt. 
Vor Inkubation des ersten Antikörpers erfolgte die Permeabilisierung des Gewebes mit vorgewärmtem Triton-X $\left(0,05 \%\right.$ in PBS) für 10 Minuten bei $37^{\circ} \mathrm{C}$ und die Blockade der Bindungsstellen für den zweiten Antikörper mit $10 \%$ igem NGS für 30 Minuten. Der erste Antikörper wurde dann über Nacht bei $4{ }^{\circ} \mathrm{C}$ inkubiert. Die Inkubation des zweiten Antikörpers erfolgte für 60 Minuten bei Raumtemperatur.

Verwendete Antikörper und Verdünnungen:

\begin{tabular}{llll}
\hline & Antikörper & Verdünnung & Best.-Nr. \\
\hline 1. AK & F4/80 & $1: 50$ & MCA 497G, AbD Serotec, Raleigh, NC, USA \\
\hline 2. AK & goat anti-rat 555 & $1: 400$ & MFP-A2434, MoBiTec GmbH, Göttingen, D \\
\hline Kerne & DAPI & $1: 500$ & D9542, Sigma-Aldrich, St. Louis, MO, USA \\
\hline
\end{tabular}

Tab. 2.3. Antikörper für die F4/80-Immunfluoreszenz

\subsection{Nachweis von VCAM-1 auf aktiviertem Gefäßendothel}

Zur Darstellung der Aktivierung des Gefäßendothels wurden die Schnitte auf das vaskuläre Zelladhäsionsmolekül VCAM-1 (CD106) angefärbt. Das Sialoglykoprotein wird nach Stimulation der Endothelzellen durch Zytokine exprimiert und vermittelt die Adhäsion Integrin a4-positiver Leukozyten im Rahmen der Diapedese während einer interstitiellen Entzündungsreaktion. Die Hochregulation ist Folge einer erhöhten Gentranskription, die TNF $\alpha$ - und Interleukin-1-vermittelt abläuft und für etwa 24 Stunden anhält. VCAM-1 dient in erster Linie als endothelialer Ligand für das Integrin $\alpha_{4} \beta_{1}$, nachdem die Leukozyten Zytokinvermittelt die Konformation des Integrins verändert und dadurch die Affinität erhöht hatten.

Die Färbung wurde gemäß o. a. Protokoll durchgeführt.

Vor der Inkubation des ersten Antikörpers erfolgte die Blockade der Bindungsstellen für den zweiten Antikörper mit einer 10 \%igen Rinderserumalbumin-Lösung in PBS für 30 Minuten. Die Inkubation des ersten Antikörpers erfolgte über Nacht bei $4{ }^{\circ} \mathrm{C}$, der zweite Antikörper wurde für 60 Minuten bei RT inkubiert.

Verwendete Antikörper und Verdünnungen:

\begin{tabular}{llll}
\hline & Antikörper & Verdünnung & Best.-Nr. \\
\hline 1. AK & VCAM-1 & $1: 25$ & sc-8304, SantaCruz Biotechnology Inc., Santa Cruz, CA, USA \\
\hline 2. AK & goat anti-rabbit 555 & $1: 400$ & MFP-A2429, MoBiTec GmbH, Göttingen, D \\
\hline
\end{tabular}




Kerne DAPI 1:500 D9542, Sigma-Aldrich, St. Louis, MO, USA

Tab. 2.4 Antikörper für die VCAM-1-Immunfluoreszenz

\subsection{Nachweis von Fibronektin in der interstitiellen Matrix}

Das Vorkommen des Extrazellulärmatrix-Proteins Fibronektin und somit eines möglichen Liganden für Integrin- $\alpha_{4}$-positive Leukozyten wurde ebenfalls erfasst. Fibronektin spielt eine Rolle in der Integrin- $\alpha_{4}$-vermittelten Adhäsion und Migration von Leukozyten im Extrazellulärraum. Das von Fibroblasten sezernierte Fibronektin bildet eine unlösliche Matrix und fördert nach Fragmentierung durch Proteasen die Wundkontraktion und trägt somit erheblich zum Prozess der Wundheilung bei. Hierbei spielt die Freilegung der V-Region eine entscheidende Rolle, da hier die Bindungsstelle für Integrin $\alpha_{4} \beta_{1}$-positive Leukozyten lokalisiert ist und diese großen Anteil an der Kontraktion der Extrazellulärmatrix haben.

Die Färbung wurde gemäß o. a. Protokoll durchgeführt.

Die Fixierung erfolgte bei dieser Färbung mit 4 \%igem PFA für 10 Minuten bei RT. Die Bindungsstellen für den zweiten Antikörper wurden mit 10 \%igem NGS für 30 Minuten bei RT blockiert, bevor die Inkubation des ersten Antikörpers für 60 Minuten bei RT erfolgte. Der zweite Antikörper wurde ebenfalls für 60 Minuten bei RT inkubiert.

Verwendete Antikörper und Verdünnungen:

\begin{tabular}{llll}
\hline & Antikörper & Verdünnung & Best.-Nr. \\
\hline 1. AK & Fibronektin & $1: 50$ & ab33570, Abcam PLC, Cambridge, UK \\
\hline 2. AK & goat anti-rabbit 555 & $1: 400$ & MFP-A2429, MoBiTec GmbH, Göttingen, D \\
\hline Kerne & DAPI & $1: 500$ & D9542, Sigma-Aldrich, St. Louis, MO, USA \\
\hline
\end{tabular}

Tab. 2.5 Antikörper der Fibronektin-Immunfluoreszenz

\subsubsection{Genehmigung der im Rahmen der Studie durchgeführten Tierversuche}

Nach $\S 8$ des Tierschutzgesetzes vom Niedersächsischen Landesamt für Verbraucherschutz und Lebensmittelsicherheit wurde die tierexperimentelle Studie unter dem Aktenzeichen 33.942502-04-10/0153 am 29.07.2010 genehmigt. Die Tierhaltung und die Durchführung der Versuche erfolgte nach deutschen Bestimmungen. 


\subsection{Untersuchungen an humanem Probenmaterial}

\subsubsection{Studiendesign}

Zur Überprüfung der Ergebnisse im murinen Modell wurde eine klinisch-experimentelle Studie mit menschlichem Probenmaterial (peri-aortales Fettgewebe, Blut) etabliert. Ein positives Votum der Ethikkommission war zuvor eingeholt worden. In Kooperation mit Herrn PD Dr. med. Theodor Tirilomis, Oberarzt der Abteilung für Thorax-, Herz- und Gefäßchirurgie an der Universitätsmedizin Göttingen, wurden nach vorheriger Aufklärung und Vorliegen eines unterschriebenen Aufklärungsformulars insgesamt 22 Patienten eingeschlossen. Die Asservierung der Blutproben und Patientengewebe sowie die Speicherung und Verarbeitung der Patientendaten erfolgte pseudonymisiert, und alle an der Studie beteiligten ÄrztInnen und MedizinstudentInnen unterliegen der ärztlichen Schweigepflicht. Es wurden nur einwilligungsfähige Probanden zwischen 18 und 85 Jahren in die Studie aufgenommen.

Aus dem Patientenkollektiv wurden 16 Patienten der Interventionsgruppe und 6 Patienten der Kontrollgruppe zugeordnet. In die Kontrollgruppe wurden jene Patienten eingeschlossen, bei denen eine KHK ausgeschlossen wurde und die sich einem chirurgischen Ersatz der Aortenklappe unterzogen. Die Einschlusskriterien für die Interventionsgruppe waren die Durchführung einer kardialen Bypass-Operation mit oder ohne gleichzeitigem Ersatz der Aortenklappe bei koronarangiographisch nachgewiesener koronarer Herzkrankheit. Diese Patienten wurden nochmals nach ihrem BMI in normalgewichtig und adipös (BMI $\geq 30 \mathrm{~kg} / \mathrm{m}^{2}$ ) unterteilt. Die Patienten der Kontrollgruppe wiesen alle einen BMI $<30 \mathrm{~kg} / \mathrm{m}^{2}$ auf, daher war dies dort nicht möglich.

\subsubsection{Ethikantrag}

Die klinisch-experimentelle Studie unter dem Titel „Bedeutung des perivadventitiellen Fettgewebes für die koronare Herzkrankheit“" wurde von der Ethik-Kommission der GeorgAugust-Universität Göttingen als biomedizinisches Forschungsvorhaben unter der Antragsnummer 13/7/10 genehmigt. 


\subsubsection{Gewinnung von Patientenmaterial}

Während der Operation wurden ein Teil des Fettdepots, welches sich an der Aortenwurzel befindet, sowie ein Stück mediastinales Fettgewebe mit einem Durchmesser von etwa $5 \mathrm{~cm}$ in sterile Gefäße mit Ringerlösung überführt und zur weiteren Analyse gekühlt aus dem Operationssaal ins Labor geholt. Des Weiteren wurden bei Aortenklappenersatz der Schnittrand der Aorta sowie bei Bypass-Operationen die Aortenstanzen in sterile Ringerlösung überführt. Sämtliche entnommenen Gewebe werden normalerweise intraoperativ verworfen, um die Implantation der Bypassgefäße respektive die Einpflanzung der Herzklappe zu ermöglichen. Zusätzlich zur normalen präoperativen Blutentnahme wurden jedem Patienten insgesamt 11,5 ml Vollblut abgenommen, verteilt auf eine 9-ml-Serum- und eine 2,5-ml-EDTA-Monovette. Das Serum wurde für 10 Minuten bei $3000 \mathrm{rpm}$ zentrifugiert und für weitere Analysen bei $-80{ }^{\circ} \mathrm{C}$ weggefroren. Das EDTA-Blut wurde gekühlt und dann der FACS-Analyse zugeführt.

Die entnommenen Gefäßwandpräparate sowie Teile des Fettgewebes wurden in Paraffin eingebettet. Hierzu wurden die Gewebe zunächst 24 Stunden in $4 \%$ iges Zinkformalin gegeben. Am nächsten Tag wurden sie in beschriftete Einbettkassetten gelegt und nach folgendem Schema in Glasküvetten inkubiert:

\begin{tabular}{ll}
\hline Zeit & Medium \\
\hline 5 Minuten & $70 \%$ EtOH \\
\hline 35 Minuten & $80 \%$ EtOH \\
\hline 60 Minuten & $96 \%$ EtOH \\
\hline 60 Minuten & $100 \%$ EtOH \\
\hline 120 Minuten & Chloroform \\
\hline 75 Minuten & Paraffin \\
\hline
\end{tabular}

Tab. 2.6 Einbettschema Paraffin

Hiernach wurden die Präparate im Einbettautomaten ausgegossen und ausgehärtet. Bis zur Weiterverarbeitung wurden die Paraffinblöcke in Blockkarteikästen aufbewahrt. 


\subsubsection{Erfassung demografischer und laborchemischer Parameter}

Über einen eigens im Rahmen der Studie entworfenen Fragebogen wurden Größe, Gewicht, Body-Mass-Index, Alter sowie kardiovaskuläre Risikofaktoren und die aktuelle Medikation erfasst. Aus den Vorbefunden aus der Abteilung für Klinische Chemie wurden die entsprechenden laborchemischen Parameter, sofern vorhanden, erfasst.

\begin{tabular}{|c|c|c|c|}
\hline Demografie & Risikofaktoren & Laborchemie & Medikamente \\
\hline Alter [Jahre] & Arterielle Hypertonie & Kreatinin $[\mathrm{mg} / \mathrm{dl}]$ & Statine \\
\hline Größe $[\mathrm{cm}]$ & Rauchen & Harnstoff-N [mg/dl] & Beta-Blocker \\
\hline Gewicht [kg] & Diabetes & eGFR [ml/min] & ACE-Hemmer \\
\hline \multirow[t]{8}{*}{ Body-Mass-Index $\left[\mathrm{kg} / \mathrm{m}^{2}\right]$} & Herzinfarkt & Natrium [mmol/1] & $\begin{array}{l}\text { Calcium- } \\
\text { Antagonisten }\end{array}$ \\
\hline & Familienanamnese & Kalium [mmol/1] & TAH \\
\hline & & C-reaktives Protein $[\mathrm{mg} / \mathrm{l}]$ & Diuretika \\
\hline & & Lactatdehydrogenase [Units/1] & Orale Antidiabetika \\
\hline & & Creatinkinase [Units/1] & Insulin \\
\hline & & CK-MB [Units/l] & Cortison \\
\hline & & & Hormone \\
\hline & & & $\begin{array}{l}\text { Vitamin-K- } \\
\text { Antagonisten }\end{array}$ \\
\hline
\end{tabular}

Tab. 2.7 Erfasste Parameter der klinisch-experimentellen Studie

\subsection{Durchflusszytometrie von Blut und Fettgewebe}

\subsubsection{Allgemeines Protokoll zur Aufbereitung des Fettgewebes}

Das viszerale und perikardiale Fettgewebe wurde mit einem Skalpell in etwa $5 \mathrm{~mm}$ kleine Stücke zerteilt und in Kollagenase-Puffer transferiert. Dieses wurde im Wärmeschüttler bei $37^{\circ} \mathrm{C}$ für 45 Minuten inkubiert und anschließend durch sog. MACS Preseparation Filter (Miltenyi Biotech) filtriert. Nach Zentrifugation bei 1000 x g (3000 rpm) für 15 Minuten erfolgte ein 3-maliges Waschen in $5 \mathrm{ml} \mathrm{PBS} / 2 \%$ BSA gefolgt von jeweils 3-minütiger Zentrifugation bei 1000 x g (3000 rpm). Die Zellpellets wurden anschließend bei den humanen Geweben in $2 \mathrm{ml}$, bei den murinen Geweben in $700 \mu 11 \%$ igem PFA resuspendiert und für die Inkubation auf die entsprechende Anzahl FACS-Röhrchen aufgeteilt. 
Das humane peripher-venöse Blut wurde aus einer EDTA-S-Monovette in die FACSRöhrchen überführt, das murine Blut aus den vorbereiteten Eppendorfgefäßen.

\subsubsection{Verwendete Lösungen und Puffer}

\begin{tabular}{lll}
\hline FC-Puffer & $0,5 \%$ & $\begin{array}{l}\text { BSA } \\
\text { in 1x PBS }\end{array}$ \\
\hline \hline PBS 10X & $160 \mathrm{~g}$ & $\mathrm{NaCl}$ \\
& $4 \mathrm{~g}$ & $\mathrm{KCl}$ \\
$28,8 \mathrm{~g}$ & Natriumhydrogenphosphat \\
& $4,8 \mathrm{~g}$ & Kaliumdihydrogenphosphat \\
& auf $2000 \mathrm{ml}$ & Aqua dest. \\
& & auf pH 7,4 \\
\hline \hline Kollagenase-Puffer & $25 \mathrm{mg}$ & Kollagenase A \\
& auf $50 \mathrm{ml}$ & PBS/ $2 \% \mathrm{BSA}$ \\
\hline \hline
\end{tabular}

\subsubsection{Inkubation und Analyse der Proben}

Die mit den Proben bestückten Polystyrene-Röhrchen wurden mit $1 \mathrm{ml}$ FACS-LysingSolution gefüllt und vorsichtig mit Hilfe einer Pipette vermischt. Nach Inkubation für 10 Minuten bei RT wurde die Lyse durch Zugabe von $2 \mathrm{ml} \mathrm{FC-Puffer} \mathrm{und} \mathrm{anschließendes}$ gründliches Mischen gestoppt. Die Röhrchen wurden für 5 Minuten bei $1200 \mathrm{rpm}$ zentrifugiert und anschließend das Pellet nach Abgießen des Überstandes in 3 ml FC-Puffer resuspendiert. Dieser Vorgang wurde zweimal wiederholt. Nach der dritten Zentrifugation erfolgte die Resuspension in $100 \mu 1$ FC-Puffer. Anschließend erfolgte die Inkubation mit den entsprechenden Antikörpern für 45 Minuten bei $4{ }^{\circ} \mathrm{C}$ im Dunklen (Kühlschrank). Nach Zugabe von $2 \mathrm{ml}$ vorgekühltem FC-Puffer erfolgte eine erneute Zentrifugation für 5 Minuten bei $1200 \mathrm{rpm}$. Nach Abgießen des Überstandes wurden die Pellets in $250 \mu 11 \%$ igem PFA resuspendiert und bis zur Messung im FACSCanto II (Becton Dickinson) bei $4{ }^{\circ} \mathrm{C}$ im Dunklen gelagert.

Die Analyse der Daten erfolgte mit Hilfe der Software FACSDiva (Becton Dickinson).

Im murinen Modell wurden $100 \mu 1$ eingesetzte Probe mit $1 \mu 1$ Antikörper inkubiert. Folgende Kombinationen von Fluoreszenz-markierten Antikörpern wurden eingesetzt: 


\begin{tabular}{lllll}
\hline Zelltyp & FITC & PE & APC & PerCP/Cy5.5 \\
\hline T-Helfer-Zellen & CD4 & Integrin $\alpha_{4}$ & Leptin Rezeptor & -- \\
\hline Zytotoxische T-Zellen & CD8a & Integrin $\alpha_{4}$ & Leptin Rezeptor & -- \\
\hline Monozyten & F4/80 & Integrin $\alpha_{4}$ & Leptin Rezeptor & CD11b \\
\hline Proinflammatorische Monozyten & F4/80 & Integrin $\alpha_{4}$ & Leptin Rezeptor & Ly6C \\
\hline NK-Zellen & CD49b & Integrin $\alpha_{4}$ & Leptin Rezeptor & -- \\
\hline
\end{tabular}

Zusätzlich im Fettgewebe:

\begin{tabular}{lllll}
\hline Dendritische Zellen & F4/80 & Integrin $\alpha_{4}$ & Leptin Rezeptor & CD11c \\
\hline Leukozyten & CD45 & Integrin $\alpha_{4}$ & Leptin Rezeptor & --
\end{tabular}

Tab. 2.9 Verwendete Antikörperkombinationen in der Durchflusszytometrie des murinen Gewebes

Im humanen Modell wurden $200 \mu$ l eingesetzte Probe mit $5 \mu 1$ Antikörper inkubiert. Folgende Kombinationen von Fluoreszenz-markierten Antikörpern wurden eingesetzt:

\begin{tabular}{lllll}
\hline Zelltyp & FITC & PE & APC & PerCP/Cy5.5 \\
\hline T-Helfer-Zellen & CD4 & Integrin $\alpha_{4}$ & Leptin Rezeptor & -- \\
\hline Zytotoxische T-Zellen & CD8 & Integrin $\alpha_{4}$ & Leptin Rezeptor & -- \\
\hline Monozyten & CD14 & Integrin $\alpha_{4}$ & Leptin Rezeptor & CD16 \\
\hline NK-Zellen & CD161 & Integrin $\alpha_{4}$ & Leptin Rezeptor & CD3 \\
\hline
\end{tabular}

Zusätzlich im Fettgewebe:

\begin{tabular}{lllll}
\hline Makrophagen & CD14 & Integrin $\alpha_{4}$ & Leptin Rezeptor & CD206 \\
\hline Leukozyten & CD45 & Integrin $\alpha_{4}$ & Leptin Rezeptor & -- \\
\hline
\end{tabular}

Tab. 2.10 Verwendete Antikörperkombinationen in der Durchflusszytometrie des humanen Gewebes

\subsubsection{Verwendete Antikörper im murinen Modell}

\begin{tabular}{lllll}
\hline Antikörper & Konjugat & Epitop & Art.-Nummer & Firma \\
\hline CD4 & FITC & CD4 & 553651 & $\begin{array}{l}\text { BD Biosciences, San } \\
\text { Jose, CA, USA }\end{array}$ \\
\hline CD8a & FITC & CD8 Differenzierungs-Antigen & 553031 & BD Biosciences \\
\hline CD11b & PerCP/Cy5.5 & CR-3 alpha Kette & 550993 & BD Biosciences \\
\hline CD11c & PerCP/Cy5.5 & Integrin $\alpha_{x}$ & 117327 & $\begin{array}{l}\text { BioLegend, San Diego, } \\
\text { CA, USA }\end{array}$ \\
\hline CD45 & FITC & Pan-Leukozyten-Antigen & 553079 & BD Biosciences \\
\hline CD49d & PE & Integrin $\alpha_{4}$ Kette & 557420 & BD Biosciences \\
\hline
\end{tabular}




\begin{tabular}{lllll}
\hline CD49b & FITC & Integrin $\alpha_{2}$ Kette & 108905 & BioLegend \\
\hline CD90.1 & PerCP/Cy5.5 & CD90 & 202515 & BioLegend \\
\hline F4/80 & FITC & Pan-Makrophagen-Antigen & $11-4801$ & $\begin{array}{l}\text { eBioscience, San Diego, } \\
\text { CA, USA }\end{array}$ \\
\hline Ly-6C & PerCP/Cy5.5 & Ly-6C & 560525 & BD Biosciences \\
\hline ObR & APC & Leptin-Rezeptor & FAB867A & $\begin{array}{l}\text { R\&D Systems, } \\
\text { Minneapolis, MN, USA }\end{array}$ \\
\hline
\end{tabular}

\section{Isotypenkontrollen}

\begin{tabular}{lllll}
\hline IgG2a & FITC & --- & 553929 & BD Biosciences \\
\hline IgG2a & FITC & --- & $11-4321$ & eBioscience \\
\hline IgM & FITC & --- & 400805 & BioLegend \\
\hline IgG2a & PE & --- & 553930 & BD Biosciences \\
\hline IgG2b & APC & --- & IC0041A & R\&D Systems \\
\hline IgG1k & PerCP/Cy5.5 & --- & 400149 & BioLegend \\
\hline IgG2b & PerCP/Cy5.5 & --- & 550764 & BD Biosciences \\
\hline IgM & PerCP/Cy5.5 & --- & 560573 & BD Biosciences \\
\hline Armenian & PerCP/Cy5.5 & --- & 400931 & BioLegend \\
\hline Hamster IgG & & & & \\
\hline
\end{tabular}

Tab. 2.11 Verwendete Antikörper in der Durchflusszytometrie des murinen Gewebes

\subsubsection{Verwendete Antikörper im humanen Modell}

\begin{tabular}{lllll}
\hline Antikörper & Konjugat & Epitop & Art.-Nummer & Firma \\
\hline CD3 & PerCP/Cy5.5 & T-Zell-Oberflächen-Antigen & 560835 & BD Biosciences \\
\hline CD4 & FITC & CD4 & 555346 & BD Biosciences \\
\hline CD8 & FITC & CD8 $\alpha$-Untereinheit & 555634 & BD Biosciences \\
\hline CD14 & FITC & Lipopolysaccharid-Rezeptor & 555397 & BD Biosciences \\
\hline CD16 & PerCP/Cy5.5 & FC- - -Rezeptor & 560717 & BD Biosciences \\
\hline CD45 & FITC & Pan-Leukozyten-Antigen & 560976 & BD Biosciences \\
\hline CD49d & PE & Integrin $\alpha_{4}$-Kette & 555503 & BD Biosciences \\
\hline CD66b & FITC & & 555724 & BD Biosciences \\
\hline CD161 & FITC & & 556080 & BD Biosciences \\
\hline CD206 & FITC & Makrophagen Mannose & 551135 & BD Biosciences \\
\hline ObR & APC & Leztinrezeptor & FAB867A & R\&D Systems \\
\hline & & & & \\
\hline Isotypenkontrollen & & 555573 & BD Biosciences \\
\hline IgG2a & FITC & --- &
\end{tabular}




\begin{tabular}{lllll}
\hline IgG1k & FITC & --- & 555748 & BD Biosciences \\
\hline IgM & FITC & --- & 553474 & BD Biosciences \\
\hline IgG1k & PE & --- & 555749 & BD Biosciences \\
\hline IgG2b & APC & --- & IC0041A & R\&D Systems \\
\hline IgG1k & PerCP/Cy5.5 & --- & 550795 & BD Biosciences \\
\hline
\end{tabular}

Tab. 2.12 Verwendete Antikörper in der Durchflusszytometrie des humanen Gewebes

\subsection{RNA-Isolierung und Analyse mittels Reverser Transkriptase PCR}

\subsubsection{Verwendete Lösungen}

\begin{tabular}{lll}
\hline RT-PCR MasterMix & $4 \mu 1$ & $\mathrm{MgCl}_{2}$ \\
(Mengen pro RNA-Probe) & $4 \mu 1$ & $5 \mathrm{M}-\mathrm{MLV}$ buffer \\
& $2 \mu 1$ & dNTP's \\
& $0,2 \mu 1$ & Random hexamers \\
\hline \hline PCR MasterMix & $0,625 \mu 1$ & RNase Inhibitor \\
& $0,25 \mu 1$ & M-MLV Reverse Transkriptase \\
\hline & $22,75 \mu 1$ & $\mathrm{DEPC}_{2} \mathrm{O}$ \\
& $2 \mu 1$ & $\mathrm{MgCl}_{2}$ \\
& $10 \mu 1$ & $5 \mathrm{x}$ PCR Flexi Puffer \\
& $5 \mu 1$ & Forward Primer \\
& $5 \mu 1$ & Reverse Primer \\
\hline
\end{tabular}

\subsubsection{Extraktion der RNA}

Die bei $-80{ }^{\circ} \mathrm{C}$ tiefgefrorenen Gewebeproben wurden zur Vorbereitung aus dem Kryotube genommen, in Alufolie gewickelt und mit einem Hammer zerkleinert. Das zerkleinerte Gewebe wurde in ein beschriftetes Eppendorf-Gefäß gegeben und mit $1000 \mu 1$ TRI Reagenz bedeckt. Das Gewebe wurde homogenisiert und anschließend bei 12000 x g für 10 Minuten zentrifugiert. Der Überstand wurde in ein neues Eppendorfgefäß überführt. Nach Zugabe von $100 \mu 1$ Chloroform zur RNA-Extraktion wurden die Proben für 15 Minuten inkubiert. Nach erneuter Zentrifugation bei 12000 x g für 15 Minuten bei $4{ }^{\circ} \mathrm{C}$ wurde die wässrige Phase in ein neues Eppendorfgefäß überführt und mit $500 \mu$ I Isopropanol zur Ausfällung der RNA für 10 Sekunden gevortext und für 10 Minuten inkubiert. Es folgte eine erneute Zentrifugation für 8 Minuten bei $4{ }^{\circ} \mathrm{C}$. Der Überstand wurde hiernach verworfen und das Pellet mit $1 \mathrm{ml}$ 75 \%igem Ethanol gewaschen. Nach abschließender Zentrifugation für 5 Minuten bei $7500 \mathrm{x}$ 
g wurde der Überstand verworfen und das Pellet für einige Minuten bei geöffnetem Deckel luftgetrocknet. Zum Lösen der RNA wurde das Pellet in DEPC-Wasser resuspendiert.

\subsubsection{Konzentrationsbestimmung der RNA-Proben}

Zur Bestimmung der RNA-Konzentration der aufbereiteten Proben wurde jeweils $1 \mu 1$ RNA 1:50 in RNA-DNA-Messpuffer verdünnt und die spezifische Absorption gegen einen Leerwert ohne RNA in einem Spektrophotometer photometrisch bestimmt. Das Absorptionsmaximum von DNA und RNA liegt bei $260 \mathrm{~nm}$, daher wurde die optische Dichte $\left(\mathrm{OD}_{260}\right)$ bei dieser Wellenlänge bestimmt, wobei eine $\mathrm{OD}_{260}$ von 1 einer RNA-Konzentration von $40 \mu \mathrm{g} / \mu 1$ entspricht.

Die Konzentration der analysierten Proben wurde analog folgender Formel errechnet:

$$
\text { RNA-Konzentration }[\mu \mathrm{g} / \mu \mathrm{l}]=O D_{260} \times 40 \mu \mathrm{g} / \mu \mathrm{l} \times \text { Verdünnungsfaktor }
$$

\subsubsection{Umschreibung in cDNA}

Zur Durchführung der PCR wurde die extrahierte RNA nun zunächst in komplementäre Einzelstrang-DNA (cDNA) umgeschrieben. Hierzu wurden $1 \mu \mathrm{g}$ RNA in DEPC-Wasser auf ein Gesamtvolumen von 8,92 $\mu 1$ verdünnt und zusammen mit 11,1 $\mu 1$ des RT-PCR MasterMixes in ein PCR-Tube pipettiert und in den Thermozykler gestellt. Die Umschreibung verlief nach folgendem Programm:

\begin{tabular}{lll}
\hline & Temperatur & Zeit \\
\hline Reverse Transkription & $42^{\circ} \mathrm{C}$ & 20 Minuten \\
\hline Enzymdenaturierung & $99{ }^{\circ} \mathrm{C}$ & 5 Minuten \\
\hline Abkühlen & $5{ }^{\circ} \mathrm{C}$ & 5 Minuten \\
\hline Aufbewahrung & $4{ }^{\circ} \mathrm{C}$ bis $-20^{\circ} \mathrm{C}$ & Bis zur Verwendung zur PCR \\
\hline
\end{tabular}

Tab. 2.13 Programm RT-PCR 


\subsubsection{Durchführung der PCR}

Die gewonnen cDNA wurde nun in die PCR-Reaktion eingesetzt. $\mathrm{Zu} 5 \mu \mathrm{l}$ der cDNA-Probe wurden $45 \mu 1$ des PCR-Mastermixes pipettiert und entsprechend des eingesetzten Primers nach einem spezifischen Programm amplifiziert. Im Anschluss an die PCR wurde die amplifizierte DNA auf ein 1,5\%iges Agarosegel aufgetragen, in einem elektrischen Feld separariert und anschließend unter UV-Licht fotografiert. Zur Identifizierung der Länge der amplifizierten Fragmente wurde ein DNA-Standard mit $100 \mathrm{bp}$-Einteilung aufgetragen. Die relative Expression wurde mit Hilfe des Programms AlphaEase FC bestimmt und gegen die Expression der ribosomalen 18S-Untereinheit als konstitutiv exprimiertes Gen normiert.

Verwendete PCR-Programme:

$18 \mathrm{~S}$ und Integrin $\beta_{1}$ :

\begin{tabular}{|c|c|c|c|}
\hline & Temperatur & Zeit & \\
\hline Initialisierung & $95^{\circ} \mathrm{C}$ & 2 Minuten & \\
\hline Denaturierung & $95^{\circ} \mathrm{C}$ & 30 Sekunden & \multirow{3}{*}{35 Zyklen } \\
\hline Anlagerung & $60{ }^{\circ} \mathrm{C}$ & 30 Sekunden & \\
\hline Elongation & $72{ }^{\circ} \mathrm{C}$ & 30 Sekunden & \\
\hline Finale Elongation & $72{ }^{\circ} \mathrm{C}$ & 10 Minuten & \\
\hline
\end{tabular}

Tab. 2.14 PCR-Programm für $18 \mathrm{~S}$ und Integrin $\beta_{1}$

F4/80, Fibronektin und CD3:

\begin{tabular}{|c|c|c|c|}
\hline & Temperatur & Zeit & \\
\hline Initialisierung & $95^{\circ} \mathrm{C}$ & 2 Minuten & \\
\hline Denaturierung & $95^{\circ} \mathrm{C}$ & 30 Sekunden & \multirow{3}{*}{40 Zyklen } \\
\hline Anlagerung & $56^{\circ} \mathrm{C}$ & 1 Minute & \\
\hline Elongation & $72{ }^{\circ} \mathrm{C}$ & 30 Sekunden & \\
\hline Finale Elongation & $72{ }^{\circ} \mathrm{C}$ & 10 Minuten & \\
\hline
\end{tabular}

Tab. 2.15 PCR-Programm für F4/80, Fibronektin und CD3 


\section{Integrin $\alpha_{4}$ :}

\begin{tabular}{|c|c|c|c|}
\hline & Temperatur & Zeit & \\
\hline Initialisierung & $95^{\circ} \mathrm{C}$ & 2 Minuten & \\
\hline Denaturierung & $95^{\circ} \mathrm{C}$ & 30 Sekunden & \multirow{3}{*}{35 Zyklen } \\
\hline Anlagerung & $55^{\circ} \mathrm{C}$ & 30 Sekunden & \\
\hline Elongation & $72{ }^{\circ} \mathrm{C}$ & 30 Sekunden & \\
\hline Finale Elongation & $72{ }^{\circ} \mathrm{C}$ & 5 Minuten & \\
\hline
\end{tabular}

Tab. 2.16 PCR-Programm für Integrin $\alpha_{4}$

\section{VCAM:}

\begin{tabular}{|c|c|c|c|}
\hline & Temperatur & Zeit & \\
\hline Initialisierung & $95^{\circ} \mathrm{C}$ & 2 Minuten & \\
\hline Denaturierung & $95^{\circ} \mathrm{C}$ & 30 Sekunden & \multirow{3}{*}{40 Zyklen } \\
\hline Anlagerung & $60{ }^{\circ} \mathrm{C}$ & 30 Sekunden & \\
\hline Elongation & $72{ }^{\circ} \mathrm{C}$ & 30 Sekunden & \\
\hline Finale Elongation & $72{ }^{\circ} \mathrm{C}$ & 10 Minuten & \\
\hline
\end{tabular}

Tab. 2.17 PCR-Programm für VCAM

\section{Leptin:}

\begin{tabular}{|c|c|c|c|}
\hline & Temperatur & Zeit & \\
\hline Initialisierung & $94{ }^{\circ} \mathrm{C}$ & 2 Minuten & \\
\hline Denaturierung & $95^{\circ} \mathrm{C}$ & 15 Sekunden & \multirow{3}{*}{40 Zyklen } \\
\hline Anlagerung & $65^{\circ} \mathrm{C}$ & 1 Minute & \\
\hline Elongation & $72{ }^{\circ} \mathrm{C}$ & 1,5 Minuten & \\
\hline Finale Elongation & $72{ }^{\circ} \mathrm{C}$ & 5 Minuten & \\
\hline
\end{tabular}

Tab. 2.18 PCR-Programm für Leptin 


\subsubsection{Verwendete Primer}

Murine Primer:

\begin{tabular}{llll}
\hline Gen & forward Primer-Sequenz & reverse Primer-Sequenz & Quelle \\
\hline \multirow{2}{*}{$18 \mathrm{~S}$} & CGA AAG CAT TTG CCA AGA & GAG GTT TCC CGT GTT & \\
& AT & GAG TC & \\
\hline \multirow{2}{*}{ CD3 } & TCC CAA CCC AGA CTA TGA & GCG ATG TCT CTC CTA & Rocha VZ et al., Circ Res \\
& GC & TCT GTC A & 2008 \\
\multirow{2}{*}{ F4/80 } & CTT TGG CTA TGG GCT TCC & GCA AGG AGG ACA GAG & Weisberg SP et al. \\
& AGT C & TTT ATC GTG & \\
\hline \multirow{2}{*}{ Leptin } & & & \\
\hline \multirow{2}{*}{ VCAM-1 } & CTT CAT CCC CAC CAT TGA & TGA GCA GGT CAG GTT & \\
\hline \multirow{2}{*}{ Fibronektin } & ACA TGG CTT TAG GCG GAC & ACA TTC GGC AGG TAT & Giunti et al., Am J Physiol \\
& AA & GGT CTT G & Renal Physiol 2011 \\
\hline \multirow{2}{*}{ Integrin $\alpha_{4}$} & CCC AGG CTA CAT CGT TTT & CAT GAA TGG GGG TAA & \\
& GT & GGA TG & \\
\hline \multirow{2}{*}{ Integrin $\beta_{1}$} & GAG GTT CAA TTT GAA ATT & GGC TCT GCA CTG AAC & Desiderio et al., PLoS \\
& AGC & ACA TTC & ONE 2010 \\
\hline
\end{tabular}

Tab. 2.19 Murine Primer für RT-PCR

Humane Primer:

\begin{tabular}{llll}
\hline Gen & Sequenz forward & Sequenz reverse & Quelle \\
\hline \multirow{2}{*}{$18 \mathrm{~S}$} & CGA AAG CAT TTG CCA & GAG GTT TCC CGT GTT & \\
& AGA AT & GAG TC \\
\hline
\end{tabular}

Tab. 2.20 Humane Primer für RT-PCR

\subsection{Isolation und Analyse von Proteinen - Western Blot}

\subsubsection{Verwendetete Puffer und Lösungen}

\begin{tabular}{lll}
\hline Triton-X-Puffer & $5 \mathrm{ml}$ & $10 \mathrm{X}$ Triton-X \\
& $37,5 \mathrm{ml}$ & $2 \mathrm{M} \mathrm{NaCl}$ \\
& $50 \mathrm{ml}$ & $0,5 \mathrm{M} \mathrm{Tris} / \mathrm{HCl}$ \\
& $50 \mathrm{ml}$ & $0,5 \mathrm{M} \mathrm{EDTA}$ \\
& auf $500 \mathrm{ml}$ & Aqua dest. \\
\hline \hline $\begin{array}{l}\text { Phosphatase-Inhibitoren } \\
\text { Stammlösung NaF } 200 \mathrm{mM}\end{array}$ & $0,21 \mathrm{~g}$ & $\mathrm{NaF}$ \\
\hline \hline
\end{tabular}




\begin{tabular}{|c|c|c|}
\hline Stammlösung $\mathrm{Na}_{3} \mathrm{VO}_{4} 100 \mathrm{mM}$ & $\begin{array}{l}\text { auf } 25 \mathrm{ml} \\
0,459 \mathrm{~g} \\
\text { auf } 25 \mathrm{ml}\end{array}$ & $\begin{array}{l}\text { Aqua dest. } \\
\mathrm{Na}_{3} \mathrm{VO}_{4} \\
\text { Aqua dest. }\end{array}$ \\
\hline $\begin{array}{l}\text { Protease-Inhibitoren } \\
\text { Stammlösung PMSF } \\
(M=174,2 \mathrm{~g} / \mathrm{mol})\end{array}$ & $200 \mathrm{mM}$ & PMSF in Isopropanol \\
\hline $\begin{array}{l}\text { Stammlösung Aprotinin } \\
(M=651,2 \mathrm{~g} / \mathrm{mol})\end{array}$ & $10 \mathrm{mg} / \mathrm{ml}$ & Aprotinin in Aqua dest. \\
\hline $\begin{array}{l}\text { Stammlösung Leupeptin } \\
(M=475,6 \mathrm{~g} / \mathrm{mol})\end{array}$ & $10 \mathrm{mg} / \mathrm{ml}$ & Leupeptin in Aqua dest. \\
\hline $\begin{array}{l}\text { Stammlösung Pepstatin A } \\
(M=685,9 \mathrm{~g} / \mathrm{mol})\end{array}$ & $0,5 \mathrm{mg} / \mathrm{ml}$ & Pepstatin A in Methanol \\
\hline Triton-X-Lysepuffer & $\begin{array}{l}9 \mathrm{ml} \\
1 \mathrm{ml} \\
100 \mu \mathrm{l} \\
50 \mu \mathrm{l} \\
4 \mu \mathrm{l} \\
4 \mu \mathrm{l} \\
80 \mu \mathrm{l}\end{array}$ & $\begin{array}{l}\text { Triton-X-Puffer } \\
\mathrm{NaF}(=20 \mathrm{mM}) \\
\mathrm{Na}_{3} \mathrm{VO}_{4}(=1 \mathrm{mM}) \\
\text { PMSF }(=1 \mathrm{mM}) \\
\text { Aprotinin }(=4 \mu \mathrm{g} / \mathrm{ml}) \\
\text { Leupeptin }(=4 \mu \mathrm{g} / \mathrm{ml}) \\
\text { Pepstatin } \mathrm{A}(=4 \mu \mathrm{g} / \mathrm{ml})\end{array}$ \\
\hline Reagenzlösung für BCA Protein Assay & $1: 50$ & $\begin{array}{l}\text { BCA Protein Assay Reagent B } \\
\text { in BCA Protein Assay Reagent A }\end{array}$ \\
\hline TBS, 10X: & $\begin{array}{l}90 \mathrm{~g} \\
157 \mathrm{~g} \\
\text { in } 1000 \mathrm{ml}\end{array}$ & $\begin{array}{l}\mathrm{NaCl} \\
\text { Tris- } \mathrm{HCl} \\
\text { Aqua dest. } \\
\text { auf pH 7,5 einstellen }\end{array}$ \\
\hline TBS-T, 1X: & $\begin{array}{l}100 \mathrm{ml} \\
10 \mathrm{ml} \\
\text { auf } 1000 \mathrm{ml}\end{array}$ & $\begin{array}{l}\text { 10x TBS } \\
\text { Tween } 20 \\
\text { Aqua dest. } \\
\text { auf pH } 7,5 \text { einstellen }\end{array}$ \\
\hline Blockierungspuffer: & $\begin{array}{l}10 \mathrm{~g} \\
\text { auf } 1000 \mathrm{ml}\end{array}$ & $\begin{array}{l}\text { BSA } \\
1 \times \text { TBS-T }\end{array}$ \\
\hline Lämmli-Puffer, 2X: & $\begin{array}{l}0,151 \mathrm{~g} \\
0,4 \mathrm{~g} \\
\text { auf } 2 \mathrm{ml} \\
\text { auf } 10 \mathrm{ml} \\
10 \% \\
0,01 \%\end{array}$ & $\begin{array}{l}\text { Trizma-Base } \\
\text { SDS } \\
\text { Glycerol } \\
\text { Aqua dest. } \\
\text { auf pH } 6,8 \\
\text { Mercaptoethanol } \\
\text { Bromphenolblau }\end{array}$ \\
\hline Tris-SDS, 4X, pH 6,8: & $\begin{array}{l}15,125 \mathrm{~g} \\
1 \mathrm{~g} \\
\text { auf } 250 \mathrm{ml}\end{array}$ & $\begin{array}{l}\text { Trizma-Base } \\
\text { SDS } \\
\text { Aqua dest. } \\
\text { pH } 6,8\end{array}$ \\
\hline Tris-SDS, 4X, pH 8,8: & $\begin{array}{l}45,5 \mathrm{~g} \\
1 \mathrm{~g} \\
\text { auf } 250 \mathrm{ml}\end{array}$ & $\begin{array}{l}\text { Trizma-Base } \\
\text { SDS } \\
\text { Aqua dest. } \\
\text { pH } 8,8\end{array}$ \\
\hline Sammelgel, 4\%: & $\begin{array}{l}1,25 \mathrm{ml} \\
1,3 \mathrm{ml} \\
0,025 \mathrm{ml} \\
0,01 \mathrm{ml} \\
\text { auf } 5 \mathrm{ml}\end{array}$ & $\begin{array}{l}4 \mathrm{X} \text { Tris-SDS, pH } 6,8 \\
\text { Rotiphorese Gel } 30 \\
10 \% \text { APS } \\
\text { TEMED } \\
\text { Aqua dest. }\end{array}$ \\
\hline
\end{tabular}




\begin{tabular}{lll}
\hline \hline Trenngel, 15\%: & $3,75 \mathrm{ml}$ & 4X Tris-SDS, $\mathrm{pH} 8,8$ \\
& $5 \mathrm{ml}$ & Rotiphorese Gel 30 \\
& $0,05 \mathrm{ml}$ & $10 \%$ APS \\
& $0,01 \mathrm{ml}$ & TEMED \\
& auf $15 \mathrm{ml}$ & Aqua dest. \\
\hline Laufpuffer, 5X: & $30,2 \mathrm{~g}$ & Trizma-Base \\
& $144 \mathrm{~g}$ & Glyzin \\
& $10 \mathrm{~g}$ & SDS \\
\hline Laufpuffer, 1X: & auf $2000 \mathrm{ml}$ & Aqua dest. \\
\hline Transferpuffer, 10X: & $200 \mathrm{ml}$ & 5X Laufpuffer \\
& $800 \mathrm{ml}$ & Aqua dest. \\
\hline \hline Transferpuffer, 1X: & $78,8 \mathrm{~g}$ & Trizma-Base \\
& $288 \mathrm{~g}$ & Glyzin \\
\hline \hline
\end{tabular}

\subsubsection{Proteinextraktion}

Analog der Extraktion von RNA wurden die bei $-80{ }^{\circ} \mathrm{C}$ tiefgefrorenen Gewebeproben zur weiteren Verarbeitung aus dem Kryotube genommen und in Alufolie gewickelt mit einem Hammer zerkleinert. Das zerkleinerte Gewebe wurde in ein 2-ml-Eppendorf-Gefäß gegeben und mit $1 \mathrm{ml}$ Lysepuffer bedeckt. Nach Homogenisierung des Gewebes wurden die Proben 30 Minuten auf Eis stehen gelassen und anschließend 3 Minuten bei 13000 x g zentrifugiert. Der Überstand wurde in ein neues Eppendorf-Gefäß überführt und bis zur Proteinbestimmung und weiteren Analyse bei $-20{ }^{\circ} \mathrm{C}$ weggefroren.

\subsubsection{Bestimmung der Proteinkonzentration}

Die Bestimmung der Proteinkonzentration erfolgte kurz vor Gebrauch der Proben für die Proteinanalyse. Hierfür wurden die bei $-20{ }^{\circ} \mathrm{C}$ tiefgefrorenen Proben auf Eis aufgetaut und gut gemischt. Zunächst wurde eine Standardreihe (Albumin Standard; \#23209, Thermo Fischer Scientific) angesetzt. Der Standard mit einer Ausgangskonzentration von $2000 \mu \mathrm{g} / \mathrm{ml}$ wurde jeweils 1:1 verdünnt, so dass sich Standardproben mit folgenden Konzentrationen ergaben: $1000 ; 500 ; 250 ; 125 ; 62,5 ; 31,25 ; 15,6 ; 7,8$ und $3,9 \mu \mathrm{g} / \mathrm{ml}$. Die Proben wurden nun $1: 10$ in Aqua dest. verdünnt. Zur Messung der Proteinkonzentration wurden $25 \mu 1$ der verdünnten Proben und $200 \mu 1$ Reagenzlösung für den BCA Protein Assay pro Well einer 96-Well-Platte 
mit flachem Boden gegeben. Die Platte wurde für 30 Minuten bei $37^{\circ} \mathrm{C}$ im vorgewärmten Inkubator inkubiert.

Die spezifische Extinktion der Proben wurde bei einer Wellenlänge von $562 \mathrm{~nm}$ im Plattenfotometer bestimmt. Mit Hilfe der Standardreihe wurde eine ExtinktionsKonzentrationskurve errechnet und unter Berücksichtigung der Vorverdünnung die Proteinkonzentrationen der Proben in $[\mu \mathrm{g} / \mathrm{ml}]$ berechnet.

\subsubsection{SDS-Polyacrylamid-Gelektrophorese und Western Blot}

Zur Analyse des Leptingehalts der Fettgewebe der Mäuse, die unterschiedlich lange mit einer Hochfett-Diät worden waren und damit zur Entscheidung über die ideale Zeitspanne der Diät zur Simulation einer pathologischen Adipositas, wurden Western-Blot-Untersuchungen der entsprechenden Gewebe durchgeführt.

\subsubsection{Vorbereiten der Gele}

Nach Installation der Glasplatten in die entsprechende Vorrichtung wurde das Trenngel mit einer $1000 \mu 1$ Eppendorf-Pipette zwischen die Platten gegossen und mit $1 \mathrm{ml}$ Isopropanol überschichtet zur Bildung einer geraden Oberkante. Das Trenngel wurde für 30 Minuten ausgehärtet und nach Abgießen des Isopropanol das Sammelgel luftblasenfrei über das Trenngel gegossen. Nach Einsetzen des Probenkamms wurde das Gel erneut für 20 Minuten ausgehärtet.

\subsubsection{Vorbereitung der Proben}

Während der Vorbereitung der Gele wurden die Proben für die Elektrophorese vorbereitet. Hierzu wurden von jeder Probe $40 \mu \mathrm{g}$ Protein in $20 \mu \mathrm{l}$ Aqua dest. gelöst und dann mit $2 \mathrm{X}$ Lämmli-Puffer auf ein Gesamtvolumen vom $40 \mu$ gebracht. Somit war gewährleistet, dass in jeder Geltasche zum einen das gleiche Volumen, zum anderen die identische Proteinmenge pipettiert wurden. Ebenfalls wurde auf jedem Gel in die erste Tasche zum Auswerten der Proteinbanden eine Probe mit Proteinen definierter Größe pipettiert. Alle Proben wurden zur Proteindenaturierung für 5 Minuten auf $100{ }^{\circ} \mathrm{C}$ erhitzt. 


\subsubsection{Auftragen der Proben auf die Gele und Elektrophorese}

Nachdem die Gele in die Elektrophoresekammer eingesetzt worden waren und die Kammer mit Laufpuffer gefüllt war, wurden der Marker und die Proben in die Taschen des Sammelgels pipettiert und die Kammer verschlossen und an den Stromkreis angeschlossen. Bei einer Spannung von $140 \mathrm{~V}$ wurde beobachtet, dass die Lauffront die Grenze zwischen Sammel- und Trenngel erreichte. Sobald dies passiert war, wurde die Spannung auf $200 \mathrm{~V}$ erhöht und die Elektrophorese bei Austreten der Lauffront aus dem Gel durch Unterbrechen der Stromzufuhr gestoppt.

\subsubsection{Western Blot}

Nach Entfernen der Gele aus der Elektrophoresekammer wurde vorsichtig das Sammelgel vom Trenngel entfernt und anschließend das Trenngel von der Glasplatte gelöst und in $1 \mathrm{X}$ Transferpuffer überführt. Zudem wurden Schwämmchen, Filterpapier und Nitrozellulosemembranen in $1 \mathrm{X}$ Transferpuffer getränkt. Der Halter wurde in folgender Reihenfolge beladen: Schwämmchen, Filterpapier, Gel, Nitrozellulosemembran, Filterpapier, Schwämmchen. Nach Ausstreichen vorhandener Luftblasen wurden jeweils zwei Halter zusammen mit einem Kühlelement in die Blotapparatur eingesetzt und mit $1 \mathrm{X}$ Transferpuffer bedeckt. Der Transfer erfolgte für 60 Minuten bei einer Spannung von 100 V. Danach wurde die Membran aus dem Halter entfernt und zur Überprüfung des erfolgreichen Proteintransfers in Ponceau S geschwenkt.

\subsubsection{Antigendetektion}

Zur Blockade unspezifischer Bindungsstellen wurde die Membran zunächst 2 Stunden in 1X TBS-T/1 \% BSA geschwenkt. Anschließend erfolgte die Teilung der Membran auf Höhe von ca. $30 \mathrm{kDa}$ und die Inkubation der ersten Antikörper über Nacht bei $4{ }^{\circ} \mathrm{C}$ 1:1000 (GAPDH 1:20000) in 1x TBS-T/1 \% BSA verdünnt. Nach gründlichem Waschen für 3 mal 10 Minuten in 1x TBS-T/1 \% BSA erfolgte die Inkubation der zweiten Antikörper für 60 Minuten bei RT 1:3000 (bei GAPDH 1:20000) 1x TBS-T/1 \% BSA verdünnt. Abschließend erfolgte ein erneutes Waschen für 3 mal 10 Minuten. 


\subsubsection{Entwicklung}

Die Entwicklung der Membranen erfolgte mit Hilfe von SuperSignal Chemiluminescent Substrate. Hierzu wurden die Membranen mit ca. $4 \mathrm{ml}$ ECL-Reagenz benetzt und für 5 Minuten inkubiert. Das Reagenz wurde abgeschüttet und die Membran luftblasenfrei in eine Klarsichtfolie gewickelt und in eine Röntgenfilmkassette gelegt. In der Dunkelkammer wurde bei Sicherheitsbeleuchtung ein Röntgenfilm aufgelegt und dieser anschließend in der Entwicklermaschine entwickelt.

\subsubsection{Verwendete Antikörper und Verdünnungen}

\begin{tabular}{lllll}
\hline Antikörper & Proteingröße & Verdünnung & Art.-Nr & Firma \\
\hline Leptin & $16 \mathrm{kDa}$ & $1: 1000$ & AF498 & R\&D Systems, Minneapolis, MN, USA \\
\hline GAPDH & $36 \mathrm{kDa}$ & $1: 20000$ & $5 \mathrm{G} 4$ & Hy Test Ltd., Turku, FIN \\
\hline Anti-goat IgG & & $1: 3000$ & HAF109 & R\&D Systems, Minneapolis, MN, USA \\
\hline ECL Anti-Mouse IgG & & $1: 20000$ & NA931V & GE Healthcare UK Ltd, Little Chalfont, UK \\
\hline
\end{tabular}

Tab. 2.21 Verwendete Antikörper Western Blot.

\subsubsection{Enzyme-linked Immunosorbent Assay (ELISA) - Nachweis von Leptin im Serum und perivaskulären Fettgewebe}

Zur Bestimmung der Leptinkonzentrationen im Serum sowie im Proteinlysat der Fettgewebe wurden Quantikine ${ }^{\circledR}$ ELISA (murin: \#MOB00, R\&D Systems, human: \#DLP00, R\&D Systems) eingesetzt. Hierbei handelt es sich um Sandwich-ELISA. Die verwendeten Mikrotiterplatten sind bereits mit einem polyklonalen Antikörper beschichtet, der spezifisch murines Leptin bindet. Nach Inkubation der Proben werden die ungebundenen Substanzen heruntergewaschen und ein zweiter, löslicher polyklonaler Antikörper gegen murines Leptin, der mit einer Meerrettichperoxidase konjugiert ist, inkubiert. Mit einer Substratlösung kann man die Antikörperbindung sichtbar machen und die Extinktion im Plattenfotometer messen. Die Leptinkonzentrationen in der Probe werden anhand einer Leptin-Standardkurve berrechnet. 


\subsubsection{Verwendete Lösungen und Verdünnungen muriner ELISA}

\begin{tabular}{|c|c|c|}
\hline Maus Leptin Standard & $\begin{array}{l}\text { Rekombinantes murines Leptin in } \\
\text { gepufferter Proteinbase }\end{array}$ & $\begin{array}{l}8 \mathrm{ng} \text { verdünnt in } 2 \mathrm{ml} \text { Calibrator Diluent } \\
(\triangleq 4000 \mathrm{pg} / \mathrm{ml})\end{array}$ \\
\hline Maus Leptin Kontrolle & & verdünnt in $1 \mathrm{ml}$ deionisiertem Wasser \\
\hline Anti-Leptin Konjugat & $\begin{array}{l}\text { Polyklonaler Antikörper gegen } \\
\text { murines Leptin mit einem } \\
\text { Meerrettichperoxidase-Konjugat }\end{array}$ & $23 \mathrm{ml} \triangleq 250 \mu \mathrm{l} / \mathrm{Well}$ \\
\hline Assay Diluent & Gepufferte Proteinbase & \\
\hline Calibrator Diluent & Gepufferte Proteinbase & \\
\hline Waschpuffer-Konzentrat & $\begin{array}{l}\text { 25x konzentrierte gepufferte } \\
\text { Surfactant-Lösung }\end{array}$ & $\begin{array}{l}20 \mathrm{ml} \text { verdünnt in } 500 \mathrm{ml} \text { deionisiertem } \\
\text { Wasser }\end{array}$ \\
\hline Farbreagenz A & Stabilisiertes Wasserstoffperoxid & \multirow{2}{*}{$\begin{array}{l}\text { Äquivalente Mengen werden zur } \\
\text { Substratlösung vermischt }(12+12 \mathrm{ml})\end{array}$} \\
\hline Farbreagenz B & Stabilisiertes Tetramethylbenzidin & \\
\hline Stopplösung & Verdünnte Salzsäure & $23 \mathrm{ml} \triangleq 250 \mu \mathrm{l} / \mathrm{Well}$ \\
\hline
\end{tabular}

\subsubsection{Verwendete Lösungen und Verdünnungen humaner ELISA}

\begin{tabular}{lll}
\hline Human Leptin Standard & $\begin{array}{l}\text { Rekombinantes humanes Leptin in } \\
\text { gepufferter Proteinbase }\end{array}$ & $\begin{array}{l}10 \mathrm{ng} \text { verdünnt in 1 ml deionisiertem } \\
\text { Wasser } \\
(\hat{=} 10000 \mathrm{pg} / \mathrm{ml})\end{array}$ \\
\hline Anti-Leptin Konjugat & $\begin{array}{l}\text { Monoklonaler muriner Antikörper } \\
\text { gegen humanes Leptin mit einem } \\
\text { Meerrettichperoxidase-Konjugat }\end{array}$ & $21 \mathrm{ml}$ \\
\hline Assay Diluent & Gepufferte Proteinbase & \\
\hline $\begin{array}{l}\text { Calibrator Diluent } \\
\text { Konzentrat (5x) }\end{array}$ & Gepufferte Proteinbase & $\begin{array}{l}20 \mathrm{ml} \text { verdünnt in } 80 \mathrm{ml} \text { deionisiertem } \\
\text { Wasser }\end{array}$ \\
\hline Waschpuffer-Konzentrat & $\begin{array}{l}\text { 25x konzentrierte gepufferte } \\
\text { Surfactant-Lösung }\end{array}$ & $\begin{array}{l}20 \mathrm{ml} \text { verdünnt in } 500 \mathrm{ml} \text { deionisiertem } \\
\text { Wasser }\end{array}$ \\
\hline Farbreagenz A & Stabilisiertes Wasserstoffperoxid & $\begin{array}{l}\text { Äquivalente Mengen werden zur } \\
\text { Substratlösung vermischt (12+12 ml) }\end{array}$ \\
\hline Farbreagenz B & Stabilisiertes Tetramethylbenzidin & \\
\hline Stopplösung & 2 N Schweflige Säure & \\
\hline \hline
\end{tabular}

\subsubsection{Durchführung der ELISA}

Zunächst wurden die eingesetzten Serum- und Fettgewebeproben 100-fach (Human: Serum 40-fach, Fettgewebe 10-fach) in Calibrator Diluent verdünnt. Die Standardreihe wurde durch eine 2-fach-Verdünnungsreihe des Leptin-Standards in jeweils $200 \mu 1$ Calibrator Diluent erstellt, so dass sich eine Konzentrationsreihe von $2000 \mathrm{pg} / \mathrm{ml}$ bis $62,5 \mathrm{pg} / \mathrm{ml}$ ergab. Als Negativkontrolle diente reines Calibrator Diluent. 
Die Angaben in Klammern entsprechen den eingesetzten abweichenden Mengen im humanen ELISA.

Nach Vorbereiten der Proben und des Standards wurde in jedes Well der 96-WellMikrotiterplatte $50 \mu \mathrm{l}(100 \mu \mathrm{l})$ Assay Diluent gegeben und $50 \mu \mathrm{l}(100 \mu \mathrm{l})$ der Proben und des Standards in Doppelbestimmung hinzugegeben. Nach vorsichtigem Mischen durch einminütiges, vorsichtiges Klopfen mit einem Finger an die Platte wurde die Platte mit einer Schutzfolie beklebt und für 2 Stunden bei RT inkubiert. Hiernach wurde die Platte fünfmal gründlich mit $400 \mu \mathrm{l}$ Waschpuffer, welcher mit einer Multipipette appliziert wurde, gewaschen. Nach jedem Waschschritt wurde der gesamte Puffer durch kräftiges Ausschütteln vollständig aus der Platte entfernt, um ein optimales Ergebnis zu erzielen. Nach dem letzten Waschschritt wurde die Platte vorsichtig auf einem sauberen Papierhandtuch ausgeklopft. Nach Zugabe von jeweils $100 \mu \mathrm{l}(200 \mu \mathrm{l})$ konjugiertem Antikörper wurde die Platte erneut versiegelt und für 2 Stunden (1 Stunde) bei RT inkubiert. Es folgte ein erneutes gründliches fünfmaliges Waschen. Die Wells wurden nun mit $100 \mu \mathrm{l}(200 \mu \mathrm{l})$ Substratlösung bestückt und für 30 Minuten lichtgeschützt bei RT inkubiert. Nach Zugabe von je $100 \mu 1(50 \mu 1)$ Stopplösung wurde die Extinktion umgehend im Plattenfotometer bei $450 \mathrm{~nm}$ mit einer Wellenlängenkorrektur bei $540 \mathrm{~nm}$ bestimmt. Zur Auswertung wurden die Mittelwerte der in Doppelbestimmungen gemessenen OD berechnet und der Mittelwert der OD der Negativkontrolle hiervon abgezogen. Über die Standardkurve wurde aus der finalen OD dann die jeweilige Probenkonzentration in $[\mathrm{pg} / \mathrm{ml}]$ berechnet.

\subsection{Statistische Auswertung}

Die statistische Auswertung erfolgte mit Hilfe der Programme GraphPad Prism (Version 5.0) sowie SPSS Statistics (Version 20.0). Die quantitativen Daten sind jeweils als arithmetisches Mittel \pm Standardfehler (SEM) angegeben. Die Normalverteilung wurde mittels D'Agostino $\&$ Pearson omnibus normality-test getestet. Statistische Unterschiede zwischen zwei Gruppen wurde mittels unpaired Student's t-test untersucht, bei nicht normalverteilten Daten wurde der Mann-Whitney-test angewandt. Bei Vergleichen der klinischen Parameter zwischen den einzelnen Gruppen der humanen Studie wurde der $\chi^{2}$-Test (chi-squared-test) angewandt. Das Signifikanzniveau wurde jeweils auf $\mathrm{p} \leq 0,05$ festgesetzt. 


\section{ERGEBNISSE}

\subsection{Auswirkungen von Übergewicht auf die perivaskuläre Fettgewebs- inflammation im Tiermodell}

\subsubsection{Charakterisierung des Mauskollektivs}

\subsubsection{Körpergewicht und Gewicht des viszeralen Fettdepots}

Zur Registrierung der Änderung des Körpergewichtes wurden die Mäuse regelmäßig gewogen und das Gewicht protokolliert. Die Entwicklung des Körpergewichts über die Zeit ist in Abb. 3.1 dargestellt. Unter Fütterung mit Hochfettdiät kam es schon nach zwei Wochen $(26,9 \pm 0,36 \mathrm{~g})$ zu einem signifikanten Anstieg des Körpergewichts sowohl im Vergleich zum Ausgangsgewicht $(21,7 \pm 0,24 \mathrm{~g}, \mathrm{p}<0,001)$ als auch im Vergleich zur Kontrollgruppe auf Normaldiät $(24,3 \pm 0,31 \mathrm{~g}, \mathrm{p}<0,001)$. Bei Abschluss der Diät nach 8 Wochen wiesen die Mäuse auf HFD ein Körpergewicht von 35,3 $\pm 0,69 \mathrm{~g}$ auf, jene auf $\mathrm{NC}$ wogen 28,5 $\pm 0,35 \mathrm{~g}$ $(\mathrm{p}<0,001)$.

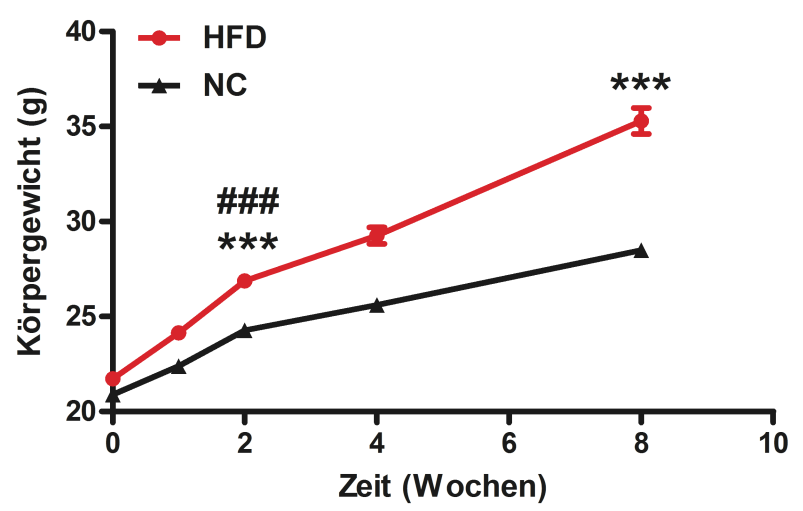

Abb. 3.1 Entwicklung des Körpergewichts mit Normalfettfutter (NC) bzw. unter Hochfettdiät (HFD). ***p<0,001 für Vergleich HFD vs. NC zum gleichen Zeitpunkt (2 Wochen, 8 Wochen) und ${ }^{\# \#} \mathrm{p}<0,001$ für Vergleich HFD Startgewicht vs HFD nach 2 Wochen

Nach Entnahme der abdominellen Fettdepots wurden diese ebenfalls gewogen. Auch hier waren die Gewichte bei den HFD-Mäusen, wie in Abb. 3.2 ersichtlich, signifikant höher als in der Kontrollgruppe $(1751 \pm 103$ g vs. $477 \pm 29,7$ g, p $<0,001)$. 


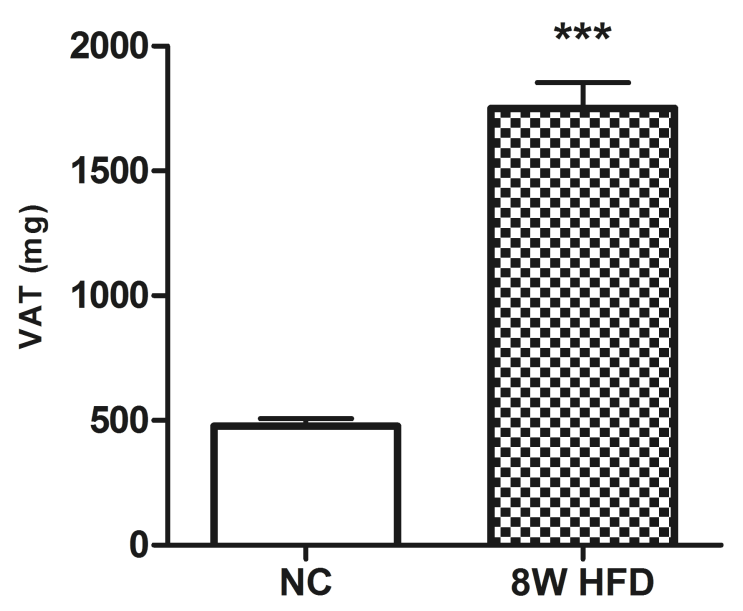

Abb. 3.2 VAT-Gewicht der viszeralen Fettgewebe (VAT) mit Normalfettfutter (NC) und unter 45 \%iger Hochfettdiät (HFD). ${ }^{* * *} \mathrm{p}<0,001$ für Vergleich $8 \mathrm{~W}$ HFD vs. NC

\subsubsection{Messungen der Leptinspiegel im Serum}

Mittels ELISA wurden die Leptinspiegel im Serum bestimmt. Hierbei zeigte sich, wie in Abb. 3.3 dargestellt, eine signifikante Erhöhung der Leptinspiegel bereits nach 4 Wochen Hochfettdiät $(4,2 \pm 1,1 \mathrm{ng} / \mathrm{ml}, \mathrm{p}<0,05)$ im Vergleich zur Kontrollgruppe $(1,7 \pm 0,2 \mathrm{ng} / \mathrm{ml})$. Nach 8 Wochen Hochfettdiät zeigte sich ein hochsignifikanter Anstieg der Serumspiegel $(28,5 \pm 3,9 \mathrm{ng} / \mathrm{ml}, \mathrm{p}<0,001)$.

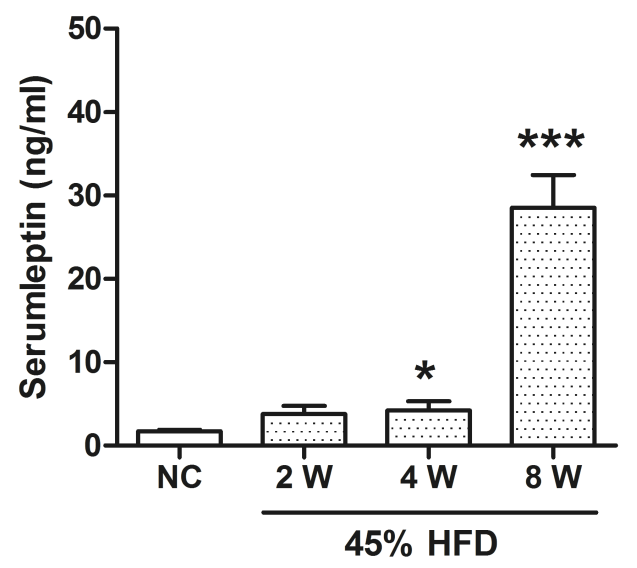

Abb. 3.3 Leptinspiegel im Serum mit Normalfettfutter (NC) und unter 45 \%iger Hochfettdiät (HFD). *p<0,05 und $* * * \mathrm{p}<0,001$ für HFD vs. NC 


\subsubsection{Zunahme des perivaskulären Fettgewebe und der perivaskulären Leptinexpression bei Übergewicht}

Bereits makroskopisch zeigte sich in den HFD-gefütterten Mäusen eine Zunahme des perivaskulären Fettgewebe bei Übergewicht, wohingegen dieses bei mit Normalfutter ernährten Tieren kaum sichtbar war.

Aus diesem Grund und weil die Entnahme des gesamten perivaskulären Fettgewebes nicht möglich war, konnte dies nicht gewogen und verglichen werden

Zusätzlich konnten Nativfärbungen den bereits makroskopisch erhobenen Befund bestätigen. Abb. 3.4 zeigt in repräsentativen MTC- und Öl-Rot-Färbungen die Zunahme des perivaskulären Binde- und Fettgewebes über die Zeit.
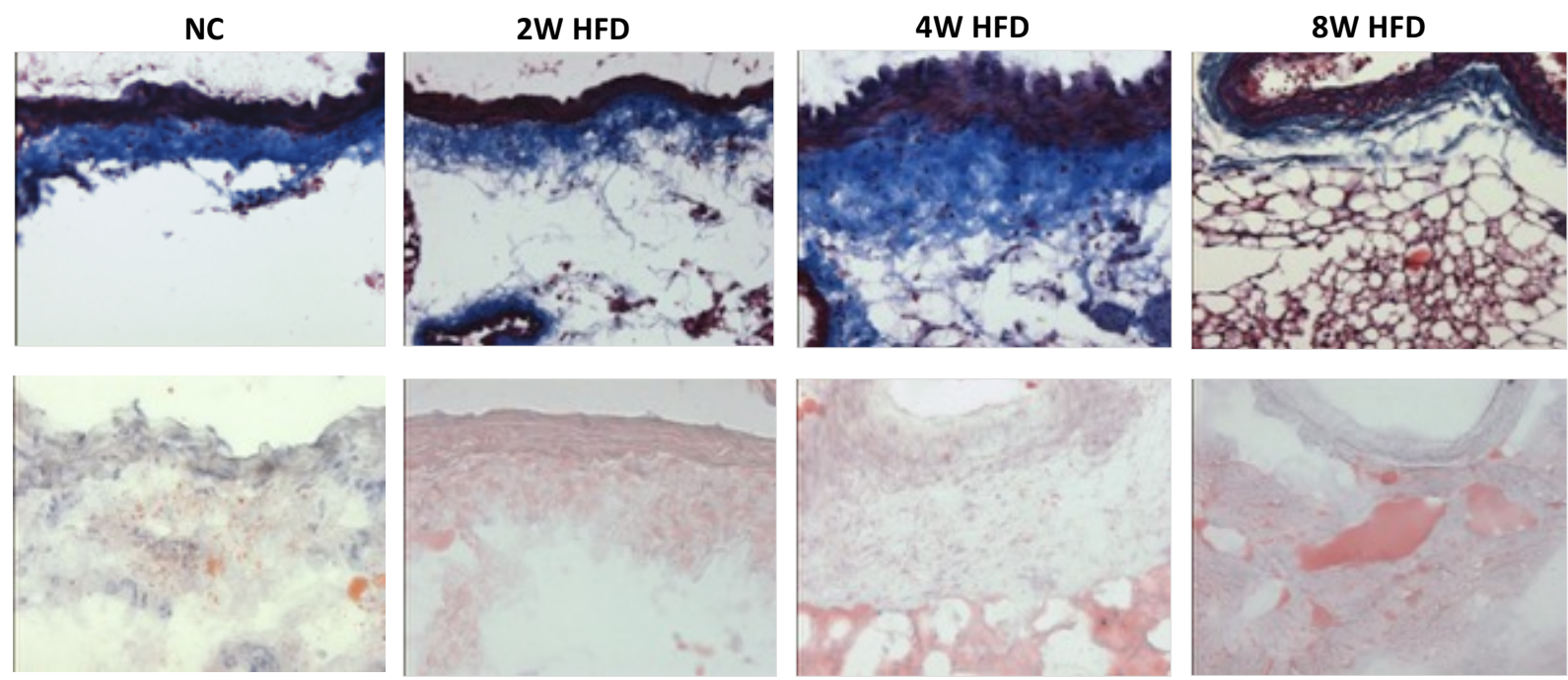

Abb. 3.4 Fettgewebs- und Bindegewebsvermehrung unter Einfluss von Übergewicht über die Zeit. Es werden jeweils repräsentative Schnitte ohne (NC) sowie nach 2, 4 und 8 Wochen HFD gezeigt. Die obere Reihe zeigt die Zunahme des perivaskulären Bindgewebes in MTC-Färbungen, die untere Reihe zeigt die Zunahme der perivaskulären Lipide und somit des Fettgewebes in Öl-Rot-Färbungen.

Um quantitative Aussagen zur Leptinexpression in den unterschiedlichen Fettgeweben treffen zu können, wurde der Nachweis mit Hilfe von PCR und ELISA durchgeführt. Hier zeigten sich zusätzlich zum signifikant erhöhten viszeralen Fettgewicht und den höheren zirkulierenden Leptinspiegeln auch perivaskulär eine erhöhte Leptinexpression in den übergewichtigen Tieren. In Übereinstimmung mit den übrigen Ergebnissen ergaben sich 
sowohl für das perivaskuläre als auch für das viszerale Fettgewebe in der HochfettdiätGruppe signifikant höhere mRNA- (Abb. 3.5a) und Proteinexpressionen (Abb. 3.5b) für Leptin im Vergleich zur Kontrollgruppe auf Normalfutter. Es zeigte sich ein Anstieg der Expression von Leptin-mRNA in der HFD-Gruppe auf das 2,7-Fache der Werte in der Kontrollgruppe $(p<0,01)$. Im ELISA zeigte sich eine hochsignifikant gesteigerte Expression von Leptin im PVAT im Vergleich zur Kontrollgruppe $(2602 \pm 278 \mathrm{ng} / \mathrm{ml}$ vs. $165 \pm$ 32,6 ng/ml, p<0,001). Auch Western-Blot-Analysen der Fettgewebe mit Leptin-Antikörpern bestätigten den Anstieg der Leptin-Menge unter Hochfettdiät.

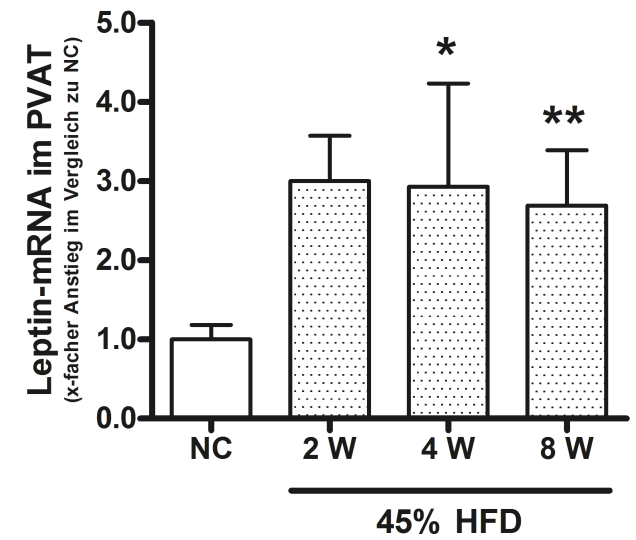

a

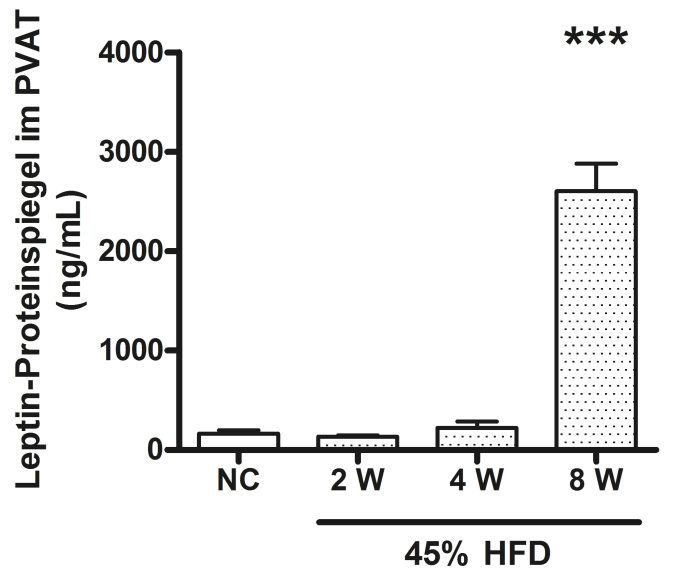

b

Abb. 3.5 Zusammenfassung der Ergebnisse zur (a) mRNA-Expression in Relation zur NC-Kontrollgruppe und (b) Proteinspiegel in ng/ml von Leptin im Perivaskulären Fettgewebe. ${ }^{*} \mathrm{p}<0,05,{ }^{* *} \mathrm{p}<0,01$ und ${ }^{* * *} \mathrm{p}<0,001$ für den Vergleich HFD vs. NC

\subsubsection{Einfluß von Übergewicht auf die Zahl zirkulierender Integrin $\alpha_{4}$-positiver Zellen}

Wenn der Anstieg des Leptins im perivaskulären Fettgewebe einen Einfluss auf die präinflammatorischen Reaktionen hat, sollte sich das auch in den dafür zuständigen Leukozytenpopulationen zeigen. Mittels durchflusszytometrischer Analysen wurde so zunächst das periphere Blut der Mäuse auf die Zahl Integrin- $\alpha_{4}$ - und Leptinrezeptor-positiver Zellen analysiert. Hierbei ergab sich eine signifikante Abnahme der Integrin $\alpha_{4}$-positiven sowie Integrin $\alpha_{4} /$ Leptinrezeptor (ObR)-doppeltpositiven Leukozyten in der HFD-Gruppe im Vergleich zur Kontrollgruppe (Abb. 3.6c). Für den Anteil ObR-positiver Zellen ergab sich hingegen ein Anstieg im Vergleich zur Kontrollgruppe (Abb. 3.6b). Nach Verabreichung des monoklonalen anti-Integrin $\alpha_{4}$-Antikörpers Natalizumab (Tysabri $\left.{ }^{\circledR}\right)$ zeigte sich eine völlige 
Umkehr der Expression auf den zirkulierenden Leukozyten. Ein Effekt auf die Zahl ObR-

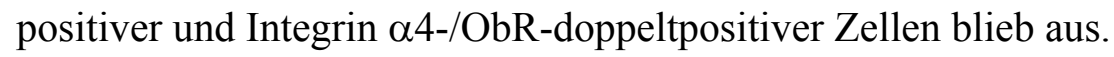

a

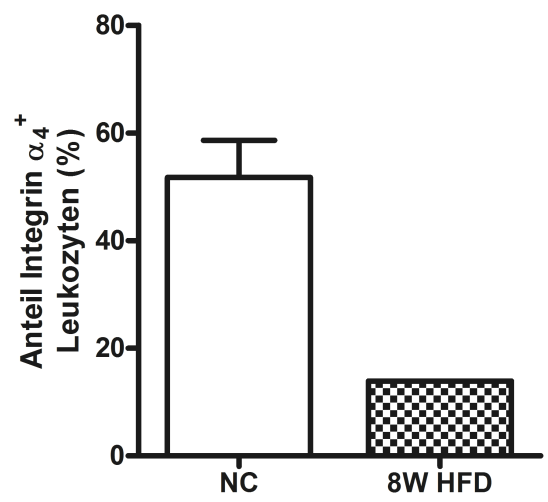

b

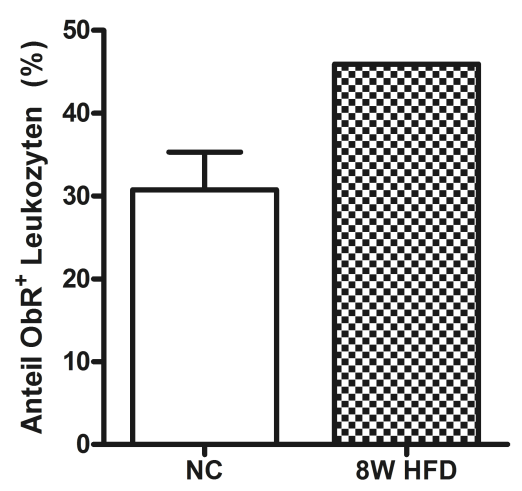

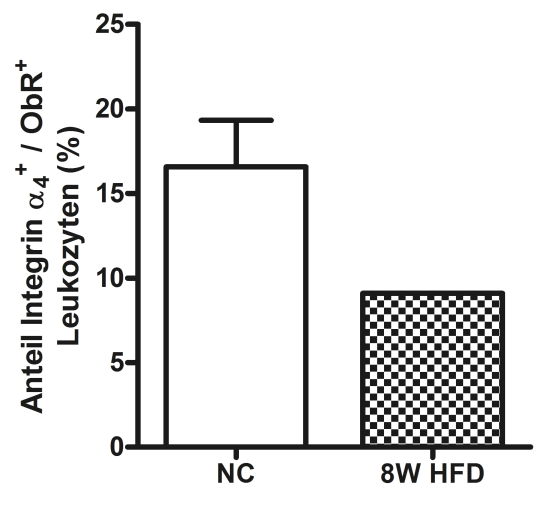

Abb. 3.6 Durchflußzytometrische Analyse zirkulierender Leukozyten: Expression von (a) Integrin $\alpha_{4}$ und (b) ObR; (c) Koexpression

\subsubsection{Anstieg der Integrin $\alpha_{4^{-}}$und Integrin $\alpha_{4} /$ Leptinrezeptor-doppeltpositiven Zellen im perivaskulären Fettgewebe bei Übergewicht}

Um zu untersuchen, ob sich der im Vollblut festgestellte Abfall von Integrin $\alpha_{4}$-positiven sowie Integrin $\alpha_{4}-/$ Leptinrezeptor (ObR)-doppeltpositiven Leukozyten auf eine vermehrte Rekrutierung dieser Zellen in das Fettgewebe zurückführen ließ, wurde deren Verteilung im perivaskulären Fettgewebe bestimmt. Als Kontrolle dienten $o b / o b$-Leptin- sowie $d b / d b$ Leptinrezeptor-defiziente Mäuse, um einen eventuellen Einfluss des Leptins zu sehen.

Die durchflusszytometrische Untersuchungen des perivaskulären Fettgewebes ergaben signifikant erhöhte Werte für die Integrin $\alpha_{4}$-positiven sowie Integrin $\alpha_{4}-/$ Leptinrezeptor (ObR)-doppeltpositiven Leukozyten bei Übergewicht sowohl durch Hochfettdiät als auch bei Leptin- und Leptinrezeptor-defizienten Mäusen. Nach 6 Monaten zeigte sich ein 
hochsignifikanter Anstieg beider Leukozytenarten sowohl im Vergleich zur Kontrollgruppe als auch im Vergleich zu den Mäusen nach 8 Wochen HFD. Die Ergebnisse der Messungen sind in Abb. 3.7 dargestellt.

Die Anzahl der Integrin $\alpha_{4}$-positiven Zellen erhöhte sich während der Fütterung signifikant

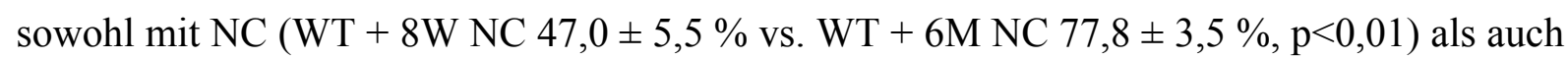
unter HFD (WT $+8 \mathrm{~W}$ HFD 51,5 $\pm 3,5 \%$ vs. WT $+6 \mathrm{M}$ HFD $89,7 \pm 0,8 \%, \mathrm{p}<0,01$ ). Gleichzeitig zeigten die prozentualen Anteile aber auch eine deutlich stärkere Zunahme der Integrin $\alpha_{4}$-positiven Zellen bei den WT $+6 \mathrm{M}$ HFD-Mäusen gegenüber den WT $+6 \mathrm{M}$ NC-

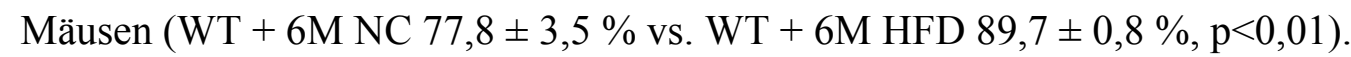

Der Anteil der Integrin $\alpha_{4}-/$ Leptinrezeptor-doppeltpositiven Leukozyten nach 6 Monaten Fütterung (WT $+6 \mathrm{M} \mathrm{NC} 66,6 \pm 3,0 \%, \mathrm{p}<0,01$ vs. WT $+6 \mathrm{M}$ HFD 82,7 $\pm 1,1 \%, \mathrm{p}<0,01$ ) verhielt sich ähnlich den Integrin $\alpha_{4}$-positiver Zellen. Allerdings war der Anstieg gegenüber den Anfangsmessungen bei 8 Wochen deutlich stärker (WT $+8 \mathrm{~W}$ NC 13,6 \pm 1,3\% sowie WT +8 W HFD 10,7 $\pm 1,4 \%$ ).

Die Messungen nach 8 Wochen NC bei der Kontrollgruppe der Leptin-defizienten Mäusen bewegten sich bei den Integrin $\alpha_{4}$-Zellen in einem ähnlichen prozentualen Bereich. Für die Integrin $\alpha_{4}-/$ Leptinrezeptor-doppeltpositiven Leukozyten konnte jedoch ein signifikanter Anstieg gegenüber den WT-Mäusen beobachtet werden (WT + NC 8W 13,6 \pm 1,3\% vs. $o b / o b+\mathrm{NC} 8 \mathrm{~W} 29,5 \pm 1,2 \%, \mathrm{p}<0,05)$.

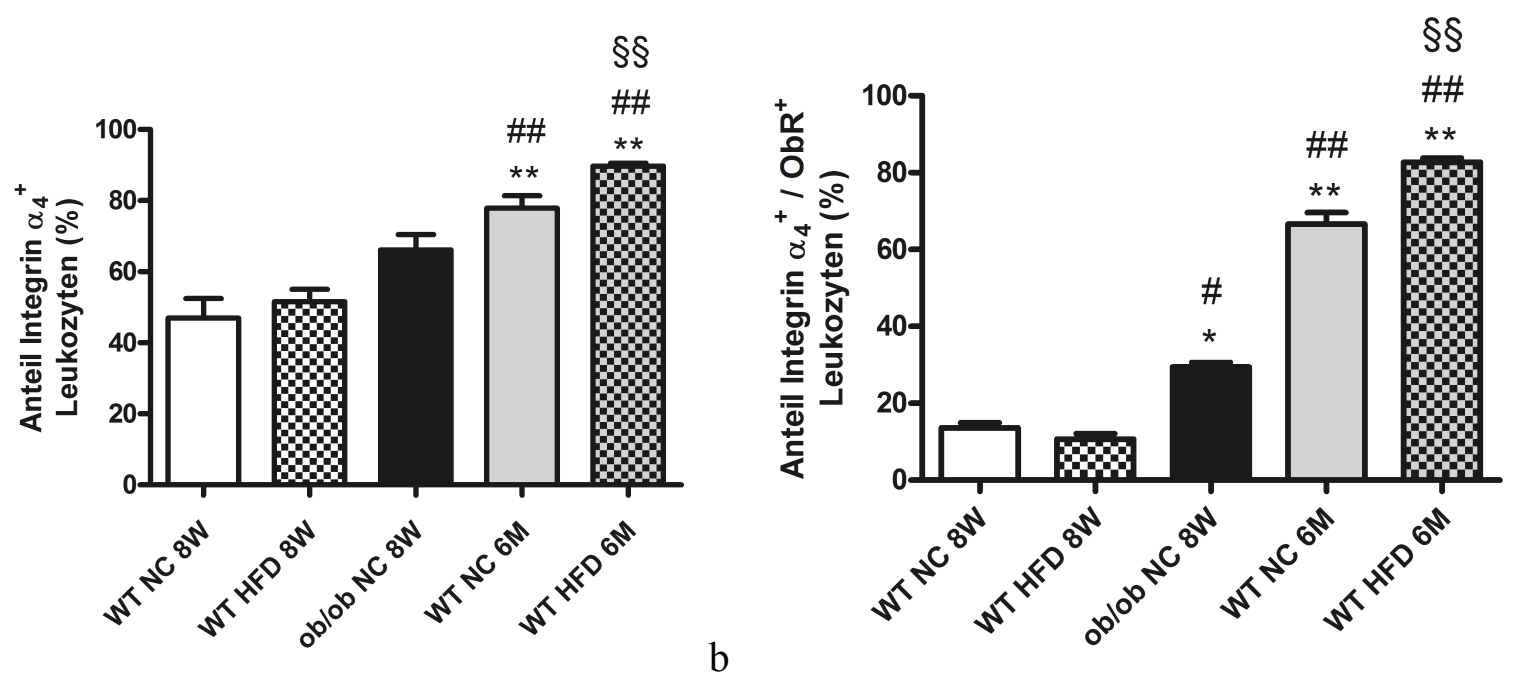

Abb. 3.7 Durchflußzytometrische Analyse residenter Leukozyten im perivaskulären Fettgewebe: Anteil von (a) Integrin $\alpha_{4}$ - und (b) Integrin $\alpha_{4}$-/ Leptinrezeptor-doppeltpositiven Zellen $* \mathrm{p}<0,05$ und ${ }^{* *} \mathrm{p}<0,01$ für den Vergleich vs. WT NC $8 \mathrm{~W}$, ${ }^{\#} \mathrm{p}<0,05$ und ${ }^{\# \#} \mathrm{p}<0,01$ für den Vergleich vs. WT HFD $8 \mathrm{~W},{ }^{\S \S} \mathrm{p}<0,01$ für den Vergleich WT HFD 6M vs. WT NC 6M 


\subsubsection{Untersuchung der Expression potentieller Liganden von Integrin $\alpha_{4}$ im} perivaskulären Fettgewebe: VCAM-1 und Fibronektin

Um eine Korrelation der Integrin $\alpha_{4}$-positiven Zellen mit den potentiellen Faktoren einer Präinflammation des perivaskulären Fettgewebes, VCAM-1 und Fibronektin, zu untersuchen, wurden Immunofluoreszenzfärbungen des perivaskulären Fettgewebes durchgeführt. Sie zeigen in Gewebeschnitten der WT +8 W HFD-Gruppe deutlich erhöhte Signale sowohl für die endothelialen (VCAM-1) als auch für die bindegewebigen (Fibronektin) Adhäsionsmoleküle für Integrin $\alpha_{4}$. Abb. 3.8 zeigt repräsentative Färbungen der WT $+2 \mathrm{~W}$ NC-Kontrollgruppe, sowie nach 2, 4 und 8 Wochen HFD für VCAM-1.
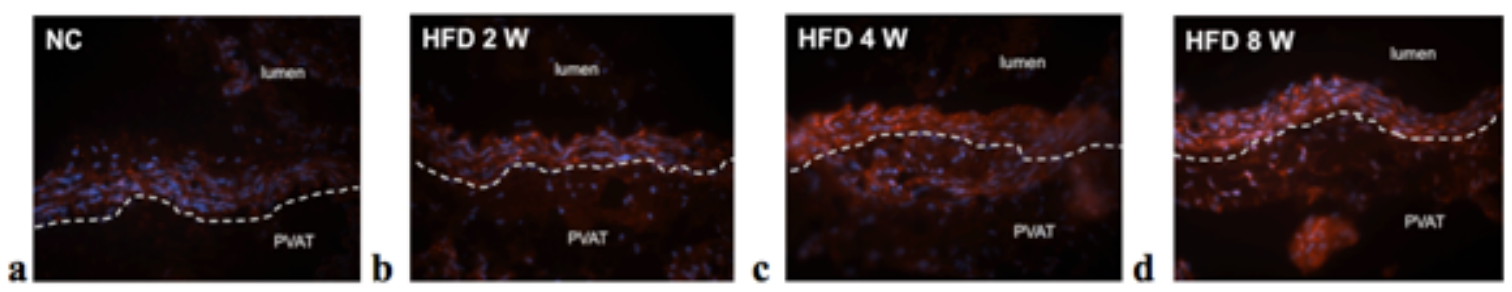

Abb. 3.8 Fluoreszenzfärbung mit DAPI zur Kernanfärbung: Zunahme der Expression von VCAM-1 (rot) unter Einfluss von Übergewicht

RT-PCR-Analysen konnten diese Ergebnisse bestätigen. Für die mRNA-Menge von VCAM konnte zwar nur eine schwache Erhöhung durch die HFD gezeigt werden, die von Fibronektin stieg jedoch signifikant an nach 4 und 8 Wochen HFD. (Abb. 3.9).

$\mathbf{a}$

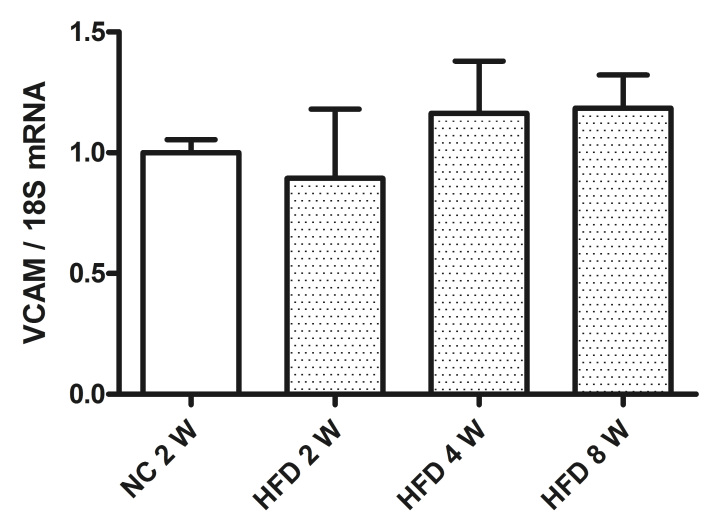

b

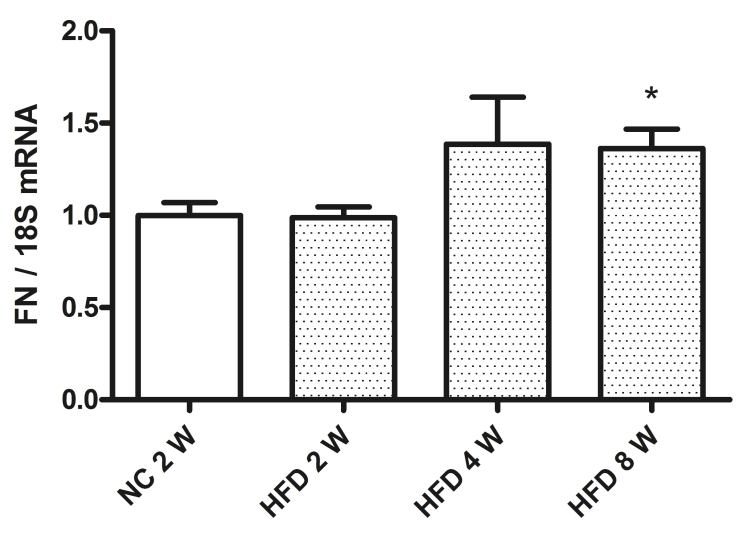

Abb. 3.9 Zusammenfassung der Ergebnisse der mRNA-Expression im perivaskulären Fettgewebe: VCAM (a), Fibronektin (b). ${ }^{*} \mathrm{p}<0,05$ für den Vergleich HFD $8 \mathrm{~W}$ vs. NC $2 \mathrm{~W}$ 


\subsubsection{Untersuchungen zur Anzahl und Differenzierung der Leukozyten im perivaskulären Fettgewebe unter Einfluss von Hochfettdiät}

Zur Charakterisierung der zellulären Zusammensetzung des Fettgewebes wurden durchflusszytometrische Analysen durchgeführt. Mit Hilfe des Pan-Leukozytenmarkers CD45 wurde der Gesamtanteil der Leukozyten an allen Zellen im viszeralen und perivaskulären Fettgewebe bestimmt (Abb. 3.10). Hierbei zeigte sich für das viszerale Fettgewebe ein leichter Anstieg des Anteils der Leukozyten in der Hochfettdiätgruppe (42,6 \pm 5,4 \% vs. 54,7 $\pm 3,8 \%, \mathrm{p}=0,08)$. Für das perivaskuläre Fettgewebe zeigte sich ein Rückgang der Leukozyten im Vergleich zur WT $+8 \mathrm{~W}$ NC Kontrollgruppe, der allerdings nicht signifikant war $(43,4 \pm$ $10,1 \%$ vs. $31,8 \pm 7,6 \%, p=0,38)$.

a

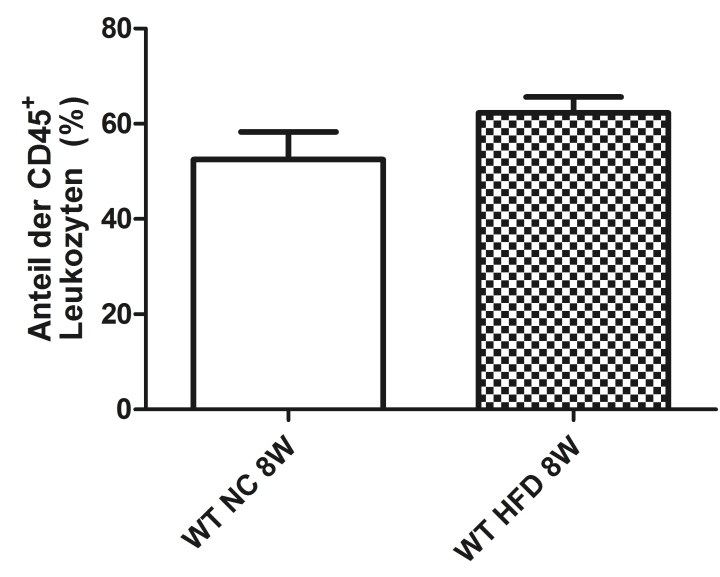

b

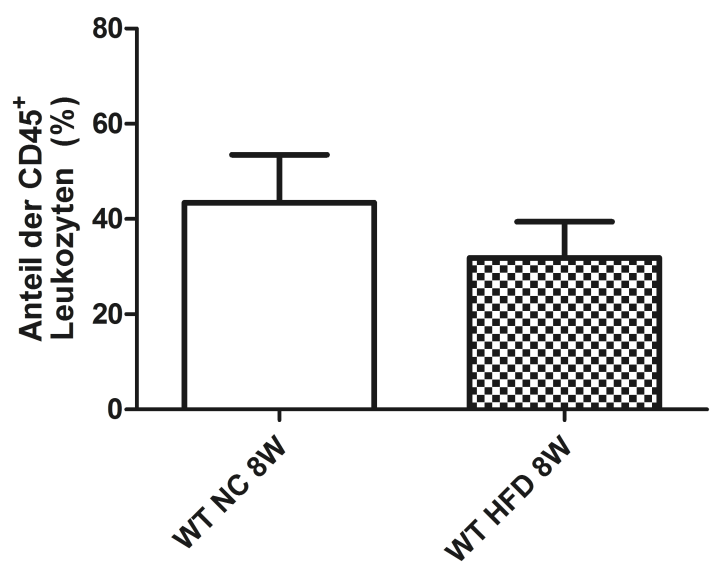

Abb. 3.10 Zusammenfassung der Durchflusszytometrischen Analysen: (a) Anteil der CD45-positiven Leukozyten unter Einfluss von Übergewicht (a) im viszeralen Fettgewebe, (b) im perivaskulären Fettgewebe

In einem nächsten Schritt wurde das perivaskuläre Fettgewebe auf das Vorkommen spezifischer inflammatorischer Zellen wie Monozyten und Lymphozyten untersucht. Hierfür wurden zunächst Immunfluoreszenzfärbungen erstellt. Außerdem wurden Fettgewebsproben mittels PCR und Durchflusszytometrie auf die Expression von bzw. ihren Gehalt an spezifischen Molekülen untersucht. Mit Hilfe von Antikörpern gegen spezifische Oberflächenantigene wurden die vorhandenen Leukozyten den entsprechenden Subpopulationen zugeordnet.

\subsubsection{Monozytäre Zellen}

Monozyten sind an der Proinflammation beteiligt und unterscheiden sich durch spezifische Rezeptoren auf der Zelloberfläche. mRNA- Analysen und Immunfluoreszenzfärbungen des 
perivaskulären Fettgewebes wurden zu deren Spezifizierung eingesetzt. Zur Detektion monozytärer Zellen im Gewebe wurde ein Antikörper gegen den Transmembranrezeptor F4/80 verwendet. Der mRNA-Nachweis mittels RT-PCR sowie Immunfluoreszenzfärbungen zeigten einen signifikanten Anstieg der F4/80-Expression im perivaskulären Fettgewebe bereits nach 4 Wochen Hochfettdiät und weisen auf eine frühe Aktivierung interstitieller Monozyten als Antwort auf das beginnende Übergewicht hin. (Abb. 3.11)

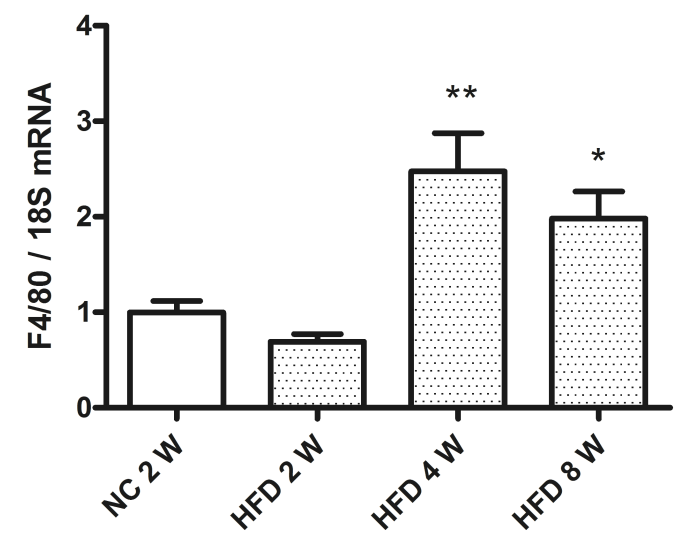

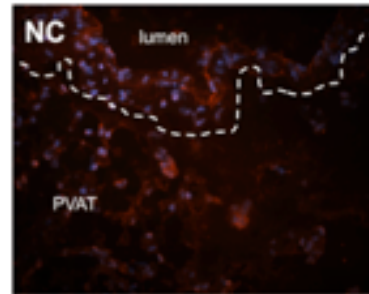
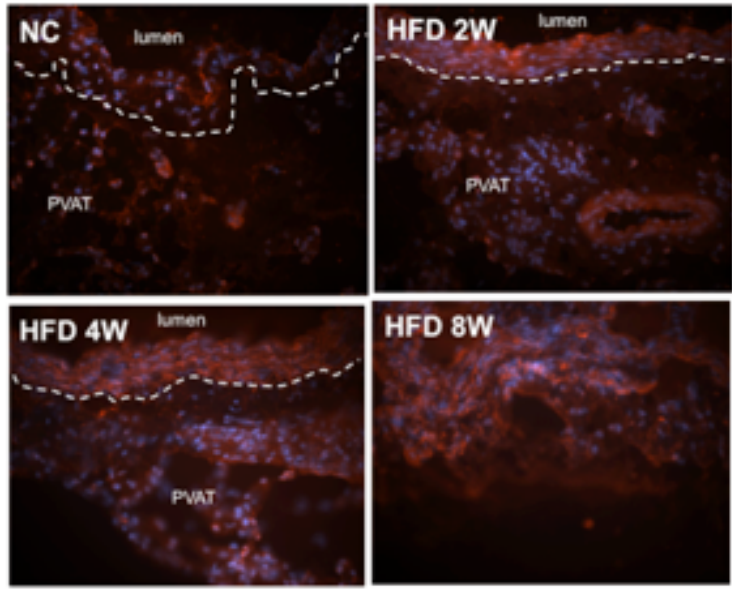

b

Abb. 3.11 Zusammenfassung der Ergebnisse zur (a) mRNA-Expression sowie (b) Immunfluoreszenz von F4/80positiven Monozyten im perivaskulären Fettgewebe (PVAT) unter Einfluss von Übergewicht. (a) *p $<0,05$ und **p $<0,01$ für den Vergleich vs. NC 2W, (b) Anfärbung F4/80-positiver Monozyten in rot und Kernanfärbung in DAPI

Eine weitere Spezifizierung der Monozyten erfolgte mit Hilfe durchflusszytometrischer Analysen. Doppelfärbungen der Zellen erlaubten eine Unterscheidung der F4/80-positiven Monozyten in CD11b-positive Monozyten, Ly6C-positive proinflammatorische Monozyten sowie CD11c-positive dendritische Zellen.

Für die WT + 8W HFD-Gruppe ergab sich für alle 3 monozytären Subspezies ein nicht signifikanter Anstieg im Vergleich zur WT $+2 \mathrm{~W}$ NC-Kontrollgruppe (siehe Abb. 3.12): (a) CD11b: 8,7 $\pm 2,8 \%$ vs 2,6 $\pm 1,1 \%, p=0,11$; (b) Ly6C: $10,3 \pm 3,4 \%$ vs. $2,6 \pm 1,7 \%, p=0,11$; (c) CD11c: $8,7 \pm 2,8 \%$ vs. $2,6 \pm 1,1 \%$, p=0,1). 


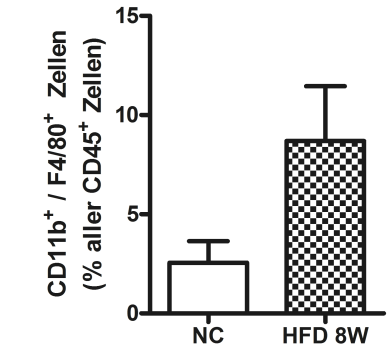

a

Abb. 3.12 Zusammenfassung der Durchflusszytometrischen Ergebnisse: Monozyten im perivaskulären Fettgewebe: (a) $\mathrm{CD} 11 \mathrm{~b}^{+} / \mathrm{F} 4 / 80^{+}$Monozyten; (b) Ly6C $\mathrm{C}^{+} / \mathrm{F} 4 / 80^{+}$proinflammatorische Monozyten; (c) $\mathrm{CD} 11 \mathrm{c}^{+} / \mathrm{F} 4 / 80^{+}$dendritische Zellen.

\subsubsection{T-lymphozytäre Zellen}

Die Präsenz lymphozytärer Zellen im perivaskulären Fettgewebe wurde ebenfalls zunächst mittels Immunfluoreszenz nachgewiesen. Hierzu wurde der T-Zell-Rezeptor-Komplex CD3 angefärbt und weiterhin mittels RT-PCR die CD3 mRNA-Expression im perivaskulären Gewebes bestimmt. Die Ergebnisse zeigen eine deutliche, aber nicht signifikante Erhöhung der T-lymphozytären Zellen im perivaskulären Fettgewebe unter Einfluss von Hochfettdiät (Abb. 3.13).

$\mathbf{a}$

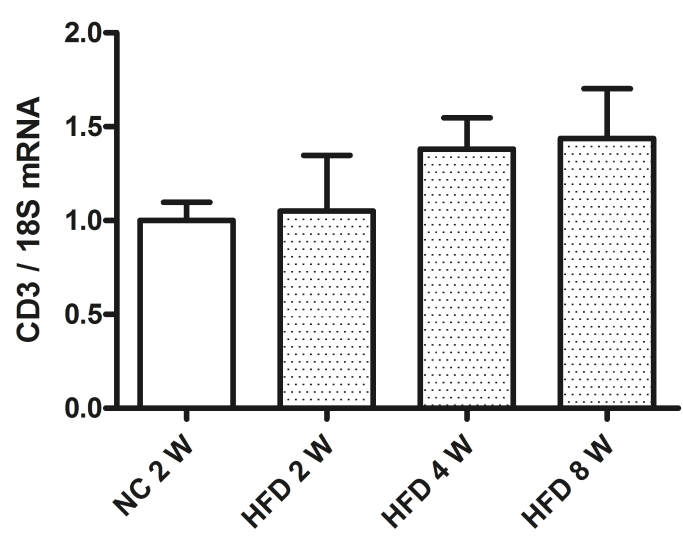

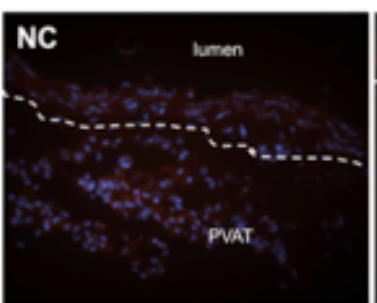
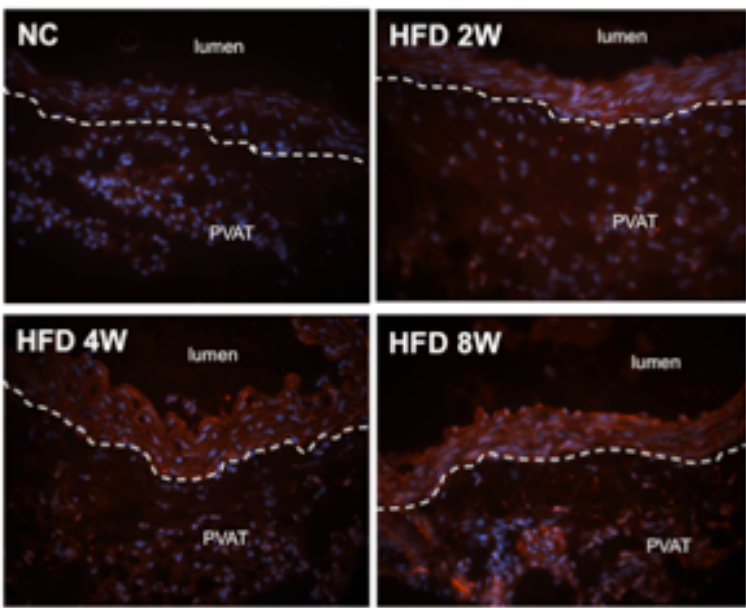

Abb. 3.13 Zusammenfassung der Ergebnisse zur (a) mRNA-Expression sowie (b) Immunfluoreszenz von CD3positiven T-Lymphozyten im perivaskulären Fettgewebe (PVAT) unter Einfluss von Übergewicht. (b) Anfärbung der CD3-positiven T-Lymphozyten in rot und Kernanfärbung in DAPI

Die weitere Analyse der Subgruppen der T-Lymphozyten erfolgte durchflusszytometrisch. Untersucht wurde die Höhe der Expression von CD4 (T-Helfer-Zellen), CD8 (zytotoxische T- 
Zellen) sowie CD49b (natürliche Killer T-Zellen). Für die T-Helfer- und die zytotoxischen TZellen ergab sich eine nicht-signifikante Zunahme der Expression unter Einfluss von Übergewicht im Vergleich zur WT +2 W NC-Kontrollgruppe. Einzig für die Subgruppe der NKT-Zellen konnte ein deutlicher Anstieg unter Hochfettdiät gegenüber der Gruppe mit Normalfettfutter gezeigt werden. Abb. 3.14 veranschaulicht die Ergebnisse: (a) T-HelferZellen $22,6 \pm 1,3 \%$ vs. $11,8 \pm 5,3 \%$, p=0,12; (b) zytotoxische T-Zellen: $25,9 \pm 4,3 \%$ vs. $19,6 \pm 6,9 \%, p=0,48$; (c) NKT Zellen: $11,4 \pm 4,6 \%$ vs. $2,4 \pm 0,9 \%, p=0,13$.

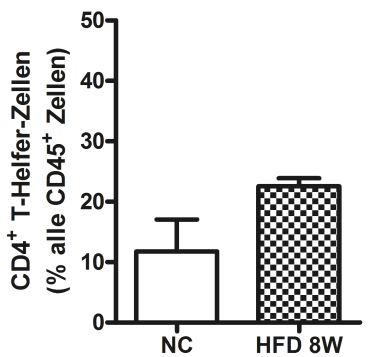

Abb. 3.14 Zusammenfassung der Fettgewebe: (a) $\mathrm{CD}^{+} \mathrm{T}$-Helfer-Zellen; (b)

b

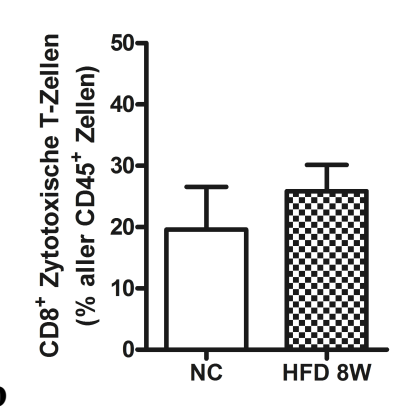

C

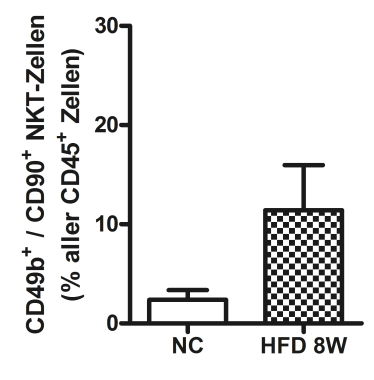

c

urchflusszytometrischen Ergebnisse: T-Lymphozyten im perivaskulären (b) $\mathrm{CD}^{+}$zytotoxische T-Zellen; (c) $\mathrm{CD}_{9} 9 \mathrm{~b}^{+} / \mathrm{CD} 90^{+}$NKT-Zellen

\subsubsection{Untersuchung der Abhängigkeit der perivaskulären Inflammation von Übergewicht und Leptin}

Zusätzlich zur Analyse sowohl der Gesamtleukozytenzahlen als auch der Leukozytensubpopulationen im perivaskulären Fettgewebe bei WT-Mäusen erfolgte die Analyse des Gesamtgehalts an Leukozyten in genetisch übergewichtigen, Leptin-defizienten Mäusen sowie in WT-Mäusen nach 6-monatiger HFD. Diese Gruppe wurde als Kontrollgruppe für das übermäßig hohe Körpergewicht der $o b / o b$-Mäuse gewählt um Gewichtseinflüsse auszuschließen. Zu diesen Zeitpunkten hatten die $o b / o b$-Mäuse das gleiche Übergewicht.wie die WT-HFD-Mäuse. Hier zeigte sich, wie in Abb. 3.15 ersichtlich, in beiden übergewichtigen Gruppen ein signifikanter Anstieg der Leukozytenzahl im perivaskulären Fettgewebe im Vergleich zur normalgewichtigen Kontrollgruppe (WT+6M NC $56,1 \pm 3,1 \%$ vs $o b / o b+8 \mathrm{~W}$ NC 77,8 $\pm 2,6 \%, \mathrm{p}=0,003$ vs. WT $+6 \mathrm{M}$ HFD 75,5 $\pm 0,1 \%$, $\mathrm{p}<0,0002)$. Ein signifikanter Unterschied zwischen den beiden übergewichtigen Gruppen bestand nicht $(\mathrm{p}=0,26)$. 


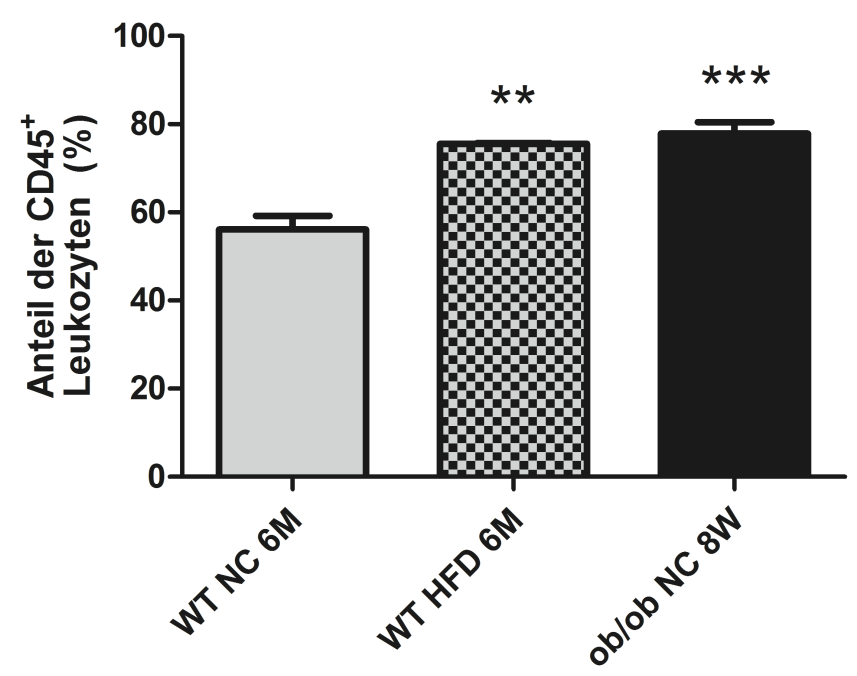

Abb. 3.15 Zusammenfassung der durchflusszytometrischen Analysen: Anteil der CD45-positiven Leukozyten im perivaskulären Fettgewebe unter Einfluss von Übergewicht. ${ }^{* *} \mathrm{p}<0,01$ und ${ }^{* * *} \mathrm{p}<0,001$ für den Vergleich vs. WT $+6 \mathrm{M}$ $\mathrm{NC}$

\subsubsection{Wirkung von Übergewicht auf die viszerale Fettgewebsinflammation mit und ohne} Leptin

Zur weiteren Untersuchung des Einflusses von Übergewicht auf die Fettgewebsinflammation wurde viszerales Fettgewebe von WT und $o b / o b$-Mäusen jeweils nach 8 Wochen auf Normalfutter sowie HFD durchflusszytometrisch untersucht. Diese Analysen ergaben eine signifikant erhöhte Fettgewebsinflammation in den übergewichtigen Leptin-defizienten ob/ob-Mäusen, die unter Normalfettfutter eine gegenüber den WT-Mäusen reduzierte Anzahl der analysierten Zellen aufwiesen.

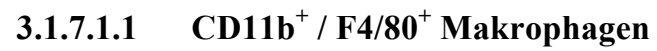

Die Untersuchung der CD1 $1 \mathrm{~b}^{+} / \mathrm{F} 4 / 80^{+}$Makrophagen im VAT ergab in der Wildtypgruppe unter Einfluss von HFD (13,6 \pm 1,3 \%) keinen Unterschied im Vergleich zur Kontrollgruppe $(12,3 \pm 2,2 \%, \mathrm{p}=0,63)$. Setzte man jedoch Leptin-defiziente $o b / o b$-Mäuse für 8 Wochen auf HFD (30,7 $\pm 3,3 \%)$ zeigten sie eine hochsignifikante Zunahme der Makrophagen sowohl im Vergleich zur Kontrollgruppe $(\mathrm{p}<0,001)$, als auch zur Vergleichsgruppe ob/ob auf Normalfutter $(4,0 \pm 0,3 \%, \mathrm{p}<0,001)$, wobei der drastische Anstieg der $o b / o b$-Mäuse unter HFD auch darauf zurückzuführen war, dass unter Normalfettfutter nur eine sehr geringe Zahl 
an Makrophagen im viszeralen Fettgewebe vorhanden war. Abb. 3.16 zeigt die Ergebnisse sowie repräsentative Dot Plots.

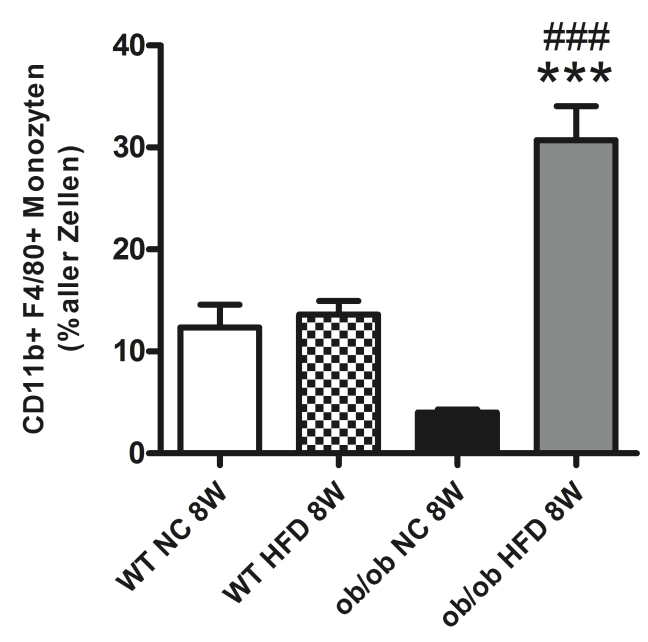

a

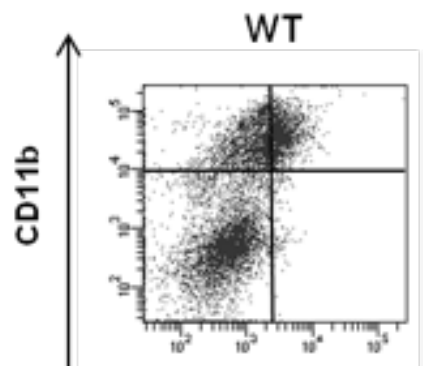

WT+HFD

ob/ob

oblob+HFD

b
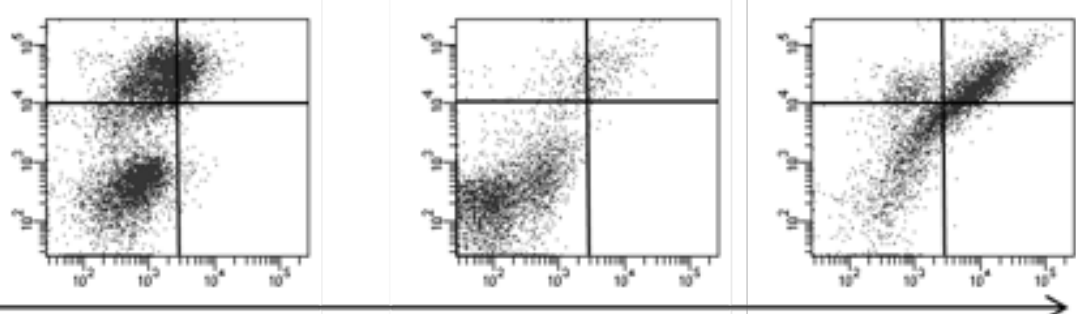

F4/80

Abb. 3.16 Darstellung der durchflusszytometrischen Analysen im VAT (a): Anteil der CD11b / F4/80-positiven Makrophagen. (b) Repräsentative Dot plots $* * * \mathrm{p}<0,001$ für den Vergleich von $o b / o b+8 \mathrm{~W}$ HFD vs. WT $+8 \mathrm{~W}$ NC, ${ }^{\#} \mathrm{p}<0,001$ für den Vergleich von $o b / o b+8 \mathrm{~W}$ HFD vs. $o b / o b+8 \mathrm{~W}$ NC

\subsubsection{2 $\quad \mathrm{Ly}^{6} \mathrm{C}^{+} / \mathrm{F} 4 / 80^{+}$proinflammatorische Monozyten}

Für die proinflammatorischen $\mathrm{Ly} 6 \mathrm{C}^{+} / \mathrm{F} 4 / 80^{+}$Monozyten zeigten sich ebenfalls keine Veränderungen unter HFD in der Wildtypgruppe $(1,6 \pm 0,6$ vs. 1,3 $\pm 0,2 \%, p=0,61)$. Das übermäßige Gewicht der $o b / o b$-Mäuse führte nach 8 Wochen HFD jedoch zu einem hochsignifikanten Anstieg der Monozyten im VAT (12,6 $\pm 0,8 \%$ ) sowohl im Vergleich zur Kontrollgruppe $(\mathrm{p}<0,001)$ als auch zur Gruppe ob/ob-NC $(0,8 \pm 0,1 \%, \mathrm{p}<0,001)$. Abb. 3.17 zeigt repräsentative Dot Plots der Durchflusszytometrie. 


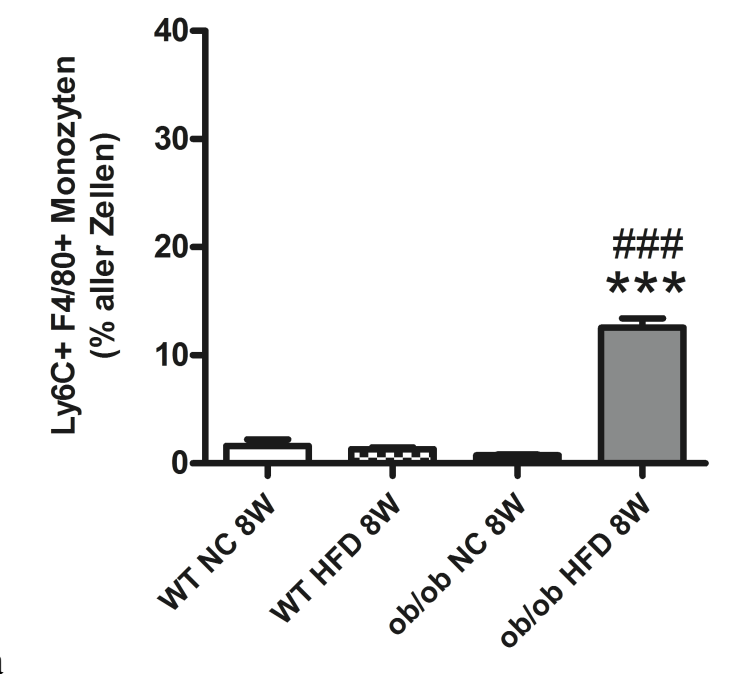

$\mathbf{a}$

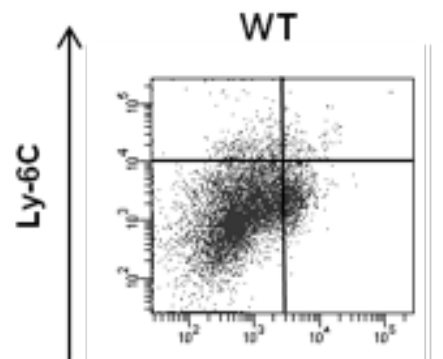

WT+HFD

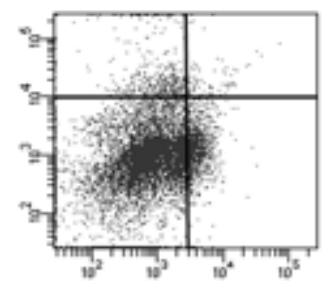

ob/ob

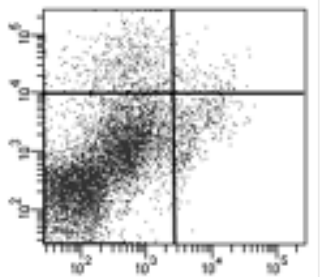

ob/ob+HFD

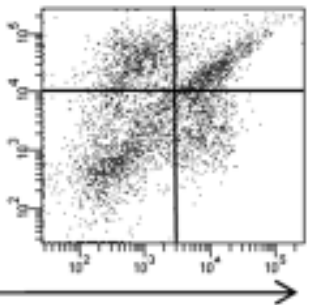

b

F4/80

Abb. 3.17 Darstellung der durchflusszytometrischen Analysen im VAT (a): Anteil der Ly-6C / F4/80-positiven proinflammatorischen Monozyten. (b) Repräsentative Dot plots *** $<0,001$ für den Vergleich von $o b / o b+8 \mathrm{~W}$ HFD vs. $\mathrm{WT}+8 \mathrm{~W}$ NC, ${ }^{\prime \prime} \mathrm{p}<0,001$ für den Vergleich von $o b / o b+8 \mathrm{~W}$ HFD vs. $o b / o b+8 \mathrm{~W}$ NC

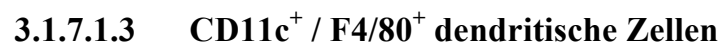

Als dritte Population wurden die CD11 $\mathrm{c}^{+} / \mathrm{F} 4 / 80^{+}$dendritischen Zellen untersucht. Hier ergaben sich analog zu den Ergebnissen der beiden anderen monozytären Populationen keine Unterschiede zwischen WT+HFD- und WT+NC-Mäusen $(2,7 \pm 0,6$ vs. $1,3 \pm 0,3 \%, p=0,06)$. Die Gruppe der Leptin-defizienten $o b / o b$-Mäuse zeigte unter Einfluss von 8 Wochen HFD eine hochsignifikante Erhöhung der dendritischen Zellen $(10,5 \pm 0,4 \%, p<0,001)$ im Vergleich zur Kontrollgruppe sowie zur Gruppe der $o b / o b+8 \mathrm{~W}-\mathrm{NC}(\mathrm{p}<0,01)$. Abb. 3.18 zeigt die graphische Zusammenfassung der Ergebnisse sowie repräsentative Dot Plots. 

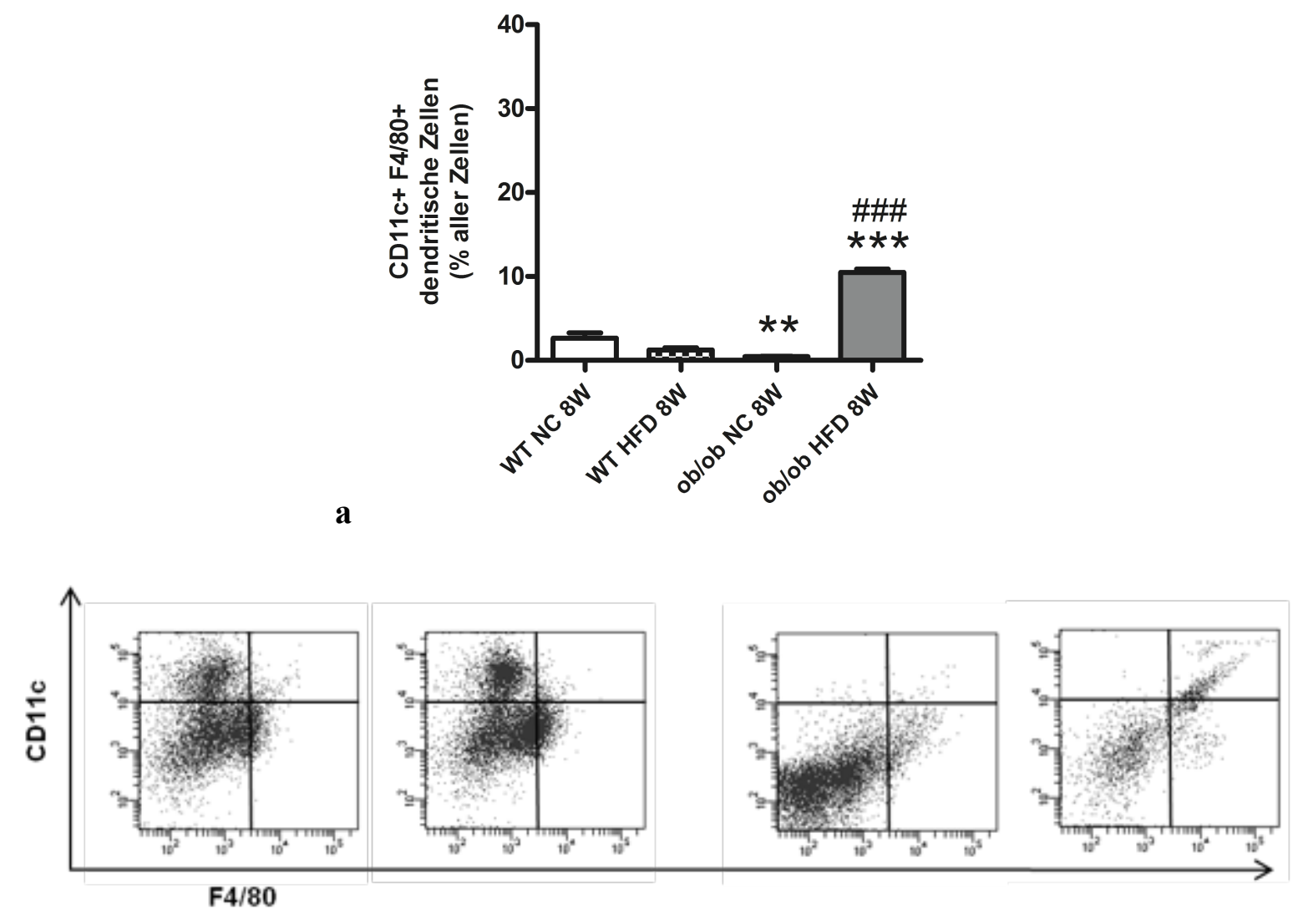

Abb. 3.18 Darstellung der durchflusszytometrischen Analysen im VAT: Anteil der CD11c / F4/80-positiven dendritischen Zellen. ${ }^{* *} \mathrm{p}<0,01$ und ${ }^{* * *} \mathrm{p}<0,001$ für den Vergleich von $o b / o b+8 \mathrm{~W}$ HFD vs. WT $+8 \mathrm{~W}$ NC, ${ }^{\# \#} \mathrm{p}<0,001$ für den Vergleich von $o b / o b+8 \mathrm{~W}$ HFD vs. $o b / o b+8 \mathrm{~W}$ NC

\subsection{CD4 $^{+}$T-Helfer-Lymphozyten}

Neben den monozytären Zellen wurden auch die T-Lymphozyten des VAT untersucht. Auch hier zeigte sich keine Veränderung innerhalb der WT-Gruppe unter Einfluss von Übergewicht $(1,9 \pm 0,6$ vs. $1,1 \pm 0,3 \%, \mathrm{p}=0,30)$. Die $o b / o b$-Mäuse zeigten unter Einfluss von HFD eine hochsignifikante Steigerung der Anzahl der T-Helfer-Zellen im VAT $(13,0 \pm 1,8 \%, p<0,01)$ im Vergleich zur Kontrollgruppe sowie zur Gruppe der $o b / o b+8 \mathrm{~W}-\mathrm{NC}(\mathrm{p}<0,01)$. Zudem zeigte die $o b / o b+8 \mathrm{~W}-\mathrm{NC}-$ Gruppe eine signifikante Reduktion im Vergleich zur WT+8W NCKontrollgruppe $(\mathrm{p}<0,01)$. Abb. 3.19 stellt die Ergebnisse grafisch dar. 


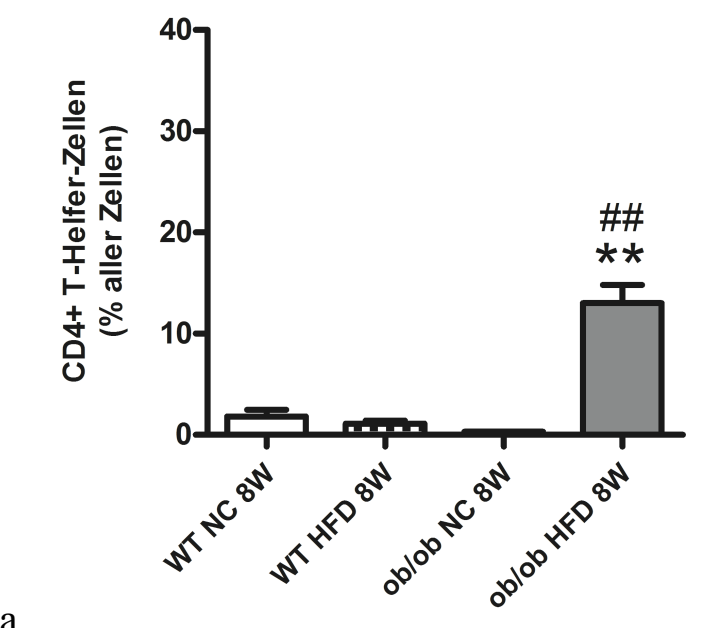

a
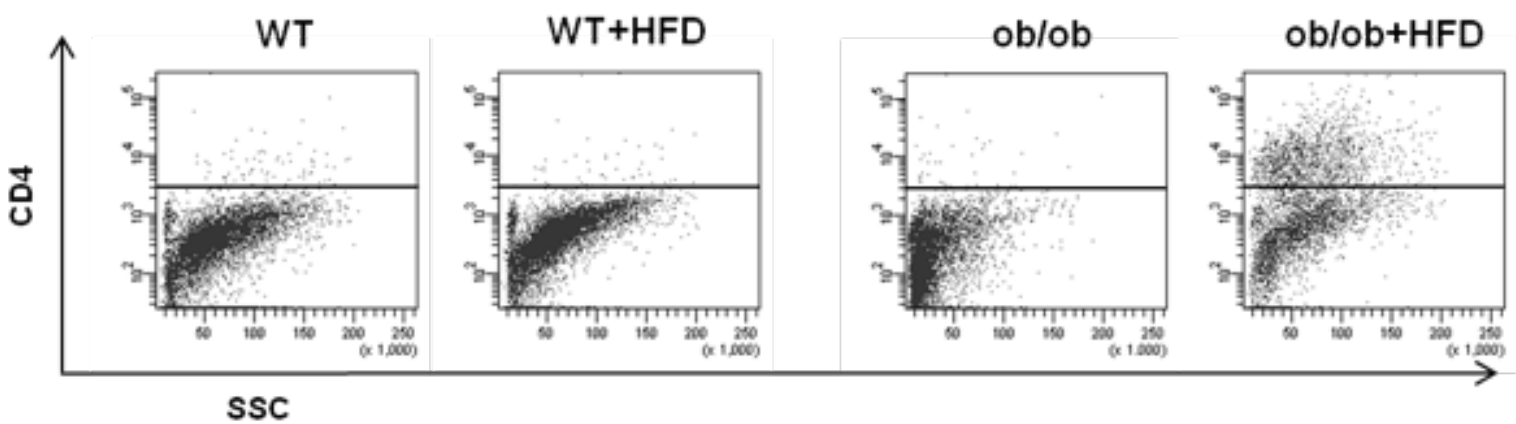

b

Abb. 3.19 Darstellung der durchflusszytometrischen Analysen im VAT (a): Anteil der CD4-positiven T-HelferLymphozyten. (b) Repräsentative Dot plots ${ }^{*} * \mathrm{p}<0,01$ für den Vergleich von $o b / o b+8 \mathrm{~W}$ HFD vs. WT $+8 \mathrm{~W}$ NC, ${ }^{\#} \mathrm{p}<0,01$ für den Vergleich von $o b / o b+8 \mathrm{~W}$ HFD vs. $o b / o b+8 \mathrm{~W} \mathrm{NC}$

\subsubsection{5 $\quad \mathrm{CD8}^{+}$zytotoxische T-Lymphozyten}

Neben den T-Helfer-Zellen wurde auch der Gehalt an zytotoxischen CD8 ${ }^{+}$Lymphozyten untersucht. Hier zeigte sich kein Einfluss des Übergewichts auf die viszerale Präsenz von zytotoxischen T-Zellen bei den WT-Mäusen (WT+8W NC 1,2 $\pm 0,2$ vs. WT+8W HFD 1,3 \pm $0,2 \%, \mathrm{p}=0,83)$, jedoch zeigten die Leptin-defizienten $o b / o b$-Mäuse einen signifikanten Anstieg im Vergleich zur WT+8W NC-Kontrollgruppe $(13,6 \pm 1,8 \%, \mathrm{p}=0,0001)$. In Abb. 3.20 sind die Ergebnisse sowie repräsentative Dot Plots dargestellt. 

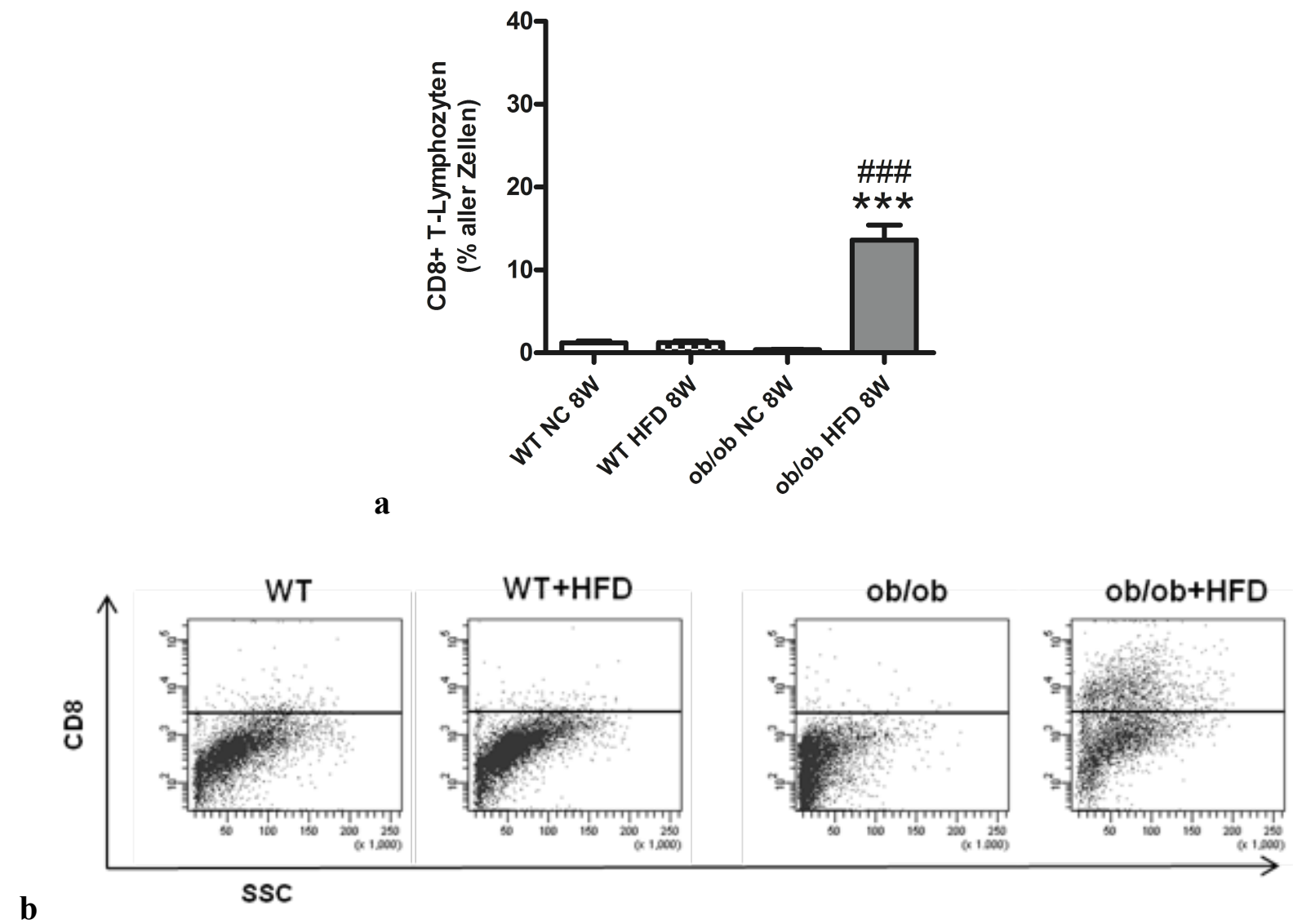

Abb. 3.20 Darstellung der durchflusszytometrischen Analysen im VAT (a): Anteil der CD8-positiven zytotoxischen TLymphozyten. (b) Repräsentative Dot plots $* * * \mathrm{p}<0,001$ für den Vergleich von $o b / o b+8 \mathrm{~W}$ HFD vs. WT $+8 \mathrm{~W} \mathrm{NC}$, $\#$ p $<0,001$ für den Vergleich von $o b / o b+8 \mathrm{~W}$ HFD vs. $o b / o b+8 \mathrm{~W}$ NC 


\subsection{Humane Studie}

\subsubsection{Klinische und laborchemische Charakterisierung des Patientenkollektivs}

Für die Charakterisierung und Analyse des Patientenkollektivs wurden sowohl demografische und laborchemische Parameter, als auch kardiovaskuläre Risikofaktoren und die aktuelle Medikation erfasst. Unter den KHK-Patienten befanden sich mehrheitlich Männer, wodurch ein eventueller geschlechtsspezifischer Faktor vermindert werden sollte. In Tab. 3.1 bis Tab. 3.6 sind die Daten sowie die Auswertung in Abhängigkeit vom Vorliegen einer KHK und des BMI ersichtlich.

\begin{tabular}{|c|c|c|c|}
\hline & \multicolumn{2}{|c|}{ KHK } & \multirow[t]{2}{*}{$\mathbf{p}$} \\
\hline & $\mathrm{BMI}<\mathbf{3 0}$ & $\mathbf{B M I}>\mathbf{3 0}$ & \\
\hline $\mathrm{n}$ & 10 & 6 & \\
\hline Alter (Jahre) & $76,3 \pm 2,9$ & $66,5 \pm 4,6$ & 0,13 \\
\hline Geschlecht $(\%$ ठ & $8(80)$ & $6(100)$ & 0,24 \\
\hline Körpergewicht (kg) & $78,2 \pm 3,7$ & $97,5 \pm 5,2$ & $0,04 *$ \\
\hline $\operatorname{BMI}\left(\mathrm{kg} / \mathrm{m}^{2}\right)$ & $26,2 \pm 0,5$ & $34,9 \pm 1,6$ & $<0,001 * * *$ \\
\hline \multicolumn{4}{|c|}{$\underline{\text { Kardiovaskuläre Risikofaktoren }}$} \\
\hline Rauchen & $3(19 \%)$ & $2(33 \%)$ & 0,89 \\
\hline Diabetes & $5(50 \%)$ & $2(33 \%)$ & 0,52 \\
\hline Art. Hypertonie & $9(90 \%)$ & $6(100 \%)$ & 0,42 \\
\hline \multicolumn{4}{|c|}{$\underline{\text { Kardiovaskuläre Erkrankungen }}$} \\
\hline$K H K$ & $10(100 \%)$ & $6(100 \%)$ & $\mathrm{n} / \mathrm{v}$ \\
\hline \multicolumn{4}{|l|}{$\underline{\text { Medikation }}$} \\
\hline$A S S$ & $7(78 \%)$ & $6(100 \%)$ & 0,14 \\
\hline Statine & $4(44 \%)$ & $5(83 \%)$ & 0,09 \\
\hline ACE- / AT1-Hemmer & $6(67 \%)$ & $6(100 \%)$ & 0,07 \\
\hline$\beta$-Blocker & $4(44 \%)$ & $5(83 \%)$ & 0,09 \\
\hline $\begin{array}{l}\text { Insulin / orale } \\
\text { Antidiabetika }\end{array}$ & $2(22 \%)$ & $2(33 \%)$ & 0,55 \\
\hline \multicolumn{4}{|l|}{$\underline{\text { KHK-Schweregrad }}$} \\
\hline 1-Gefäß-KHK & $0(0 \%)$ & $0(0 \%)$ & $\mathrm{n} / \mathrm{v}$ \\
\hline 2-Gefäß-KHK & $1(10 \%)$ & $1(17 \%)$ & 0,70 \\
\hline 3-Gefäß-KHK & $9(90 \%)$ & $5(83 \%)$ & 0,70 \\
\hline $\mathrm{EF}(\%)$ & $49,5 \pm 4,1$ & $48,3 \pm 3,3$ & 0,84 \\
\hline
\end{tabular}

Tab. 3.1 Klinische Merkmale der Studienpatienten: Einfluss von Adipositas bei vorliegender KHK 


\begin{tabular}{|c|c|c|c|}
\hline & keine KHK & KHK & $\mathbf{p}$ \\
\hline$n$ & 6 & 16 & \\
\hline Alter (Jahre) & $67,7 \pm 4,3$ & $72,6 \pm 2,7$ & 0,35 \\
\hline Geschlecht $(\%$ ठ $)$ & $3(50 \%)$ & $14(88 \%)$ & 0,06 \\
\hline Körpergewicht (kg) & $80,3 \pm 7,6$ & $85,4 \pm 3,8$ & 0,52 \\
\hline BMI $\left(\mathrm{kg} / \mathrm{m}^{2}\right)$ & $26,1 \pm 2,1$ & $29,5 \pm 1,3$ & 0,18 \\
\hline \multicolumn{4}{|c|}{ Kardiovaskuläre Risikofaktoren } \\
\hline Rauchen & $1(17 \%)$ & $5(31 \%)$ & 0,49 \\
\hline Diabetes & $0(0 \%)$ & $7(44 \%)$ & $0,04 *$ \\
\hline Art. Hypertonie & $3(50 \%)$ & $15(94 \%)$ & $0,02 *$ \\
\hline \multicolumn{4}{|c|}{$\underline{\text { Kardiovaskuläre Erkrankungen }}$} \\
\hline$K H K$ & $0(0 \%)$ & $16(100 \%)$ & $\mathrm{n} / \mathrm{v}$ \\
\hline \multicolumn{4}{|l|}{$\underline{\text { Medikation }}$} \\
\hline$A S S$ & $1(17 \%)$ & $13(81 \%)$ & $0,005 * *$ \\
\hline Statine & $1(17 \%)$ & $9(56 \%)$ & 0,09 \\
\hline ACE-/AT1-Hemmer & $3(50 \%)$ & $12(75 \%)$ & 0,26 \\
\hline$\beta$-Blocker & $4(67 \%)$ & $9(56 \%)$ & 0,66 \\
\hline $\begin{array}{l}\text { Insulin / orale } \\
\text { Antidiabetika }\end{array}$ & $0(0 \%)$ & $4(25 \%)$ & 0,18 \\
\hline Diuretika & $2(33 \%)$ & $8(50 \%)$ & 0,48 \\
\hline \multicolumn{4}{|l|}{ KHK-Schweregrad } \\
\hline 1-Gefäß-KHK & $0(0 \%)$ & $0(0 \%)$ & $\mathrm{n} / \mathrm{v}$ \\
\hline 2-Gefäß-KHK & $0(0 \%)$ & $2(13 \%)$ & 0,36 \\
\hline 3-Gefäß-KHK & $0(0 \%)$ & $14(88 \%)$ & $0,0001 * * *$ \\
\hline
\end{tabular}

Tab. 3.2 Klinische Merkmale der Studienpatienten: Einfluss von KHK

\begin{tabular}{|c|c|c|c|}
\hline & BMI $<30 \mathrm{~kg} / \mathrm{m}^{2}$ & $\mathrm{BMI}>30 \mathrm{~kg} / \mathrm{m}^{2}$ & $\mathbf{p}$ \\
\hline $\mathrm{n}$ & 14 & 8 & \\
\hline Alter (Jahre) & $74,7 \pm 2,3$ & $65,3 \pm 4,3$ & $0,04 *$ \\
\hline Geschlecht (\% Љ゙) & $10(71 \%)$ & $7(88 \%)$ & 0,39 \\
\hline Körpergewicht (kg) & $77,2 \pm 3,7$ & $96,0 \pm 4,1$ & $0,004 * *$ \\
\hline BMI $\left(\mathrm{kg} / \mathrm{m}^{2}\right)$ & $25,5 \pm 0,8$ & $33,8 \pm 1,4$ & $<0,001 * * *$ \\
\hline \multicolumn{4}{|c|}{$\underline{\text { Kardiovaskuläre Risikofaktoren }}$} \\
\hline Rauchen & $1(7 \%)$ & $3(38 \%)$ & 0,08 \\
\hline Diabetes & $3(21 \%)$ & $2(25 \%)$ & 0,85 \\
\hline Art. Hypertonie & $11(79 \%)$ & $7(88 \%)$ & 0,60 \\
\hline \multicolumn{4}{|c|}{$\underline{\text { Kardiovaskuläre Erkrankungen }}$} \\
\hline KHK & $10(71 \%)$ & $6(75 \%)$ & 0,86 \\
\hline Medikation & & & \\
\hline
\end{tabular}




\begin{tabular}{rccc}
\hline ASS & $8(57 \%)$ & $7(75 \%)$ & 0,14 \\
\hline Statine & $5(35 \%)$ & $6(75 \%)$ & 0,08 \\
\hline ACE-/AT1-Hemmer & $8(56 \%)$ & $8(100 \%)$ & $0,03 *$ \\
\hline -Blocker & $7(50 \%)$ & $7(88 \%)$ & 0,53 \\
\hline $\begin{array}{r}\text { Insulin / orale } \\
\text { Antidiabetika }\end{array}$ & $2(14 \%)$ & $2(25 \%)$ & 0,74 \\
\hline Diuretika & $6(42 \%)$ & $4(50 \%)$ & $\mathrm{n} / \mathrm{v}$ \\
\hline KHK-Schweregrad & $0(0 \%)$ & $0(0 \%)$ & 0,52 \\
\hline 1-Gefäß-KHK & $1(7 \%)$ & $1(13 \%)$ & 0,93 \\
\hline 3-Gefäß-KHK 3 -KHK & $9(64 \%)$ & $5(63 \%)$ & \\
\hline
\end{tabular}

Tab. 3.3 Klinische Merkmale der Studienpatienten: Einfluss von Adipositas

\begin{tabular}{lccc}
\hline & & KHK & p \\
& BMI $<\mathbf{3 0 ~} \mathbf{~ k g} / \mathbf{m}^{\mathbf{2}}$ & $\mathbf{B M I}>\mathbf{3 0} \mathbf{~ k g} / \mathbf{m}^{\mathbf{2}}$ & 0,76 \\
\hline Leukozyten $\left(10^{3} / \mu \mathrm{l}\right)$ & $9,2 \pm 1,5$ & $8,6 \pm 1,3$ & 0,18 \\
\hline $\mathrm{Hb}(\mathrm{g} / \mathrm{dl})$ & $12,6 \pm 0,8$ & $14,2 \pm 0,5$ & 0,75 \\
\hline Thrombozyten $\left(10^{3} / \mu \mathrm{l}\right)$ & $239 \pm 14,9$ & $229 \pm 28,8$ & 0,51 \\
\hline Kreatinin $(\mathrm{mg} / \mathrm{dl})$ & $1,21 \pm 0,2$ & $1,07 \pm 0,1$ & 0,36 \\
\hline GFR (ml/min) & $68,1 \pm 8,2$ & $81,6 \pm 12,7$ & 0,88 \\
\hline CRP $(\mathrm{mg} / \mathrm{l})$ & $4,0 \pm 0,9$ & $8,1 \pm 3,6$ & 0,14 \\
\hline Leptin im Serum $(\mathrm{ng} / \mathrm{ml})$ & $10,5 \pm 5,0$ & $18,8 \pm 3,9$ & 0,91 \\
\hline Leptin im PVAT $(\mathrm{ng} / \mathrm{ml})$ & $2,7 \pm 0,7$ & $2,3 \pm 0,02$ & 0,31 \\
\hline Leptin im VAT $(\mathrm{ng} / \mathrm{ml})$ & $4,9 \pm 1,4$ & $7,8 \pm 0,2$ & 0,28
\end{tabular}

Tab. 3.4 Laborchemische Parameter der Studienpatienten: Einfluss von Adipositas bei vorliegender KHK

\begin{tabular}{lccc}
\hline & keine KHK & KHK & p \\
\hline Leukozyten $\left(10^{3} / \mu \mathrm{l}\right)$ & $7,6 \pm 0,9$ & $9,0 \pm 1,1$ & 0,35 \\
\hline $\mathrm{Hb}(\mathrm{g} / \mathrm{dl})$ & $12,1 \pm 0,7$ & $13,2 \pm 0,6$ & 0,33 \\
\hline Thrombozyten $\left(10^{3} / \mu \mathrm{l}\right)$ & $241 \pm 22,8$ & $235 \pm 13,7$ & 0,84 \\
\hline Kreatinin $(\mathrm{mg} / \mathrm{dl})$ & $1,30 \pm 0,2$ & $1,16 \pm 0,1$ & 0,47 \\
\hline GFR $(\mathrm{ml} / \mathrm{min})$ & $58,2 \pm 10,6$ & $73,2 \pm 6,9$ & 0,27 \\
\hline CRP $(\mathrm{mg} / \mathrm{l})$ & $2,1 \pm 0,9$ & $8,1 \pm 3,5$ & 0,35 \\
\hline Leptin im Serum $(\mathrm{ng} / \mathrm{ml})$ & $4,4 \pm 2,8$ & $10,3 \pm 2,6$ & 0,30 \\
\hline Leptin im PVAT $(\mathrm{ng} / \mathrm{ml})$ & $2,7 \pm 1,4$ & $2,7 \pm 0,6$ & 0,98 \\
\hline Leptin im VAT $(\mathrm{ng} / \mathrm{ml})$ & $3,8 \pm 1,8$ & $5,4 \pm 1,2$ & 0,49
\end{tabular}

Tab. 3.5 Laborchemische Parameter der Studienpatienten: Einfluss von KHK 


\begin{tabular}{lccc}
\hline & BMI $<\mathbf{3 0} \mathbf{~ k g} / \mathbf{m}^{\mathbf{2}}$ & $\mathbf{B M I}>\mathbf{3 0} \mathbf{~ k g} / \mathbf{m}^{\mathbf{2}}$ & $\mathbf{p}$ \\
\hline Leukozyten $\left(10^{3} / \mu \mathrm{l}\right)$ & $8,7 \pm 1,1$ & $8,1 \pm 1,2$ & 0,70 \\
\hline $\mathrm{Hb}(\mathrm{g} / \mathrm{dl})$ & $12,4 \pm 0,6$ & $14,1 \pm 0,4$ & $\mathbf{0 , 0 7}$ \\
\hline Thrombozyten $\left(10^{3} / \mu \mathrm{l}\right)$ & $244 \pm 12,1$ & $222 \pm 25,4$ & 0,39 \\
\hline Kreatinin $(\mathrm{mg} / \mathrm{dl})$ & $1,27 \pm 0,1$ & $1,06 \pm 0,1$ & 0,27 \\
\hline GFR $(\mathrm{ml} / \mathrm{min})$ & $63,4 \pm 6,7$ & $79,0 \pm 10,6$ & 0,21 \\
\hline CRP $(\mathrm{mg} / \mathrm{l})$ & $7,6 \pm 4,0$ & $6,9 \pm 2,8$ & 0,85 \\
\hline Leptin im Serum $(\mathrm{ng} / \mathrm{ml})$ & $8,9 \pm 3,0$ & $9,6 \pm 3,4$ & 0,89 \\
\hline Leptin im PVAT $(\mathrm{ng} / \mathrm{ml})$ & $2,9 \pm 0,6$ & $2,0 \pm 0,3$ & 0,38 \\
\hline Leptin im VAT $(\mathrm{ng} / \mathrm{ml})$ & $5,0 \pm 1,1$ & $4,8 \pm 2,8$ & 0,93 \\
\hline
\end{tabular}

Tab. 3.6 Laborchemische Parameter der Studienpatienten: Einfluss von Adipositas

\subsubsection{Charakterisierung der zirkulierenden Leukozyten}

Zunächst erfolgte eine durchflusszytometrische Analyse des peripher-venösen Vollblutes. Hierdurch erfolgte eine Charakterisierung der zirkulierenden Leukozyten. Tab. 3.7 zeigt die Aufteilung der Leukozytensubpopulationen.

\begin{tabular}{llc}
\hline \multicolumn{1}{c}{ Zelltyp } & Antigen & Anteil an den Gesamtleukozyten (\%) \\
\hline Neutrophile Granulozyten & CD66b & $59 \pm 1,5$ \\
\hline Monozyten & CD14 & $8,9 \pm 1,2$ \\
\hline Natürliche Killerzellen & CD161 & $22 \pm 4,5$ \\
\hline T-Helfer-Zellen & CD4 & $20 \pm 1,5$ \\
\hline Zytotoxische T-Lymphozyten & CD8 & $13 \pm 1,3$ \\
\hline B-Lymphozyten & CD19 & $3,6 \pm 0,9$ \\
\hline
\end{tabular}

Tab. 3.7 Charakterisierung der zirkulierenden Leukozyten.

In weiteren Untersuchungen wurde die Expression sowohl des Integrins $\alpha_{4}$ als auch des Leptinrezeptors sowie deren Koexpression auf den einzelnen Subpopulationen untersucht. Wie in Tab. 3.8 ersichtlich, zeigt die Expression deutliche Schwankungen zwischen den einzelnen Leukozytenpopulationen. 


\begin{tabular}{|c|c|c|c|}
\hline Zelltyp & $\begin{array}{c}\text { Anteil Integrin } \alpha_{4}^{+} \\
\text {Zellen (\%) }\end{array}$ & $\begin{array}{c}\text { Anteil ObR }{ }^{+} \text {Zellen } \\
(\%)\end{array}$ & $\begin{array}{c}\text { Anteil Integrin } \alpha_{4}^{+}, \\
\text {ObR }^{+} \text {Zellen (\%) }\end{array}$ \\
\hline Neutrophile Granulozyten & $9,9 \pm 2,4$ & $84 \pm 3,7$ & $7,8 \pm 2,0$ \\
\hline Monozyten & $100 \pm 0,0$ & $99 \pm 0,4$ & $99 \pm 0,3$ \\
\hline Natürliche Killerzellen & $31 \pm 10$ & $86 \pm 3,1$ & $27 \pm 9,6$ \\
\hline T-Helfer-Zellen & $54 \pm 3,1$ & $79 \pm 7,8$ & $44 \pm 5,4$ \\
\hline Zytotoxische T-Lymphozyten & $67 \pm 6,5$ & $71 \pm 5,3$ & $47 \pm 3,7$ \\
\hline B-Lymphozyten & $99 \pm 1,1$ & $100 \pm 0,0$ & $100 \pm 0,0$ \\
\hline
\end{tabular}

Tab. 3.8 Expression von Integrin $\alpha_{4}$ und Leptinrezeptor auf Leukozytensubpopulationen

Weiterhin wurde untersucht inwieweit sich die Expression von Integrin $\alpha_{4}$ unter Einfluss von Übergewicht sowie mit und ohne Vorliegen einer KHK verändert (Abb. 3.21). Hier ergaben die Analysen mittels Durchflusszytometrie einen im Vergleich zur Kontrollgruppe (43,3 \pm $1,2 \%)$ signifikant niedrigeren Anteil Integrin $\alpha_{4}$-positiver Leukozyten sowohl bei übergewichtigen Patienten $(36,6 \pm 1,3 \%, \mathrm{p}<0,01)$ als auch bei denen mit manifester KHK ohne Übergewicht $(34,4 \pm 2,5 \%, \mathrm{p}<0,01)$. Auch innerhalb der Gruppe der übergewichtigen Patienten hat das Vorliegen einer KHK einen kongruenten Einfluss (36,6 $\pm 1,3 \%$ vs. 27,6 \pm $1,5 \%, \mathrm{p}<0,05)$.

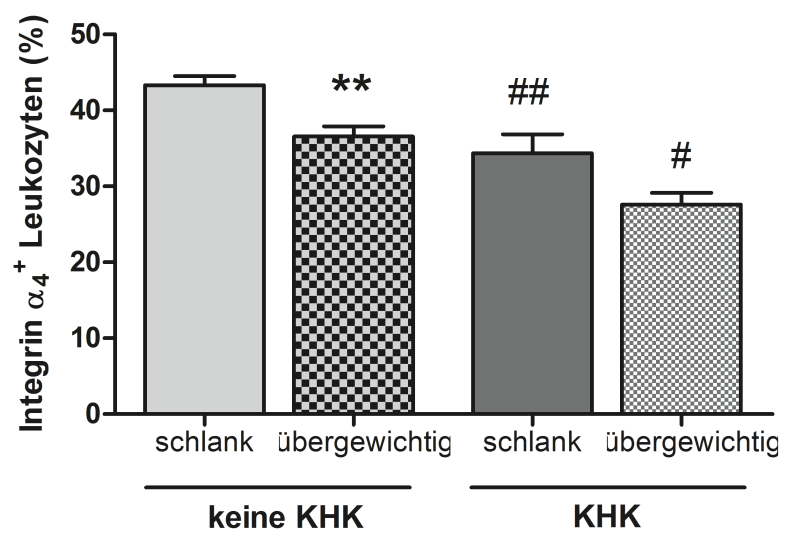

Abb. 3.21 Darstellung der durchflusszytometrischen Analysen im peripheren Blut: Expression von Integrin $\alpha_{4}$ auf Immunzellen unter Einfluss von KHK und Übergewicht. ${ }^{* *} \mathrm{p}<0,01$ für den Vergleich übergewichtig/keine KHK vs. schlank/keine KHK, ${ }^{\#}<0,05$ und ${ }^{\# \#} \mathrm{p}<0,01$ für den Vergleich KHK vs. keine KHK bei gleicher BMI-Gruppe 
Abb. 3.22 zeigt repräsentative Dot Plots zur Koexpression von Integrin $\alpha_{4}$ und ObR. Hier zeigt sich eine verminderte Koexpression bei Vorliegen einer KHK, analog zum Rückgang der Expression von Integrin $\alpha_{4}$.
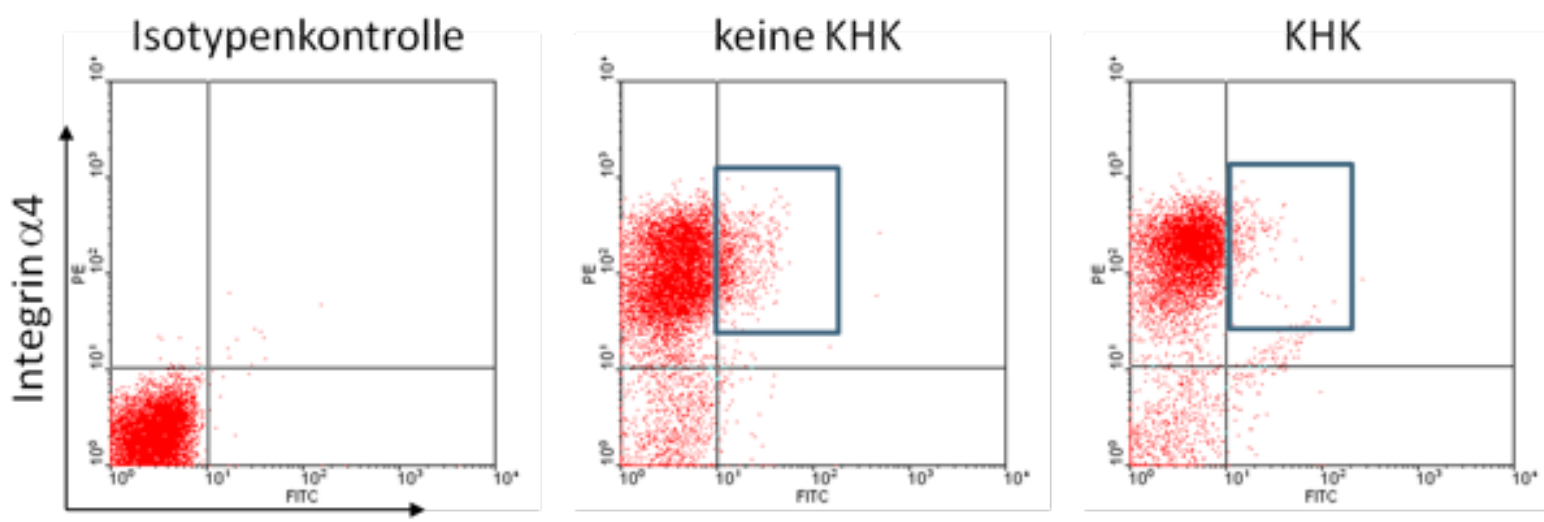

ObR

Abb. 3.22 Darstellung der durchflusszytometrischen Analysen: Repräsentative Dot Plots der Koexpression von Integrin $\alpha_{4}$ und ObR auf peripheren Immunzellen bei Vorliegen einer KHK

\subsubsection{Charakterisierung der Leukozyten im perikardialen Fettgewebe}

Analog zu den Analysen im murinen Modell wurde auch im humanen Modell das perivaskuläre Fettgewebe von Probanden mit und ohne KHK durchflusszytometrisch charakterisiert und der Gehalt an Leukozyten und den einzelnen Subpopulationen bestimmt. Hier ergaben sich für alle untersuchten Zelllinien keine signifikanten Unterschiede sowohl unter Einfluss von Übergewicht als auch Vorhandensein einer koronaren Herzerkrankung. Weder die Gesamtheit der Leukozyten (CD45-positive Zellen), noch die Lymphozyten (CD3, CD4- und CD8-positive Leukozyten), NK-Zellen (CD161-positive Leukozyten), Monozyten (CD14- und CD16-positive Leukozyten) oder Makrophagen (CD206-positive Leukozyten) zeigten Veränderungen in der FACS-Analyse. Ebenso zeigt sich kein Unterschied in der Zahl Integrin $\alpha_{4}$ - und ObR-positiver- Leukozyten. Tab. 3.9 bis Tab. 3.11 zeigen die Ergebnisse der Auswertungen, auch in Hinblick auf den Einfluss von KHK und Adipositas. 


\begin{tabular}{|c|c|c|c|}
\hline $\begin{array}{l}\text { Zellmarker } \\
\text { (alle Angaben in \%) }\end{array}$ & Keine КHК & КНK & $\mathbf{p}$ \\
\hline CD45 & $47,6 \pm 6,5$ & $53,2 \pm 2,7$ & 0,37 \\
\hline \multicolumn{4}{|l|}{ Anteil aller CD45 $^{+}$} \\
\hline \multicolumn{4}{|l|}{ Leukozyten: } \\
\hline CD3 & $55,4 \pm 14,1$ & $46,7 \pm 7,3$ & 0,56 \\
\hline CD4 & $29,1 \pm 9,5$ & $23,3 \pm 5,8$ & 0,62 \\
\hline CD8 & $24,7 \pm 1,7$ & $21,3 \pm 2,5$ & 0,48 \\
\hline CD14 & $48,5 \pm 12,5$ & $30,5 \pm 5,5$ & 0,18 \\
\hline CD16 & $61,2 \pm 7,1$ & $67,8 \pm 7,2$ & 0,58 \\
\hline $\mathrm{CD} 14^{+} / \mathrm{CD} 16^{+}$ & $33,0 \pm 6,2$ & $27,7 \pm 8,0$ & 0,68 \\
\hline CD161 & $26,5 \pm 6,4$ & $17,2 \pm 6,4$ & 0,40 \\
\hline CD206 & $27,5 \pm 5,7$ & $18,4 \pm 5,0$ & 0,30 \\
\hline $\mathrm{CD} 206^{+} / \mathrm{CD} 16^{+}$ & $25,3 \pm 5,3$ & $15,3 \pm 5,0$ & 0,26 \\
\hline Integrin $\alpha_{4}$ & $46,0 \pm 7,8$ & $36,2 \pm 6,3$ & 0,38 \\
\hline ObR & $80,2 \pm 7,6$ & $82,9 \pm 3,6$ & 0,73 \\
\hline Integrin $\alpha_{4}^{+} / \mathrm{ObR}^{+}$ & $41,9 \pm 9,5$ & $31,2 \pm 6,4$ & 0,37 \\
\hline
\end{tabular}

Tab. 3.9 Leukozyten im PVAT: Einfluss von KHK

\begin{tabular}{|c|c|c|c|}
\hline $\begin{array}{l}\text { Zellmarker } \\
\text { (alle Angaben in \%) }\end{array}$ & BMI $<30 \mathrm{~kg} / \mathrm{m}^{2}$ & $\mathrm{BMI}>30 \mathrm{~kg} / \mathrm{m}^{2}$ & $\mathbf{p}$ \\
\hline CD45 & $50,0 \pm 3,2$ & $54,1 \pm 5,8$ & 0,52 \\
\hline \multicolumn{4}{|l|}{$\underline{\text { Anteil aller CD45 }}{ }^{+}$} \\
\hline \multicolumn{4}{|l|}{ Leukozyten: } \\
\hline CD3 & $56,1 \pm 7,9$ & $36,6 \pm 7,2$ & 0,16 \\
\hline CD4 & $27,9 \pm 6,4$ & $21,0 \pm 7,5$ & 0,51 \\
\hline $\mathrm{CD} 8$ & $23,0 \pm 2,2$ & $21,2 \pm 3,8$ & 0,67 \\
\hline CD14 & $49,9 \pm 8,6$ & $25,0 \pm 3,4$ & 0,09 \\
\hline CD16 & $63,7 \pm 5,5$ & $69,5 \pm 12,7$ & 0,63 \\
\hline $\mathrm{CD} 14^{+} / \mathrm{CD} 16^{+}$ & $36,4 \pm 6,5$ & $15,6 \pm 3,6$ & 0,07 \\
\hline CD161 & $25,0 \pm 6,4$ & $10,9 \pm 2,5$ & 0,18 \\
\hline CD206 & $25,4 \pm 5,0$ & $13,4 \pm 2,9$ & 0,16 \\
\hline $\mathrm{CD}_{206^{+}} / \mathrm{CD} 16^{+}$ & $22,4 \pm 5,3$ & $11,0 \pm 2,7$ & 0,19 \\
\hline Integrin $\alpha_{4}$ & $42,9 \pm 6,5$ & $32,6 \pm 6,7$ & 0,36 \\
\hline ObR & $79,4 \pm 4,4$ & $87,2 \pm 2,3$ & 0,27 \\
\hline Integrin $\alpha_{4}^{+} / \mathrm{ObR}^{+}$ & $38,5 \pm 7,2$ & $27,2 \pm 5,5$ & 0,34 \\
\hline
\end{tabular}

Tab. 3.10 Leukozyten im PVAT: Einfluss von Adipositas 


\begin{tabular}{|c|c|c|c|}
\hline \multirow{2}{*}{$\begin{array}{l}\text { Zellmarker } \\
\text { (alle Angaben in \%) }\end{array}$} & \multicolumn{2}{|c|}{ КНK } & \multirow[t]{2}{*}{$\mathbf{p}$} \\
\hline & BMI $<30 \mathrm{~kg} / \mathrm{m}^{2}$ & BMI $>30 \mathrm{~kg} / \mathrm{m}^{2}$ & \\
\hline CD45 & $52,4 \pm 1,7$ & $54,1 \pm 5,8$ & 0,80 \\
\hline \multicolumn{4}{|l|}{ Anteil aller CD45 $^{+}$} \\
\hline \multicolumn{4}{|l|}{ Leukozyten: } \\
\hline CD3 & $56,8 \pm 10,5$ & $36,6 \pm 7,2$ & 0,19 \\
\hline CD4 & $26,7 \pm 12,3$ & $21,0 \pm 7,5$ & 0,70 \\
\hline CD8 & $21,4 \pm 4,5$ & $21,2 \pm 3,8$ & 0,97 \\
\hline CD14 & $38,7 \pm 12,7$ & $25,0 \pm 3,4$ & 0,28 \\
\hline CD16 & $66,2 \pm 9,7$ & $69,5 \pm 12,7$ & 0,85 \\
\hline $\mathrm{CD}_{14}{ }^{+} / \mathrm{CD} 16^{+}$ & $39,8 \pm 12,6$ & $15,6 \pm 3,6$ & 0,14 \\
\hline CD161 & $23,5 \pm 12,7$ & $10,9 \pm 2,5$ & 0,38 \\
\hline CD206 & $23,4 \pm 9,5$ & $13,4 \pm 2,9$ & 0,37 \\
\hline $\mathrm{CD} 206^{+} / \mathrm{CD} 16^{+}$ & $19,5 \pm 10,1$ & $11,0 \pm 2,7$ & 0,46 \\
\hline Integrin $\alpha_{4}$ & $39,8 \pm 11,8$ & $32,6 \pm 6,7$ & 0,62 \\
\hline ObR & $78,5 \pm 6,3$ & $87,2 \pm 2,3$ & 0,26 \\
\hline Integrin $\alpha_{4}^{+} / \mathrm{ObR}^{+}$ & $35,1 \pm 12,5$ & $27,2 \pm 5,5$ & 0,60 \\
\hline
\end{tabular}

Tab. 3.11 Leukozyten im PVAT: Einfluss von Adipositas bei Vorliegen einer KHK

\subsubsection{Untersuchng von Integrin $\alpha_{4}$-positiven Leukozyten im perikardialen Fettgewebe}

Zusätzlich zur Untersuchung der Leukozytensubpopulationen wurde das Fettgewebe auf den Anteil gewebsständiger Integrin $\alpha_{4}$-positiver Leukozyten analysiert. Hier ergab sich, dass sowohl im viszeralen als auch im perivaskulären Fettgewebe ein signifikanter Anstieg in Abhängigkeit des Vorliegens einer KHK festgestellt werden konnte (Abb. 3.23). Dies kann als Ausdruck der vermehrten Rekrutierung im Rahmen der Atherosklerose gewertet werden. Auch der Anteil doppeltpositiver Leukozyten (Integrin $\alpha_{4} / \mathrm{ObR}$ ) stieg bei KHK-Patienten im Vergleich zur Kontrollgruppe an (Abb. 3.24). 


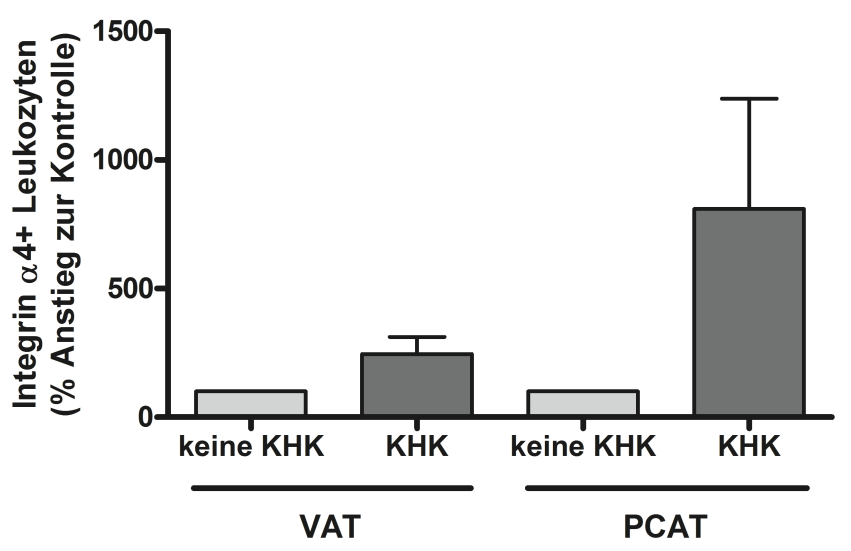

Abb. 3.23 Darstellung der durchflusszytometrischen Analysen Integrin $\alpha_{4}$-positiver Leukozyten im viszeralen und perivaskulären Fettgewebe unter Einfluss von KHK
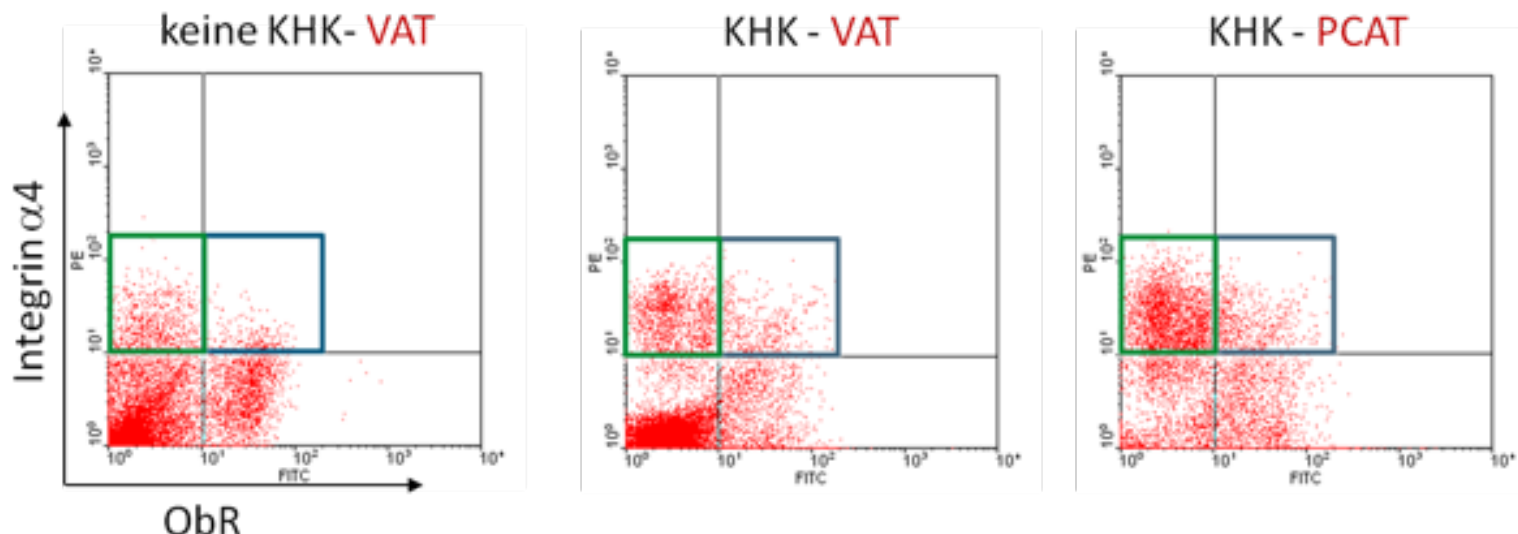

Abb. 3.24 Darstellung der durchflusszytometrischen Analysen: Repräsentative Dot Plots der Koexpression von Integrin $\alpha_{4}$ und ObR auf peripheren Immunzellen bei Vorliegen einer KHK: Expression von Integrin $\alpha_{4}$ und ObR im viszeralen und perivaskulären Fettgewebe 


\section{DISKUSSION}

Adipositas gehört $\mathrm{zu}$ den Hauptrisikofaktoren für die Entwicklung kardiovaskulärer Erkrankungen und ist außerdem mit der Entstehung und Eskalation weiterer Krankheiten wie zum Beispiel Diabetes mellitus, pAVK, Apoplexie, arterielle Hypertonie, Lipidstoffwechselstörungen, Cholezystolithiasis, Schlafapnoe, die Entstehung bestimmter Malignome sowie funktionelle Einschränkungen an den Gelenken und am Skelett assoziiert (Mensink et al. 2013). Durch hohe Leptin- und Insulinspiegel kommt es unter Übergewicht zu einem chronischen systemischen proinflammatorischen Status (Berg und Scherer 2005; Hajer et al. 2008). Die erhöhte Konzentration von Zytokinen (v.a. IL-1 und TNF- $\alpha$ ) und AkutePhase-Proteinen (v.a. CRP) bewirkt eine Aktivierung des Endothels mit vermehrter Expression des Adhäsionsmoleküls VCAM-1 (Carlos et al. 1990). Durch Wechselwirkung von Integrinen auf der Oberfläche von Leukozyten - insbesondere das in dieser Arbeit untersuchte Integrin $\alpha_{4} \beta_{1}$ - mit VCAM-1 kommt es zu einer gesteigerten Adhäsion von Leukozyten an das aktivierte Endothel, ein entscheidender Schritt in der Pathogenese der Atherosklerose (Shih et al. 1999). Eingewanderte Immunzellen (z.B. Monozyten), wandeln sich in Makrophagen um und werden durch Aufnahme von Lipiden zu Schaumzellen. Dies bildet die Grundlage für die Bildung atherosklerotischer Plaque (Lusis 2000).

Die Prozesse der Immunzellrekrutierung über die das Gefäßlumen auskleidende Endothelzellen sind gut untersucht. Übergewicht geht u. a. mit einer Vermehrung des perivaskulären Fettgewebes und der Leptinexpression einher und zahlreiche Arbeiten, u. a. der eigenen Arbeitsgruppe, haben gezeigt, dass Leptin die Verbindung zwischen Adipositas und kardiovaskulärem Risiko darstellen könnte. In Vorarbeiten der eigenen Gruppe wurde gefunden, dass Leptin die Aktivität von Integrin $\alpha_{4} \beta_{1}$ erhöht und auf diese Weise die EPCRekrutierung fördert. Ziel dieser Arbeit war nun, zu untersuchen ob Leptin über die Aktivierung von Integrin $\alpha_{4} \beta_{1}$ auf Leukozyten bzw. bestimmten Subpopulationen zur Fettgewebsinflammation bei Übergewicht beiträgt und so die Atherosklerose fördert.

Der Einfluss von systemischem Leptin auch auf die Thrombogenese ist Bestandteil vorhergehender Untersuchungen gewesen (Konstantinides et al. 2001).

Wenig ist jedoch bekannt über den parakrinen Einfluss des vom perivaskulären Fettgewebe sezernierten Leptins auf die Prozesse in der Gefäßwand und somit über die Adventitia als 
Quelle schädigender Einflussfaktoren auf die Gefäßwand. Es konnte bereits gezeigt werden, dass Übergewicht auch eine Erhöhung der perivaskulären Expression von Leptin zur Folge hat (Payne et al. 2010). Weiterführende In-vivo-Analysen in unserer Arbeitsgruppe konnten zeigen, dass durch lokale perivaskuläre Überexpression von Leptin unabhängig von Übergewicht und systemischer Hyperleptinämie eine vermehrte Neointimabildung nach arterieller Verletzung auftritt und somit einen weiteren Risikofaktor in der Entstehung kardiovaskulärer Erkrankungen bei Adipositas darstellt (Schroeter et al. 2013).

Die vorliegende Arbeit beschäftigt sich mit dem Einfluss des Übergewichts auf die Zusammensetzung des perivaskulären Fettgewebes und die Ausprägung der Inflammation in der Gefäßwand. Im Mausmodell wurde mit Hilfe einer hochkalorischen Diät, in der $60 \%$ der Kalorien aus Fett stammten, Übergewicht induziert.

Als erste Antwort auf die HFD zeigte sich nach 2 Wochen eine erhöhte Leptinexpression im Serum, wohingegen sich das Leptin-Protein erst nach 8 Wochen signifikant vermehrt im Serum und im perivaskulärem Fettgewebe nachweisen ließ. Histologische Untersuchungen des viszeralen Fettgewebes bestätigten die parallel dazu auftretende Vermehrung von Fettsowie Bindegewebszellen. Um einen Zusammenhang dieser morphologischen Veränderungen mit dem erhöhten Leptin näher zu analysieren, wurden die im perivaskulärem Fettgewebe vermehrt rekrutierten Leukozyten auf Integrin $\alpha_{4^{-}}$und ObR-positive Zellen untersucht. Als Kontrolle dienten Leptin-defiziente Mäuse. Hierbei bestätigte sich bei den WT-Mäusen eine Akkumulierung doppelt-positiver Zellen bei Übergewicht, bei den $o b / o b$-Mäusen konnte dies erwartungsgemäß nur für Integrin $\alpha_{4}$-exprimierende Zellen gezeigt werden.

Da für die Integrin-abhängige Rekrutierung von Leukozyten die Interaktion mit zugehörigen Liganden essentiell ist, wurde sowohl die Expression endothelialen VCAM-1 sowie perivaskulären Fibronektins untersucht und deren Expression unter Einfluss einer 8-wöchigen Hochfettdiät analysiert. Es zeigte sich, dass die Expression der Adhäsionsmoleküle sowohl auf mRNA- als auch auf Proteinebene mit den Daten für die Anzahl von Integrin $\alpha_{4}$ exprimierenden Zellen im Fettgewebe korrelierten. Weiterhin wurde die Präsenz von Immunzellen im perivaskulären Fettgewebe mittels zusätzlicher Methoden, wie RT-PCR für F4/80-Expression von Monozyten sowie CD3-Expression von T-Lymphozyten und deren Detektion via Immunofluoreszenz untersucht. Außerdem wurde durchflusszytometrisch im viszeralen und perivaskulären Fettgewebe der Anteil CD45-positiver Leukozyten, 


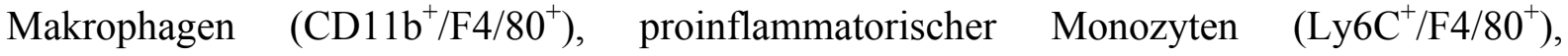
dendritischer Zellen $\left(\mathrm{CD} 11 \mathrm{c}^{+} / \mathrm{F} 4 / 80^{+}\right)$, CD4-posititver T-Helfer-Zellen sowie CD8-positiver zytotoxischer T-Lymphozyten untersucht. Hierbei zeigte sich Leptin-abhängig eine erhöhte Anzahl vor allem der monozytären Immunzellen, im Speziellen von dendritischen $\mathrm{CD} 11 \mathrm{c}^{+} / \mathrm{F} 4 / 80^{+}$Monozyten, deren Rekrutierung eine entscheidende Rolle in der Entwicklung atherosklerotischer Plaques spielt (Elices et al. 1990). Die CD4- und CD8-positiven TLymphozyten waren ebenfalls erhöht. Leider konnte eine zweite Versuchsreihe in denen die Monozyten der WT-Mäuse -/+HFD mit denen von leptindefizienten -/+HFD verglichen werden sollten, diese Tendenzen nicht bestätigen. Was sich allerdings erkennen ließ, war, dass $o b / o b$-Mäuse nach 8 Wochen $\mathrm{NC}$, als sie bereits übergewichtig waren, für alle untersuchten Monozytenspezies eine den WT-Mäusen gegenüber verminderte Anzahl im perivaskulären Fettgewebe zeigten. Dieses könnte auf eine Stimulation der Monozytenrekrutierung durch Leptin hinweisen. Allerdings verhielten sich die $o b / o b$-Mäuse nach 8 Wochen HFD komplett gegenteilig und ergaben extrem hohe Monozytenanteile im PVAT. Vielleicht unterliegt die Inflammation in diesen sehr adipösen Mäusen aber auch einem weiteren bislang nicht bekannten Faktor.

Die Untersuchungen an humanem Material sollten die Ergebnisse im murinen Modell weiterführen und eine Charakterisierung des perivaskulären Fettgewebes in Abhängigkeit von Adipositas und KHK ermöglichen. Hierzu wurde perivaskuläres bzw. perikardiales Fettgewebe durchflusszytometrisch untersucht. Der Mechanismus der Rekrutierung von Immunzellen könnte dabei der gleiche wie bei der Maus sein. Dies zeigt sich in der Verteilung von Integrin $\alpha_{4}$-positiven Zellen im Serum und PVAT unter dem Einfluss von KHK und Adipositas. Währenddessen die Anzahl der monolymphozytären Zellen in der Gefäßwand keine signifikanten Unterschiede aufwies.

Zusammenfassend deuten die Ergebnisse auf einen Zusammenhang zwischen Übergewicht und verstärkter perivaskulärer Inflammation als Bestandteil des pathogenetischen Prozesses der Atherosklerose hin. Im Folgenden sollen diese detailliert diskutiert werden. 


\subsection{Einfluss von Adipositas auf die perivaskuläre Fettgewebsinflammation}

\subsubsection{Zunahme der Leptinexpression sowohl im Serum als auch im perivaskulären} Fettgewebe bei Übergewicht

Die Mäuse der HFD-Gruppe wiesen nach 8 Wochen ein um 25 \% höheres Körpergewicht und eine um mehr als 3,5-fach erhöhte Masse des viszeralen Fettgewebes auf. Zudem zeigten sich bereits nach 4 Wochen Hochfettdiät 2,5-fach erhöhte Serumleptinspiegel im Vergleich zur Kontrollgruppe, nach 8 Wochen waren die Spiegel im Vergleich zur Kontrollgruppe 15-fach erhöht. Auch im perivaskulären Fettgewebe zeigte sich eine signifikante Erhöhung der Leptin-mRNA (2,7-fach) und Leptin-Protein-Menge (15-fach) im Vergleich zur Kontrollgruppe. Diese Ergebnisse sind auf die erhöhte Fettmasse - gemessen über das Gewicht des abdominellen Fettdepots - sowie auf das erhöhte Körpergewicht der Tiere zurückzuführen. Diese Daten bestätigen die Analysen anderer Arbeitsgruppen (Park et al. 2005; Relling et al. 2006) und sind Ausdruck einer manifesten Adipositas mit systemischen und metabolischen Funktionsstörungen. Weitere Studien zeigen, dass bei KHK-Patienten im Vergleich zu einer gesunden Kontrollgruppe eine erhöhte Expression von Leptin sowie erhöhte Spiegel proinflammatorischer Zytokine wie TNF- $\alpha$ und IL-6 im epikardialen Fettgewebe vorhanden sind. Hierbei wurde jedoch dem abdominellen Fettgewebe eine weitaus größere Beeinflussung der chronischen niedriggradigen Inflammation zugeschrieben, da dort die Zytokin- und Leptinspiegel im Vergleich zum epikardialen Gewebe signifikant erhöht waren (Cheng et al. 2008).

4.1.2 Rückgang der zirkulierenden Integrin $\alpha_{4}$-positiven Leukozyten bei gleichzeitigem Anstieg der Integrin $\alpha_{4^{-}}$und ObR-Expression der residenten Fettgewebsleukozyten bei Übergewicht

Durchflusszytometrische Analysen des venösen Blutes der HFD-Mäuse ergaben eine Reduktion der zirkulierenden Integrin $\alpha_{4}$-positiven sowie der Integrin $\alpha_{4}-/ O b R-$ doppeltpositiven Leukozyten. Gleichzeitig zeigte sich tendenziell eine erhöhte Expression der beiden Marker auf den residenten Leukozyten des perivaskulären Fettgewebes. Da sich gleichzeitig bei den massiv übergewichtigen $o b / o b$-Mäusen bereits nach 8 Wochen eine deutliche Steigerung der Integrin $\alpha_{4}$-Expression und eine signifikante Erhöhung der Anzahl 
Integrin $\alpha_{4} /$ ObR-doppeltpositiver Leukozyten im PVAT ergab, entschieden wir uns, für den Nachweis perivaskulärer Inflammation zusätzlich WT-Mäuse für 6 Monate auf Hochfettdiät zu setzen und eine Kontrolle mittels 6 Monate alter Tiere auf Normalfutter durchzuführen. Hierbei ergaben sich im Vergleich zur 8W NC-Kontrollgruppe allein durch das Alter eine 1,5fach höhere Expression des Integrin $\alpha_{4}$ und eine 3-fache Erhöhung der doppeltpositiven

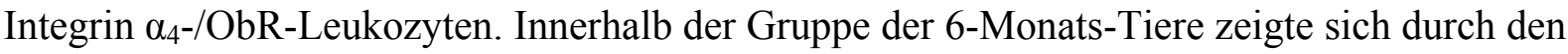
Einfluss des Übergewichts ein weiterer Anstieg der Expression von Integrin $\alpha_{4}$ und ObR, den bereits die Analysen der ob/ob-Mäuse vermuten ließen, der jedoch Leptin-abhängig signifikant verstärkt war. Diese Ergebnisse bestätigen die Untersuchungen und Studien, die eine Integrin-abhängige Rekrutierung von Leukozyten - vor allem monolymphozytärer Zellen - in die Gefäßwand beschreiben (Postigo et al. 1991). Caspar-Bauguil et al. (2006) zeigten jedoch in ihren Analysen, dass der Prozess der Rekrutierung von Lymphozyten insbesondere im viszeralen Fettgewebe größtenteils Leptin-abhängig stattfindet, da in Leptin-defizienten Mäusen keine Erhöhung der $\gamma \delta$-T-Lymphozyten feststellbar war. Sie konnten jedoch auch zeigen, dass die Anzahl der $\alpha \beta$-T-Lymphozyten unabhängig vom Leptinspiegel mit verstärkter Adipositas - definiert über das Gewicht der Fettdepots - im Fettgewebe anstieg (Caspar-Bauguil et al. 2006). Hierüber könnte der unspezifische Anstieg der Immunzellen im Fettgewebe erklärt werden, da bekannterweise bei verstärkter Adipositas ein steigender Gehalt an inflammatorischen Zytokinen im Fettgewebe feststellbar ist (Cheng et al. 2008). Diese könnte eine unspezifische Immunreaktion mit Rekrutierung von Leukozyten im vaskulären System bewirken.

\subsubsection{Hochregulierung der Adhäsionsmoleküle für Integrin $\alpha_{4}$ in der Gefäßwand bei Übergewicht}

Analog zur gesteigerten Rekrutierung der Integrin $\alpha_{4}$-positiven Leukozyten ins perivaskuläre Fettgewebe konnte unter Einfluss von Übergewicht eine verstärkte Expression des endothelialen Adhäsionsmoleküls VCAM-1 sowie des bindegewebigen Adhäsionsmoleküls Fibronektin in der Gefäßwand beobachtet werden. Das Vorliegen einer chronischen, niedriggradigen Inflammationsreaktion im Rahmen des Übergewichts (Hajer et al. 2008) führt durch erhöhte Konzentrationen von CRP, TNF $\alpha$ und IL-1 zu einer vermehrten Expression des Zelladhäsionsmoleküls auf dem Endothel und damit zu einer gesteigerten Leukozyten- 
diapedese (Carlos et al. 1990). Diese Ergebnisse gehen einher mit Analysen anderer Arbeitsgruppen: Burris et al. (2014) konnten zeigen, dass es in ApoE-Knockout-Mäusen durch Sojadiät $\mathrm{zu}$ einer Abnahme der LPS-induzierten chronischen inflammatorischen Antwort im Vergleich zu Tieren auf Caseinfutter kam. Dies führte über eine verringerte Aktivierung von NF- $\mathrm{B} \quad \mathrm{zu}$ erniedrigter Expression von VCAM-1 sowie der proinflammatorischen Zytokine IL-6 und MCP-1 (Burris et al. 2014). In einer anderen Studie konnten Wang et al. (2011) mittels In-vitro-Analysen zeigen, dass auf kultivierten humanen Endothelien durch Inkubation mit isolierten Triglyceriden (TG) aus postprandialem humanem Serum eine TG-Konzentrations-abhängige endotheliale Aktivierung stattfand. Diese war nach Stimulation mit TNF- $\alpha$ in Form von erhöhter Expression von VCAM-1, ICAM-1 und ESelektin im Vergleich zum nicht-stimulierten Endothel nachweisbar (Wang et al. 2011). Auch Kralisch et al. (2008) konnten in vitro zeigen, dass humane Endothelzellen (HUVEC, Human umbilical vein endothelial cells) und HCAEC (Human coronary artery endothelial cells) nach Inkubation mit Überständen aus Adipozyten eine signifikant höhere Monozytenadhäsion sowie eine Hochregulation von VCAM-1, ICAM-1 und E-Selektin zeigten. Durch Hemmen der Wirkung von NFאB und TNFa mit Hilfe monoklonaler Antikörper wurde diese Regulation vermindert. Somit konnte ebenfalls eine Beteiligung einer chronisch niedriggradigen Inflammation an der Aktivierung des Endothels gezeigt werden (Kralisch et al. 2008).

\subsubsection{Gesteigerte perivaskuläre Inflammation bei Übergewicht durch Einwanderung mononukleärer Leukozyten}

Die Immunfluoreszenzfärbungen und PCR-Analysen des perivaskulären Fettgewebes ergaben eine 2,5-fache Erhöhung der F4/80-positiven Monozyten bereits nach 4 Wochen HFD sowie einen 1,5-fachen Anstieg der CD3-positiven T-Lymphozyten nach 8 Wochen HFD. Die differenzierte Untersuchung der Monozyten- und Lymphozytensubpopulationen mittels Durchflusszytometrie ergab nach 8 Wochen HFD nahezu signifikante Anstiege sowohl der

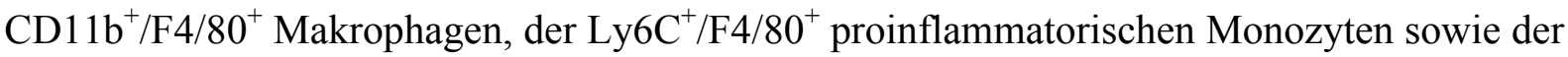
$\mathrm{CD} 11 \mathrm{c}^{+} / \mathrm{F} 4 / 80^{+}$dendritischen Zellen um mehr als $100 \%$ im Vergleich zur Kontrollgruppe. Die $\mathrm{CD}^{+}{ }^{+} \mathrm{T}$-Helfer-Lymphozyten, die $\mathrm{CD}^{+} \mathrm{T}$-Lymphozyten sowie die $\mathrm{CD} 49 \mathrm{~b}^{+}$NK-Zellen stiegen nur leicht an im Vergleich zur Kontrollgruppe. 
Der höhere und schnellere Anstieg der Monozyten im Vergleich zu den Lymphozyten vor allem auf mRNA-Ebene bestätigt die bisher vorliegenden Daten in der Literatur. Es ist bekannt, dass der erste und entscheidende Schritt in der Entstehung atherosklerotischer Plaques die Adhäsion und Diapedese von Monozyten in die Gefäßwand und deren dortige Transformation zu Makrophagen darstellt (Mestas und Ley 2008). Es konnte gezeigt werden, dass das Fehlen des chemotaktischen MCP-1 (monocyte chemoattractant protein-1) zu einer verringerten Atherosklerose durch eine verringerte Monozytenrekrutiertung führt $(\mathrm{Gu}$ et al. 1998). Diese spezifische Rekrutierung von monolymphozytären Zellen in die Gefäßwand geschieht durch Endothel-ständige Zelladhäsionsmoleküle - vor allem vermittelt durch die Interaktion von VCAM-1 mit dem Leukozyten-ständigen Integrin $\alpha_{4}$ (Cybulsky und Gimbrone 1991; Li et al. 1993). In einer kombinierten In-vivo- und In-vitro-Studie konnten Rocha et al. (2008) zeigen, dass unter Einfluss von Hochfettdiät in männlichen WT-Mäusen im viszeralen Fettgewebe eine signifikant höhere Anzahl sowohl F4/80 $0^{+}$Monozyten als auch $\mathrm{CD}^{+}$und $\mathrm{CD}^{+}$T-Lymphozyten durchflusszytometrisch nachweisbar war. Zudem konnten sie auch, wie in unseren Analysen, immunhistochemisch eine vermehrte Akkumulation von Monozyten und T-Lymphozyten zeigen. Die Tatsache, dass sowohl in der Kontrollgruppe als auch in der HFD-Gruppe signifikant weniger Lymphozyten als Monozyten/Makrophagen nachweisbar sind, deutet auf eine starke regulatorische Funktion der Lymphozyten im Rahmen der Inflammation der Gefäßwand hin. Den Monozyten/Makrophagen hingegen wird eine „Effektor“-Funktion zugeschrieben (Rocha et al. 2008). Daher kann die Beziehung von Lymphozyten und Monozyten/Makrophagen als ähnlich der eines Generals und den Soldaten einer Armee oder eines Dirigenten und den Musikern seines Orchesters beschrieben werden (Libby 2012). In einer weiteren In-vivo-Studie konnten Hagita et al. (2011) zeigen, dass WTMäuse nach perivaskulärer Transplantation viszeralen Fettgewebes eine vermehrte Adhäsion von Monozyten an der Gefäßwand aufwiesen. Diese war zusätzlich verstärkt bei der Transplantation von viszeralem Fett übergewichtiger Mäuse im Vergleich zur Kontrollgruppe (Transplantaten aus normalgewichtigen Tieren). Zusätzlich konnte durchflusszytometrisch nach Transplantation eine Hochregulation von CD11b auf den peripheren Leukozyten nachgewiesen werden. Die Untersuchung des transplantierten Fettgewebes zeigte unter Einfluss von HFD eine vermehrte Akkumulation sowohl von inflammatorischen Zytokinen (wie IL-6 und MCP-1) als auch proinflammatorischer Leukozyten bzw. aktivierten Monozyten und dendritischen Zellen (Hagita et al. 2011). 


\subsubsection{Perivaskuläre Inflammation unabhängig vom Leptinspiegel bei Übergewicht}

Weiterführende durchflusszytometrische Analysen zeigten, dass sowohl Leptin-defiziente ob/ob-Mäuse als auch WT-Mäuse, die 6 Monate mit Hochfettdiät gefüttert wurden, aufgrund ihres massiven Übergewichts eine signifikant höhere Expression von $\mathrm{CD} 45^{+}$-Leukozyten im perivaskulären Fettgewebe aufwiesen. Das Ausbleiben einer vermehrten Expression sowohl in der Gruppe der jüngeren übergewichtigen als auch bei den älteren normalgewichtigen Tieren verdeutlicht den gewichtsabhängigen Einfluss auf die perivaskuläre Inflammation möglicherweise als Ausdruck der chronisch niedriggradigen Entzündungsreaktion bei Übergewicht. Bereits in einer früheren Studie konnten Weisberg et al. (2003) eine körpergewichts- und fettgewebsabhängige Akkumulation von $\mathrm{F} 4 / 80^{+}$Makrophagen in viszeralem Fettgewebe unabhängig von der Expression von Leptin nachweisen. So zeigten WT genauso wie $o b / o b$-Mäuse eine proportional zur Schwere der Adipositas zunehmende Zahl der Makrophagen im Fettgewebe (Weisberg et al. 2003).

Diese Ergebnisse unterstützen Untersuchungen anderer Arbeitsgruppen, die zeigen konnten, dass in Abhängigkeit vom Körpergewicht im perivaskulären Fettgewebe eine erhöhte Expression proinflammatorischer Zytokine sowie eine Akkumulation von Leukozyten nachweisbar ist. Henrichot et al. (2005) konnten zum einen histologisch eine übergewichtsabhängige Zunahme des perivaskulären Fettgewebes zeigen, zum anderen wiesen sie immunhistochemisch eine vermehrte Akkumulation von sowohl T-Lymphozyten als auch Monozyten im Fettgewebe nach. Außerdem ergaben sich in ELISA-Analysen aus der Zellkultur eine erhöhte Expression proinflammatorischer Zytokine wie MCP-1 und IL-8. Durch Chemotaxis-Assays konnte gezeigt werden, dass das perivaskuläre Fettgewebe eine ausgeprägte chemotaktische Fähigkeit besitzt und dadurch die Migration von Leukozyten ins Fettgewebe verstärkt (Henrichot et al. 2005). In einer weiteren In-vivo-Studie konnten Moe et al. (2013) mittels Injektion von TNF $\alpha$ eine chronische Entzündungsreaktion - wie sie charakteristisch bei Adipositas auftritt - induzieren. Sie beobachteten dadurch einen signifikanten Anstieg der Anzahl an Immunzellen - insbesondere von $\mathrm{CD}^{+}{ }^{+} \mathrm{T}$-Lymphozyten und $\mathrm{CD}^{+} 8^{+}$Makrophagen - sowie der Expression von VCAM-1 im Endothel. Weiterhin zeigte sich ein signifikantes Fortschreiten der atherosklerotischen Läsionen in den mit TNF $\alpha$ behandelten Tieren mit einer erhöhten Intima-Media-Dicke und einer vermehrten Zahl von 
glatten Gefäßmuskelzellen sowie einer Reduktion der elastischen Fasern in der Adventitia (Moe et al. 2013). Hieraus lässt sich ableiten, dass Übergewicht - vermittelt über eine chronisch niedriggradige systemische Entzündungsreaktion - zu einer gesteigerten Expression chemotaktischer Zytokine im perivaskulären Fettgewebe führen und dadurch wiederum eine gesteigerte Rekrutierung von monolymphozytären Immunzellen bewirken kann.

\subsubsection{Leptin-abhängige viszerale Fettgewebsinflammation bei übergewichtigen Mäusen}

Weiterführende durchflusszytometrische Analysen des viszeralen Fettgewebes wiesen auf eine verstärkte Inflammation bei fehlender Expression von Leptin und gleichzeitigem massiven Übergewicht hin. So zeigten adipöse WT-Mäuse sowie Leptin-defiziente $o b / o b$ Mäuse keinen signifikanten Unterschied in der Expression monozytärer und lympozytärer Oberflächenmarker auf den Leukozyten im Vergleich zur normgewichtigen Kontrollgruppe. Jedoch wiesen die massiv übergewichtigen $o b / o b$-Mäuse unter Einfluss von Hochfettdiät durch ihre große metabolische Dysregulation einen deutlich erhöhten Anteil an Mono- und Lymphozyten im Vergleich zur Kontrollgruppe auf. Weisberg et al. (2003) konnten bereits zeigen, dass bei den $o b / o b$-Mäusen aufgrund der schwerwiegenden Adipositas eine deutlich vermehrte Akkumulation von $\mathrm{F} 4 / 80^{+}$Makrophagen im viszeralen Fettgewebe vorlag. Die Untersuchung weiterer Fettgewebe auch bei WT-Mäusen ergab, dass der Gehalt an Makrophagen und die Fettgewebs- und Adipozytengröße in positiver Beziehung standen, so dass eine Abhängigkeit der Inflammation von der Masse des Fettgewebes und damit der Schwere des Übergewichts festgestellt werden konnte (Weisberg et al. 2003). In einer neueren Studie konnten Kitamura et al. (2013) jedoch einen Rückgang der Fettgewebsinflammation in ob/ob-Mäusen nach Injektion einer antiinflammatorischen Substanz ohne signifikante Veränderung des Körpergewichts und der Nahrungsaufnahme zeigen. So kam es nach Injektion zu einem signifikanten Rückgang der Expression von CD11b als Makrophagenmarker in der Durchflusszytometrie (Kitamura et al. 2013). Dies deutet auf einen Effekt abhängig von der Zusammensetzung des Fettgewebes und nicht allein der Masse - bezogen auf den Inflammationsstatus hin. In diesem Sinne ist die Fettgewebsinflammation in den Leptin-defizienten Tieren nicht allein auf ihr Körpergewicht, sondern zusätzlich auf die 
begleitende systemische Entzündungsreaktion und die begleitende Hochregulierung proinflammatorischer Zytokine zurückzuführen.

Candela et al. (2017) berichten übereinstimmend über eine NO-Synthase-vermittelte Aktivierung residenter Makrophagen im perivaskulären Fettgewebe und einer daraus folgenden endothelialen Dysfunktion bei Übergewicht.

Verschafft man sich einen Überblick über die aktuelle Literatur über den Einfluss perivaskulärer Fettgewebsinflammation auf die Pathogenese der Atherosklerose findet man immer mehr Hinweise, dass das epikardiale perivaskuläre Fettgewebe - also das Fettgewebe in das die Koronarien eingebettet ist - eine andere Funktion besitzt als das periaortale Fettgewebe, welches im Rahmen der vorliegenden Arbeit untersucht wurde. In mehreren Studien wurde ein Zusammenhang zwischen Übergewicht und der Masse des epikardialen Fettgewebes mit bildgebenden Verfahren dargestellt (Alexopoulos et al. 2010; Corradi et al. 2004; Silaghi et al. 2008). Auch bei Vorliegen einer KHK konnte eine Zunahme des Fettgewebes im Vergleich zur Kontrollgruppe gezeigt werden (Silaghi et al. 2008). Andere Untersuchungen konnten zeigen, dass das perikoronarielle Fettgewebe eine hohe Expression proatherogener und inflammatorischer Gene aufweist (Chatterjee et al. 2013) und daher mit einer vermehrten Fettgewebsinflammation einhergehen müsste. Weiterhin konnte bereits eine vermehrte zelluläre Infiltration in Fettgewebe mit direktem Bezug zu atherosklerotischen Läsionen dargestellt werden (Henrichot et al. 2005; Mazurek et al. 2003). Zudem ist die Aorta ascendens als elastisches Gefäß auch weitaus weniger anfällig für atherosklerotische Läsionen als die Koronararterien und die Karotiden, welche jeweils vom muskulären Typ sind und die Lokalisationen mit den häufigsten atherosklerotischen Komplikationen darstellen.

Bestätigen konnten diese herausragende Rolle des epikardialen PVAT im Vergleich zum arteriellen PVAT der A. mammaria interna Drosos et al. (2016). Sie konnten eine signifikant höhere Anzahl CD68-positiver Makrophagen sowie eine erhöhte Konzentration von Leptin sowie Leptin-exprimierender Transkriptionsfaktoren im epikardialen Fettgewebe nachweisen. Die Zusammenschau dieser Ergebnisse könnte die erhöhte Anfälligkeit für die Bildung atherosklerotischer Plaques in den Koronararterien verdeutlichen.

Im Rahmen eines weiteren Projekts in unserer Arbeitsgruppe wurde hierzu durch Herrn Dr. med. Norman Eschholz das viszerale leptinreiche Fettgewebe perivaskulär um die A. carotis von athymen Nacktmäusen transplantiert, um den parakrinen Effekt von Leptin und perivaskulärer Inflammation auf die Neointimabildung zu analysieren. Es ergab sich eine 
verstärkte Hyperplasie der Neointima bei Transplantation von VAT aus übergewichtigen WTMäusen aber auch aus übergewichtigen $o b / o b$-Mäusen, allerdings nur, wenn diese zusätzlich mit HFD gefüttert worden waren. Die Neointimazunahme war unabhängig von Übergewicht und einer systemischer Hyperleptinämie. Es zeigte sich ein spezifischer parakriner Effekt des Leptins sowie der Einfluss auch von lokalen Faktoren der perivaskulären Inflammation (Schroeter et al. 2013). Diese Ergebnisse deuten auf einen gemeinsamen Effekt von gesteigerter Leptinexpression und vermehrter Entzündungsreaktion in der Entstehung atherosklerotischer Läsionen im Rahmen von Adipositas hin.

\subsection{Einfluss von Adipositas und KHK auf die perivaskuläre Inflammation beim Menschen}

\subsubsection{Vermehrte Rekrutierung Integrin $\alpha_{4}$-positiver Immunzellen ins perivaskuläre Fettgewebe bei Übergewicht und KHK}

In durchflusszytometrischen Analysen konnte eine signifikante Abnahme zirkulierender Integrin $\alpha_{4}$-positiver Immunzellen im peripheren Blut in Abhängigkeit sowohl des Körpergewichts als auch vom Vorliegen einer KHK beobachtet werden. In Einklang damit zeigte sich die Zahl der Immunzellen im viszeralen und perikardialen Fettgewebe unter Einfluss von KHK deutlich erhöht. Hierbei zeigte das perivaskuläre eine weitaus größere Steigerung als das viszerale Fettgewebe. Diese Beobachtung konnten auch Chatterjee et al. (2013) in einer In-vitro-Analyse bereits demonstrieren. Sie zeigten eine vermehrte Expression inflammationsassoziierter Gene wie Tumornekrosefaktor, Integrine, Komplementfaktoren, Interleukine und Zelladhäsionsmoleküle im perivaskulären Fettgewebe im Vergleich zum subkutanen Fettgewebe. Migrationsassays mit konditioniertem Medium ergaben eine verstärkte Monozytenmigration unter Inkubation mit Medium des PVAT im Vergleich zum Subkutangewebe (Chatterjee et al. 2013). Bereits in einer früheren Arbeit beschrieb die Arbeitsgruppe diesen proinflammatorischen Phänotyp des perivaskulären Fettgewebes durch erhöhte Expression von proinflammatorischen Zytokinen wie IL-6, IL-8 und MCP-1 und Herunterregulierung von Adipozyten-assoziierten Genen unter Hochfettdiät. Auch neuere Arbeiten können diese Effekte belegen (Nosalski und Guzik 2017). 
Diese Ergebnisse unterstreichen ebenfalls den Einfluss einer Dysfunktion des perivaskulären Fettgewebes bei Adipositas auf die Inflammation der Gefäßwand und die Atherosklerose (Chatterjee et al. 2009). Bereits in einer frühen Studie konnten Ferri et al. (1999) zeigen, dass es bei Übergewicht zu einer vermehrten Aktivierung des Endothels durch Hochregulierung von VCAM-1, ICAM-1 und E-Selektin kommt. Diese Befunde waren bei Gewichtsabnahme deutlich rückläufig und stützen auch unsere Daten zur vermehrten Integrin $\alpha_{4}$-abhängigen Rekrutierung von Immunzellen ins perivaskuläre Fettgewebe durch gesteigerte Endothelaktivierung bei Übergewicht (Ferri et al. 1999). Feral et al. (2008) führten eine In-vivoAnalyse an WT Mäusen und Mäusen, die durch eine Mutation eine fehlerhafte Signalkaskade des Integrin $\alpha_{4}$ aufwiesen, durch. Die fehlende Wirkung des Integrin $\alpha_{4}$ konnte zeigen, dass es bei Übergewicht zu einer verringerten Rekrutierung von Monozyten ins Fettgewebe kam und damit zu verringerten metabolischen Folgeschäden. Somit konnte der Einfluss der Adipositas auf die Expression von Integrin $\alpha_{4}$ und die Rekrutierung von Immunzellen ins perivaskuläre Fettgewebe gezeigt werden (Feral et al. 2008). Es konnte zudem in vitro gezeigt werden, dass VCAM-1 nur mononukleäre Zellen bindet und im Gegensatz zu ICAM-1 nicht konstitutiv von HUVEC exprimiert wird (Carlos et al. 1990). Durch Verwendung eines monoklonalen Antikörpers gegen VCAM-1 konnte ein Rückgang der Adhäsion lymphomonozytärer Zellen an das aktivierte/stimulierte Endothel beobachtet werden (Carlos et al. 1990). Diese Ergebnisse stützen die Untersuchungen von Feral et al. (2008).

\subsubsection{Keine Unterschiede in der Fettgewebsinflammation bei humaner Adipositas}

Die weitere durchflusszytometrische Analyse des perivaskulären Fettgewebes ergab zunächst keine signifikanten Unterschiede in der Expression von $\mathrm{CD} 45^{+}$Leukozyten zwischen den einzelnen Versuchsgruppen. Weder Übergewicht noch das Vorliegen einer KHK wirkte sich auf den Gehalt des Fettgewebes an Leukozyten aus. Auch ließen sich keine signifikanten Unterschiede im Vergleich der einzelnen Leukozytensubpopulationen feststellen. Dies steht jedoch im Gegensatz zu Ergebnissen anderer Arbeitsgruppen. Aghamohammadzadeh et al. (2013) konnten zeigen, dass es unter Einfluss von massiver Adipositas zu einem Verlust der antikontraktilen Fähigkeiten des perivaskulären Fettgewebes kommt. Die Auswirkungen eines Gewichtsverlustes auf das Fettgewebe wurde an den gleichen Patienten 6 Monate nach Durchführung einer gewichtsreduzierenden bariatrischen Operation untersucht. Es zeigte sich, dass sich die antikontraktile Funktion des Fettgewebes erholte. Gleichzeitig traten 
Verbesserungen in der Expression proinflammatorischer Zytokine sowie ein Rückgang der Makrophageninfiltration des perivaskulären Fettgewebes ein (Aghamohammadzadeh et al. 2013; Bussey et al. 2016). In einer weiteren Studie analysierten Bosanska et al. (2010) die RNA- und Proteinexpression der Zelladhäsionsmoleküle VCAM-1 und ICAM-1 im viszeralen Fettgewebe und Serum sowie die Expression von $\mathrm{CD}^{+} 8^{+}$Monozyten und MCP-1 im viszeralen Fettgewebe in Abhängigkeit vom BMI. Es ergab sich eine signifikante positive Korrelation zwischen der Expression von ICAM-1 und VCAM-1 im VAT mit der Expression von CD68 zum einen und zum anderen eine positive Korrelation mit dem BMI. So konnte ein Zusammenhang zwischen Übergewicht und einer Fettgewebsinflammation durch vermehrte Rekrutierung von Immunzellen bestätigt werden (Bosanska et al. 2010).

\subsection{Mögliche Limitationen der Studie}

Die vorliegende Arbeit sollte zunächst im Tiermodell den Einfluss von Übergewicht auf das Vorliegen kardiovaskulärer Komplikationen untersuchen, um durch neue Erkenntnisse mögliche Ansatzpunkte in der Prävention und Therapie Adipositas-assoziierter kardiovaskulärer Erkrankungen zu gewinnen und weiterzuentwickeln. Dazu war es nötig, dass das Versuchsmodell eine größtmögliche Vergleichbarkeit mit den Gegebenheiten in der Pathogenese humaner Adipositas und kardiovaskulärer Erkrankungen bietet. Dazu wurde eine Hochfettdiät mit 45 \% der Kalorien aus Fett verwendet, die in ihrer Zusammensetzung mit der Ernährungsweise in der westlichen Welt, für die diese Studie repräsentativ sein sollte, relativ gut übereinstimmt. Ein limitierender Faktor ist jedoch, dass die verwendeten C57BL/6Wildtyp-Mäuse im Gegensatz zum Menschen keine wirkliche Atherosklerose mit Plaques und fatty streaks entwickeln, sondern lediglich nach Gefäßwandverletzung mit Ausbildung einer neointimalen Läsion auf proatherogene Einflüsse reagieren.

Auch die Versuchsdauer könnte eine fehlerhafte Übertragung auf den Menschen bewirken. Die maximale Lebenserwartung einer WT-Maus liegt bei etwa 800 Tagen (Rowlatt et al. 1976). Verglichen mit einer Lebenserwartung des westlichen Menschen von etwa 80 Jahren könnte eine Dauer der Hochfettdiät von 8 Wochen zur Vergleichbarkeit mit humanen Komplikationen um einiges zu kurz sein. Stewart-Phillips und Lough (1991) konnten in ihren Analysen zeigen, dass WT-Mäuse nach 10-20 Wochen Hochfettdiät Läsionen in der Aorta 
ascendens entwickelten, die den menschlichen fatty streaks ähnelten. Erst nach weiteren 15 Wochen konnten sie bindegewebig-atheromatöse Läsionen entdecken, die vergleichbar waren mit humanen atherosklerotischen Plaques (Stewart-Phillips und Lough 1991). Nicht zuletzt war auch die Größe der Versuchsgruppen mit maximal 5 Tieren vermutlich zu klein, um klare, statistisch signifikante Aussagen treffen zu können.

Dies gilt auch für die klinische Studie, bei der die Größe der zu untersuchenden Gruppen für eine statistisch signifikante Aussagekraft der Studie mit insgesamt 22 Patienten sicherlich um einiges zu klein war. Durch die Heterogenität der Gruppen und nicht eliminierte Einflussfaktoren wie Alter und Medikation sind die Ergebnisse nicht sehr eindrucksvoll. Auch kann man nicht sicher beurteilen, ob trotz dokumentiertem Ausschluss einer KHK bei den Patienten der Kontrollgruppe nicht doch eine - wenn auch nicht signifikant stenosierende - Atherosklerose vorliegt und somit eventuell gar keine wirkliche Kontrollgruppe vorlag.

So muss zum einen eine deutlich größere Patientenzahl rekrutiert werden um die Verwertbarkeit der Daten zu verbessern. Auf der anderen Seite ist es wichtig, die Alters- und Geschlechtsverteilung der Gruppen anzugleichen um eine Homogenität herzustellen und wichtige Einflussfaktoren zu eliminieren.

Ein weiterer wichtiger Aspekt, der in folgende Analysen miteinbezogen werden sollte, ist die histologische Untersuchung von Koronararterien-Präparaten im Vergleich zu gesunden Gefäßpräparaten, die in Post-Mortem-Analysen durchgeführt werden könnten. Auf diese Weise könnte in ansonsten vergleichbaren Personen direkt gezeigt werden, wie sich die Zusammensetzung der Gefäßwand bei Vorliegen einer KHK von nicht betroffenen Gefäßpräparaten unterscheidet.

Zusätzlich wäre eine Studie sinnvoll, die das epikardiale perikoronare Fettgewebe von rechten und linken Koronararterien miteinander vergleicht. Ziel dieser Studie sollte sein, zu eruieren, inwiefern sich die Morphologie des umgebenden Fettgewebes unterscheidet und somit Einfluss darauf hat, dass es deutlich häufiger links- als rechtsseitig zu atherosklerotischen Komplikationen kommt. 


\subsection{Ausblick und weiterführende Analysen}

Um eine bessere Aussagekraft im murinen Modell zu erreichen, wäre es sicherlich sinnvoll, zunächst einmal die Versuchsdauer in Hinblick auf die längere Zeit der Entwicklung der Krankheit beim Menschen zu verlängern und - wie auch in Teilen dieser Untersuchungen bereits durchgeführt (s. 3.1.4 und 3.1.7) - die Tiere für wenigstens 6 Monate auf Hochfettdiät $\mathrm{zu}$ setzen. Unsere Untersuchungen dahingehend deuten auf eine vermehrte Fettgewebsinflammation in höherem Alter und bei stärkerem Übergewicht hin. Vielleicht kann man WT und $o b / o b$-Mäusen Leptin in unterschiedlichen Dosen spritzen und diese dann auf HFD setzen. $\mathrm{Zu}$ unterschiedlichen Zeitpunkten könnte dann die Inflammation im PVAT zytologisch und histologisch analysiert werden. So könnte auch gezeigt werden, bis zu welchem Grad an Übergewicht Leptin inflammatorisch wirkt und Einfluss auf die Pathogenese der Atherosklerose hat. 


\section{ZUSAMMENFASSUNG}

Die Rekrutierung von Immunzellen in die Gefäßwand stellt einen entscheidenden Schritt in der Pathogenese der Atherosklerose dar. Durch Interaktion des Integrin $\alpha_{4}$ auf der Oberfläche zirkulierender Leukozyten mit dem Zelladhäsionsmolekül VCAM-1 auf aktivierten Endothelzellen kommt es zu einer Leukozytenmigration in die Gefäßintima. Viel ist bisher über systemische Einflussfaktoren auf diesen Prozess bekannt, darunter die Effekte des kardiovaskulären Risikofaktors Übergewicht. Jedoch wurde der Einfluss lokaler Faktoren, wie des perivaskulären Fettgewebes und dort exprimierter Adipokine, wie Leptin, auf die Entstehung und das Fortschreiten atherosklerotischer Prozesse noch wenig untersucht. Die vorliegende Arbeit analysiert in einer In-vivo-Studie im Mausmodell sowie an humanem Probenmaterial von Patienten die Bedeutung von Übergewicht für die perivaskuläre Inflammation. Insbesondere wurde untersucht, in welchem Umfang Leptinrezeptor-positive Immunzellen in das Fettgewebe bei Adipositas einwandern und welche Rolle Leptin auf die Anzahl Integrin $\alpha_{4}$-positiver Immunzellen spielt. In einem murinen Übergewichtsmodell erfolgte die Analyse der Zusammensetzung des Fettgewebes. Hier zeigte sich in durchflusszytometrischen Analysen von murinem perivaskulärem Fettgewebe eine vermehrte Inflammation unter Einfluss von Übergewicht. Es kam vor allem - was auch in mRNA- und Proteinanalysen bestätigt werden konnte - zu einer gesteigerten Expression von Monozyten und T-Lymphozyten, welche eine bedeutende Rolle in der Pathogenese atherosklerotischer Läsionen spielen. Durch Analyse übergewichtiger WT- und Leptin-defizienter $o b / o b$-Mäuse konnte gezeigt werden, dass Leptin-unabhängig ein Status chronischer niedriggradiger Inflammation bei metabolischer Dysfunktion zu einer Hochregulation der Fettgewebsinflammation führt. Es kam in beiden Gruppen zu einem hochsignifikanten Anstieg von $\mathrm{CD} 5^{+}$Leukozyten im perivaskulären Fettgewebe im Vergleich zu normalgewichtigen Tieren. Ergänzende Untersuchungen an viszeralem Fettgewebe konnten diese Befunde bestätigen.

Die klinische Bedeutung der Ergebnisse sollte durch die Analyse von periaortalem Fettgewebe von KHK-Patienten im Vergleich zu gesunden Kontrollprobanden analysiert werden. Hier zeigten sich durchflusszytometrisch keine signifikanten Unterschiede in der Infiltration des Fettgewebes mit Immunzellen. Weder Übergewicht noch das Vorliegen einer KHK führten zu einer Zunahme der Expression von Monozyten oder T-Lymphozyten. Daher 
konnten die im murinen Modell erzielten Ergebnisse mit Hilfe der durchgeführten Untersuchungen im humanen Modell nicht bestätigt werden.

Zusammenfassend kann die vorliegende Arbeit im murinen Modell die Bedeutung von Adipositas auf die Rekrutierung von Immunzellen in die Gefäßwand und die Pathogenese der Atherosklerose als einen wichtigen fördernden Einflussfaktor bestätigen. Die Bedeutung von Leptin auf diesen Prozess bleibt jedoch unklar. Es scheint sowohl Leptin-abhängige als auch davon unabhängige Prozesse im Rahmen der Adipositas zu geben, die zu einer verstärkten Inflammation des perivaskulären Fettgewebes und damit einer Verschlechterung atherosklerotischer Läsionen führen. Eine abschließende Klärung der genauen Mechanismen des Einflusses von perivaskulärem Fettgewebe bedarf weiterführender Analysen. Auch die klinische Relevanz dieser Befunde konnte die dieser Arbeit zugrundeliegende humane Studie nicht ermitteln und muss Gegenstand zukünftiger Arbeiten sein. 


\section{LITERATURVERZEICHNIS}

Aghamohammadzadeh R, Greenstein AS, Yadav R, Jeziorska M, Hama S, Soltani F, Pemberton PW, Ammori B, Malik RA, Soran H, et al. (2013): Effects of bariatric surgery on human small artery function: evidence for reduction in perivascular adipocyte inflammation, and the restoration of normal anticontractile activity despite persistent obesity. J Am Coll Cardiol 62(2), 128-135

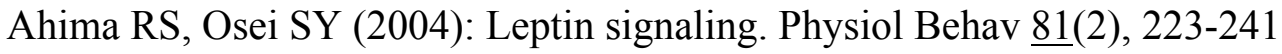

Ahima RS (2005): Central actions of adipocyte hormones. Trends Endocrinol Metab 16(7), $307-313$

Alexopoulos N, McLean DS, Janik M, Arepalli CD, Stillman AE, Raggi P (2010): Epicardial adipose tissue and coronary artery plaque characteristics. Atherosclerosis 210(1), 150154

Asahara T, Murohara T, Sullivan A, Silver M, van der Zee R, Li T, Witzenbichler B, Schatteman G, Isner JM (1997): Isolation of putative progenitor endothelial cells for angiogenesis. Science 275(5302), 964-967

Badimon L, Hernandez Vera R, Vilahur G (2013): Atherothrombotic risk in obesity. Hamostaseologie 33(4), 259-268

Bednarczyk JL, McIntyre BW (1990): A monoclonal antibody to VLA-4 alpha-chain (CDw49d) induces homotypic lymphocyte aggregation. J Immunol 144(3), 777-784

Beltowski J, Wojcicka G, Borkowska E (2002): Human leptin stimulates systemic nitric oxide production in the rat. Obes Res 10(9), 939-946

Berg AH, Scherer PE (2005): Adipose Tissue, Inflammation, and Cardiovascular Disease. Circ Res 96(9), 939-949

Bjorbaek C (1997): Divergent Signaling Capacities of the Long and Short Isoforms of the Leptin Receptor. J Biol Chem 272(51), 32686-32695

Boger RH, Bode-Boger SM, Frolich JC (1996): The L-arginine-nitric oxide pathway: role in atherosclerosis and therapeutic implications. Atherosclerosis $\underline{127(1), 1-11}$

Bosanska L, Michalsky D, Lacinova Z, Dostalova I, Bartlova M, Haluzikova D, Matoulek M, Kasalicky M, Haluzik M (2010): The influence of obesity and different fat depots on adipose tissue gene expression and protein levels of cell adhesion molecules. Physiol Res 59(1), 79-88

Burris RL, Ng HP, Nagarajan S (2014): Soy protein inhibits inflammation-induced VCAM-1 and inflammatory cytokine induction by inhibiting the NF-kappaB and AKT signaling pathway in apolipoprotein E-deficient mice. Eur J Nutr 53(1), 135-148

Bussey CE, Withers SB, Aldous RG, Edwards G, Heagerty AM (2016): Obesity-Related Perivascular Adipose Tissue Damage Is Reversed by Sustained Weight Loss in the Rat. Arterioscler Thromb Vasc Biol 36(7), 1377-1385

Busso N, So A, Chobaz-Peclat V, Morard C, Martinez-Soria E, Talabot-Ayer D, Gabay C (2002): Leptin signaling deficiency impairs humoral and cellular immune responses and attenuates experimental arthritis. J Immunol $\underline{168(2), 875-882}$

Canavan B, Salem RO, Schurgin S, Koutkia P, Lipinska I, Laposata M, Grinspoon S (2005): Effects of physiological leptin administration on markers of inflammation, platelet 
activation, and platelet aggregation during caloric deprivation. J Clin Endocrinol Metab $\underline{90}(10), 5779-5785$

Candela J, Wang R, White C (2017): Microvascular Endothelial Dysfunction in Obesity Is Driven by Macrophage-Dependent Hydrogen Sulfide Depletion. Arterioscler Thromb Vasc Biol 37(5), 889-899

Carlos TM, Schwartz BR, Kovach NL, Yee E, Rosa M, Osborn L, Chi-Rosso G, Newman B, Lobb R, et al. (1990): Vascular cell adhesion molecule-1 mediates lymphocyte adherence to cytokine-activated cultured human endothelial cells. Blood 76(5), 965970

Caspar-Bauguil S, Cousin B, Andre M, Nibbelink M, Galinier A, Periquet B, Casteilla L, Penicaud L (2006): Weight-dependent changes of immune system in adipose tissue: importance of leptin. Exp Cell Res 312(12), 2195-2202

Chatterjee TK, Stoll LL, Denning GM, Harrelson A, Blomkalns AL, Idelman G, Rothenberg FG, Neltner B, Romig-Martin SA, Dickson EW, et al. (2009): Proinflammatory phenotype of perivascular adipocytes: influence of high-fat feeding. Circ Res 104(4), 541-549

Chatterjee TK, Aronow BJ, Tong WS, Manka D, Tang Y, Bogdanov VY, Unruh D, Blomkalns AL, Piegore MG, Jr., Weintraub DS, et al. (2013): Human coronary artery perivascular adipocytes overexpress genes responsible for regulating vascular morphology, inflammation, and hemostasis. Physiol Genomics 45(16), 697-709

Cheng KH, Chu CS, Lee KT, Lin TH, Hsieh CC, Chiu CC, Voon WC, Sheu SH, Lai WT (2008): Adipocytokines and proinflammatory mediators from abdominal and epicardial adipose tissue in patients with coronary artery disease. Int J Obes (Lond) 32(2), 268-274

Claycombe K, King LE, Fraker PJ (2008): A role for leptin in sustaining lymphopoiesis and myelopoiesis. Proc Natl Acad Sci U S A 105(6), 2017-2021

Corradi D, Maestri R, Callegari S, Pastori P, Goldoni M, Luong TV, Bordi C (2004): The ventricular epicardial fat is related to the myocardial mass in normal, ischemic and hypertrophic hearts. Cardiovasc Pathol 13(6), 313-316

Cybulsky MI, Gimbrone MA, Jr. (1991): Endothelial expression of a mononuclear leukocyte adhesion molecule during atherogenesis. Science 251(4995), 788-791

de Ferranti S, Mozaffarian D (2008): The perfect storm: obesity, adipocyte dysfunction, and metabolic consequences. Clin Chem 54(6), 945-955

de Vos AM, Prokop M, Roos CJ, Meijs MF, van der Schouw YT, Rutten A, Gorter PM, Cramer MJ, Doevendans PA, Rensing BJ, et al. (2008): Peri-coronary epicardial adipose tissue is related to cardiovascular risk factors and coronary artery calcification in post-menopausal women. Eur Heart J $\underline{29}(6), 777-783$

DeVerse JS, Sandhu AS, Mendoza N, Edwards CM, Sun C, Simon SI, Passerini AG (2013): Shear stress modulates VCAM-1 expression in response to TNF-alpha and dietary lipids via interferon regulatory factor-1 in cultured endothelium. Am J Physiol Heart Circ Physiol 305(8), H1149-1157

Drosos I, Chalikias G, Pavlaki M, Kareli D, Epitropou G, Bougioukas G, Mikroulis D, Konstantinou F, Giatromanolaki A, Ritis K, et al. (2016): Differences between perivascular adipose tissue surrounding the heart and the internal mammary artery: 
possible role for the leptin-inflammation-fibrosis-hypoxia axis. Clin Res Cardiol $\underline{105}(11), 887-900$

Elices MJ, Osborn L, Takada Y, Crouse C, Luhowskyj S, Hemler ME, Lobb RR (1990): VCAM-1 on activated endothelium interacts with the leukocyte integrin VLA-4 at a site distinct from the VLA-4/fibronectin binding site. Cell 60(4), 577-584

Faggioni R, Fantuzzi G, Fuller J, Dinarello CA, Feingold KR, Grunfeld C (1998): IL-1 beta mediates leptin induction during inflammation. Am J Physiol 274(1 Pt 2), R204-208

Faggioni R, Feingold KR, Grunfeld C (2001): Leptin regulation of the immune response and the immunodeficiency of malnutrition. FASEB J 15(14), 2565-2571

Fantuzzi G, Faggioni R (2000): Leptin in the regulation of immunity, inflammation, and hematopoiesis. J Leukoc Biol 68(4), 437-446

Feral CC, Neels JG, Kummer C, Slepak M, Olefsky JM, Ginsberg MH (2008): Blockade of alpha4 integrin signaling ameliorates the metabolic consequences of high-fat dietinduced obesity. Diabetes 57(7), 1842-1851

Fernandez-Riejos P, Najib S, Santos-Alvarez J, Martin-Romero C, Perez-Perez A, GonzalezYanes C, Sanchez-Margalet V (2010): Role of leptin in the activation of immune cells. Mediators Inflamm 2010, 568343

Ferri C, Desideri G, Valenti M, Bellini C, Pasin M, Santucci A, Giancarlo De M (1999): Early Upregulation of Endothelial Adhesion Molecules in Obese Hypertensive Men. Hypertension 34(4), 568-573

Feuerer M, Herrero L, Cipolletta D, Naaz A, Wong J, Nayer A, Lee J, Goldfine AB, Benoist C, Shoelson S, et al. (2009): Lean, but not obese, fat is enriched for a unique population of regulatory $\mathrm{T}$ cells that affect metabolic parameters. Nat Med $\underline{15}(8), 930-$ 939

Fuster V, Badimon L, Badimon JJ, Chesebro JH (1992): The pathogenesis of coronary artery disease and the acute coronary syndromes (1). N Engl J Med 326(4), 242-250

Go AS, Mozaffarian D, Roger VL, Benjamin EJ, Berry JD, Blaha MJ, Dai S, Ford ES, Fox CS, Franco S, et al. (2014): Heart disease and stroke statistics--2014 update: a report from the american heart association. Circulation $\underline{129}(3)$, e28-e292

Gormez S, Demirkan A, Atalar F, Caynak B, Erdim R, Sozer V, Gunay D, Akpinar B, Ozbek U, Buyukdevrim AS (2011): Adipose Tissue Gene Expression of Adiponectin, Tumor Necrosis Factor- $\alpha$ and Leptin in Metabolic Syndrome Patients with Coronary Artery Disease. Intern Med 50(8), 805-810

Gosswald A, Schienkiewitz A, Nowossadeck E, Busch MA (2013): Prävalenz von Herzinfarkt und koronarer Herzkrankheit bei Erwachsenen im Alter von 40 bis 79 Jahren in Deutschland. Ergebnisse der Studie zur Gesundheit Erwachsener in Deutschland (DEGS1). Bundesgesundheitsblatt Gesundheitsforschung Gesundheitsschutz 56 (5-6), 650-655

Gruver AL, Ventevogel MS, Sempowski GD (2009): Leptin receptor is expressed in thymus medulla and leptin protects against thymic remodeling during endotoxemia-induced thymus involution. J Endocrinol 203(1), 75-85

Gu L, Okada Y, Clinton SK, Gerard C, Sukhova GK, Libby P, Rollins BJ (1998): Absence of monocyte chemoattractant protein-1 reduces atherosclerosis in low density lipoprotein receptor-deficient mice. Mol Cell 2 (2), 275-281 
Gustafson B, Hammarstedt A, Andersson CX, Smith U (2007): Inflamed adipose tissue: a culprit underlying the metabolic syndrome and atherosclerosis. Arterioscler Thromb Vasc Biol 27(11), 2276-2283

Hagita S, Osaka M, Shimokado K, Yoshida M (2011): Adipose inflammation initiates recruitment of leukocytes to mouse femoral artery: role of adipo-vascular axis in chronic inflammation. PLoS One $\underline{6}(5)$, e19871

Hajer GR, van Haeften TW, Visseren FL (2008): Adipose tissue dysfunction in obesity, diabetes, and vascular diseases. Eur Heart J 29(24), 2959-2971

Hemler ME, Huang C, Takada Y, Schwarz L, Strominger JL, Clabby ML (1987): Characterization of the cell surface heterodimer VLA-4 and related peptides. J Biol Chem 262(24), 11478-11485

Hemler ME (1990): VLA proteins in the integrin family: structures, functions, and their role on leukocytes. Annu Rev Immunol $\underline{8}, 365-400$

Henrichot E, Juge-Aubry CE, Pernin A, Pache JC, Velebit V, Dayer JM, Meda P, Chizzolini C, Meier CA (2005): Production of chemokines by perivascular adipose tissue: a role in the pathogenesis of atherosclerosis? Arterioscler Thromb Vasc Biol 25(12), 25942599

Howard JK, Lord GM, Matarese G, Vendetti S, Ghatei MA, Ritter MA, Lechler RI, Bloom SR (1999): Leptin protects mice from starvation-induced lymphoid atrophy and increases thymic cellularity in ob/ob mice. J Clin Invest 104(8), 1051-1059

Hukshorn CJ, van Dielen FM, Buurman WA, Westerterp-Plantenga MS, Campfield LA, Saris WH (2002): The effect of pegylated recombinant human leptin (PEG-OB) on weight loss and inflammatory status in obese subjects. Int J Obes Relat Metab Disord 26(4), 504-509

Hynes RO (1987): Integrins: a family of cell surface receptors. Cell $\underline{48(4), 549-554}$

Iacobellis G, Ribaudo MC, Assael F, Vecci E, Tiberti C, Zappaterreno A, Di Mario U, Leonetti F (2003): Echocardiographic epicardial adipose tissue is related to anthropometric and clinical parameters of metabolic syndrome: a new indicator of cardiovascular risk. J Clin Endocrinol Metab $\underline{88(11), 5163-5168}$

Janssen I, Katzmarzyk PT, Ross R (2004): Waist circumference and not body mass index explains obesity-related health risk. Am J Clin Nutr 79(3), 379-384

Kiguchi N, Maeda T, Kobayashi Y, Fukazawa Y, Kishioka S (2009): Leptin enhances CCchemokine ligand expression in cultured murine macrophage. Biochem Biophys Res Commun 384(3), 311-315

Kishimoto TK, Larson RS, Corbi AL, Dustin ML, Staunton DE, Springer TA (1989): The leukocyte integrins. Adv Immunol 46, 149-182

Kitamura H, Naoe Y, Kimura S, Miyamoto T, Okamoto S, Toda C, Shimamoto Y, Iwanaga T, Miyoshi I (2013): Beneficial effects of Brazilian propolis on type 2 diabetes in ob/ob mice: Possible involvement of immune cells in mesenteric adipose tissue. Adipocyte 2(4), 227-236

Konstantinides S, Schäfer K, Koschnick S, Loskutoff DJ (2001): Leptin-dependent platelet aggregation and arterial thrombosis suggests a mechanism for atherothrombotic disease in obesity. J Clin Invest 108(10), 1533-1540 
Konstantinides S, Schäfer K, Neels JG, Dellas C, Loskutoff DJ (2004): Inhibition of endogenous leptin protects mice from arterial and venous thrombosis. Arterioscler Thromb Vasc Biol 24(11), 2196-2201

Kralisch S, Sommer G, Stangl V, Kohler U, Kratzsch J, Stepan H, Faber R, Schubert A, Lossner U, Vietzke A, et al. (2008): Secretory products from human adipocytes impair endothelial function via nuclear factor kappaB. Atherosclerosis 196(2), 523-531

Lembo G, Vecchione C, Fratta L, Marino G, Trimarco V, d'Amati G, Trimarco B (2000): Leptin induces direct vasodilation through distinct endothelial mechanisms. Diabetes $\underline{49}(2), 293-297$

Li H, Cybulsky MI, Gimbrone MA, Libby P (1993): An atherogenic diet rapidly induces VCAM-1, a cytokine-regulatable mononuclear leukocyte adhesion molecule, in rabbit aortic endothelium. Arterioscler Thromb Vasc Biol 13(2), 197-204

Libby P, Ridker PM, Hansson GK (2009): Inflammation in atherosclerosis: from pathophysiology to practice. J Am Coll Cardiol 54(23), 2129-2138

Libby P (2012): Inflammation in atherosclerosis. Arterioscler Thromb Vasc Biol 32(9), 20452051

Loffreda S, Yang SQ, Lin HZ, Karp CL, Brengman ML, Wang DJ, Klein AS, Bulkley GB, Bao C, Noble PW, et al. (1998): Leptin regulates proinflammatory immune responses. FASEB J 12(1), 57-65

Lord GM, Matarese G, Howard JK, Baker RJ, Bloom SR, Lechler RI (1998): Leptin modulates the T-cell immune response and reverses starvation-induced immunosuppression. Nature 394(6696), 897-901

Lusis AJ (2000): Atherosclerosis. Nature 407(6801), 233-241

Madej T, Boguski MS, Bryant SH (1995): Threading analysis suggests that the obese gene product may be a helical cytokine. FEBS Lett 373(1), 13-18

Maingrette F, Renier G (2003): Leptin increases lipoprotein lipase secretion by macrophages: involvement of oxidative stress and protein kinase C. Diabetes 52(8), 2121-2128

Matarese G, Moschos S, Mantzoros CS (2005): Leptin in immunology. J Immunol 174(6), 3137-3142

Mazurek T, Zhang L, Zalewski A, Mannion JD, Diehl JT, Arafat H, Sarov-Blat L, O'Brien S, Keiper EA, Johnson AG, et al. (2003): Human epicardial adipose tissue is a source of inflammatory mediators. Circulation $\underline{108(20), 2460-2466}$

Mensink GB, Schienkiewitz A, Haftenberger M, Lampert T, Ziese T, Scheidt-Nave C (2013): Übergewicht und Adipositas in Deutschland. Ergebnisse der Studie zur Gesundheit Erwachsener in Deutschland (DEGS1). Bundesgesundheitsblatt Gesundheitsforschung Gesundheitsschutz 56(5-6), 786-794

Mestas J, Ley K (2008): Monocyte-endothelial cell interactions in the development of atherosclerosis. Trends Cardiovasc Med 18(6), 228-232

Moe KT, Naylynn TM, Yin NO, Khairunnisa K, Allen JC, Wong MC, Chin-Dusting J, Wong P (2013): Tumor necrosis factor-alpha induces aortic intima-media thickening via perivascular adipose tissue inflammation. J Vasc Res 50(3), 228-237

Monzillo LU, Hamdy O, Horton ES, Ledbury S, Mullooly C, Jarema C, Porter S, Ovalle K, Moussa A, Mantzoros CS (2003): Effect of lifestyle modification on adipokine levels in obese subjects with insulin resistance. Obes Res 11(9), 1048-1054 
Naseem KM (2005): The role of nitric oxide in cardiovascular diseases. Mol Aspects Med 26(1-2), 33-65

Nishimura S, Manabe I, Nagasaki M, Eto K, Yamashita H, Ohsugi M, Otsu M, Hara K, Ueki K, Sugiura S, et al. (2009): CD8+ effector T cells contribute to macrophage recruitment and adipose tissue inflammation in obesity. Nat Med 15(8), 914-920

Nosalski R, Guzik TJ (2017): Perivascular adipose tissue inflammation in vascular disease. Br J Pharmacol

Park SY, Cho YR, Kim HJ, Higashimori T, Danton C, Lee MK, Dey A, Rothermel B, Kim YB, Kalinowski A, et al. (2005): Unraveling the temporal pattern of diet-induced insulin resistance in individual organs and cardiac dysfunction in C57BL/6 mice. Diabetes 54(12), 3530-3540

Payne GA, Borbouse L, Kumar S, Neeb Z, Alloosh M, Sturek M, Tune JD (2010): Epicardial perivascular adipose-derived leptin exacerbates coronary endothelial dysfunction in metabolic syndrome via a protein kinase C-beta pathway. Arterioscler Thromb Vasc Biol 30(9), 1711-1717

Permana PA, Menge C, Reaven PD (2006): Macrophage-secreted factors induce adipocyte inflammation and insulin resistance. Biochem Biophys Res Commun 341(2), 507-514

Porreca E, Di Febbo C, Fusco L, Moretta V, Di Nisio M, Cuccurullo F (2004): Soluble thrombomodulin and vascular adhesion molecule-1 are associated to leptin plasma levels in obese women. Atherosclerosis 172(1), 175-180

Postigo AA, Pulido R, Campanero MR, Acevedo A, Garcia-Pardo A, Corbi AL, SanchezMadrid F, De Landazuri MO (1991): Differential expression of VLA-4 integrin by resident and peripheral blood $\mathrm{B}$ lymphocytes. Acquisition of functionally active alpha 4 beta 1-fibronectin receptors upon B cell activation. Eur J Immunol 21(10), 24372445

Rega-Kaun G, Kaun C, Wojta J (2013): More than a simple storage organ: adipose tissue as a source of adipokines involved in cardiovascular disease. Thromb Haemost 110(4), 641-650

Relling DP, Esberg LB, Fang CX, Johnson WT, Murphy EJ, Carlson EC, Saari JT, Ren J (2006): High-fat diet-induced juvenile obesity leads to cardiomyocyte dysfunction and upregulation of Foxo3a transcription factor independent of lipotoxicity and apoptosis. J Hypertens 24(3), 549-561

Rocha VZ, Folco EJ, Sukhova G, Shimizu K, Gotsman I, Vernon AH, Libby P (2008): Interferon-gamma, a Th1 cytokine, regulates fat inflammation: a role for adaptive immunity in obesity. Circ Res 103(5), 467-476

Rowlatt C, Chesterman FC, Sheriff MU (1976): Lifespan, age changes and tumour incidence in an ageing C57BL mouse colony. Lab Anim 10(4), 419-442

Ruoslahti E (1988): Fibronectin and its receptors. Annu Rev Biochem 57, 375-413

Saito M, Ishimitsu T, Minami J, Ono H, Ohrui M, Matsuoka H (2003): Relations of plasma high-sensitivity C-reactive protein to traditional cardiovascular risk factors. Atherosclerosis 167(1), 73-79

Sanchez-Margalet V, Martin-Romero C, Santos-Alvarez J, Goberna R, Najib S, GonzalezYanes C (2003): Role of leptin as an immunomodulator of blood mononuclear cells: mechanisms of action. Clin Exp Immunol 133(1), 11-19 
Santos-Alvarez J, Goberna R, Sanchez-Margalet V (1999): Human leptin stimulates proliferation and activation of human circulating monocytes. Cell Immunol 194(1), 611

Schober A, Weber C (2008): Leptin and EPCs in arterial injury: yes, we can! Circ Res 103(5), 447-449

Schroeter MR, Schneiderman J, Schumann B, Gluckermann R, Grimmas P, Buchwald AB, Tirilomis T, Schöndube FA, Konstantinides SV, Schäfer K (2007): Expression of the leptin receptor in different types of vascular lesions. Histochem Cell Biol 128(4), 323333

Schroeter MR, Leifheit M, Sudholt P, Heida NM, Dellas C, Rohm I, Alves F, Zientkowska M, Rafail S, Puls M, et al. (2008): Leptin enhances the recruitment of endothelial progenitor cells into neointimal lesions after vascular injury by promoting integrinmediated adhesion. Circ Res 103(5), 536-544

Schroeter MR, Eschholz N, Herzberg S, Jerchel I, Leifheit-Nestler M, Czepluch FS, Chalikias G, Konstantinides S, Schäfer K (2013): Leptin-dependent and leptin-independent paracrine effects of perivascular adipose tissue on neointima formation. Arterioscler Thromb Vasc Biol 33(5), 980-987

Shamsuzzaman AS, Winnicki M, Wolk R, Svatikova A, Phillips BG, Davison DE, Berger PB, Somers VK (2004): Independent association between plasma leptin and Creactive protein in healthy humans. Circulation 109(18), 2181-2185

Shih PT, Brennan ML, Vora DK, Territo MC, Strahl D, Elices MJ, Lusis AJ, Berliner JA (1999): Blocking Very Late Antigen-4 Integrin Decreases Leukocyte Entry and Fatty Streak Formation in Mice Fed an Atherogenic Diet. Circ Res 84(3), 345-351

Silaghi A, Piercecchi-Marti MD, Grino M, Leonetti G, Alessi MC, Clement K, Dadoun F, Dutour A (2008): Epicardial adipose tissue extent: relationship with age, body fat distribution, and coronaropathy. Obesity (Silver Spring) 16(11), 2424-2430

Simonds SE, Pryor JT, Ravussin E, Greenway FL, Dileone R, Allen AM, Bassi J, Elmquist JK, Keogh JM, Henning E, et al. (2014): Leptin mediates the increase in blood pressure associated with obesity. Cell $\underline{159}(6), 1404-1416$

Skurk T, Alberti-Huber C, Herder C, Hauner H (2007): Relationship between adipocyte size and adipokine expression and secretion. J Clin Endocrinol Metab 92(3), 1023-1033

Stary HC, Chandler AB, Dinsmore RE, Fuster V, Glagov S, Insull W, Jr., Rosenfeld ME, Schwartz CJ, Wagner WD, Wissler RW (1995): A definition of advanced types of atherosclerotic lesions and a histological classification of atherosclerosis. A report from the Committee on Vascular Lesions of the Council on Arteriosclerosis, American Heart Association. Arterioscler Thromb Vasc Biol 15(9), 1512-1531

Statistisches Bundesamt: Gesundheit - Todesursachen in Deutschland 2012. Fachserie 12, Reihe 4. Wiesbaden 2013

Stewart-Phillips JL, Lough J (1991): Pathology of atherosclerosis in cholesterol-fed, susceptible mice. Atherosclerosis $\underline{90}(2-3), 211-218$

Tian Z, Sun R, Wei H, Gao B (2002): Impaired natural killer (NK) cell activity in leptin receptor deficient mice: leptin as a critical regulator in NK cell development and activation. Biochem Biophys Res Commun 298(3), 297-302 
Venugopal SK, Devaraj S, Jialal I (2005): Effect of C-reactive protein on vascular cells: evidence for a proinflammatory, proatherogenic role. Curr Opin Nephrol Hypertens $\underline{14}(1), 33-37$

Wang YI, Schulze J, Raymond N, Tomita T, Tam K, Simon SI, Passerini AG (2011): Endothelial inflammation correlates with subject triglycerides and waist size after a high-fat meal. Am J Physiol Heart Circ Physiol 300(3), H784-791

Weisberg SP, McCann D, Desai M, Rosenbaum M, Leibel RL, Ferrante AW (2003): Obesity is associated with macrophage accumulation in adipose tissue. J Clin Invest 112(12), 1796-1808

Wolk R, Berger P, Lennon RJ, Brilakis ES, Johnson BD, Somers VK (2004): Plasma leptin and prognosis in patients with established coronary atherosclerosis. J Am Coll Cardiol 44(9), 1819-1824

Yudkin JS, Kumari M, Humphries SE, Mohamed-Ali V (2000): Inflammation, obesity, stress and coronary heart disease: is interleukin-6 the link? Atherosclerosis 148(2), 209-214

Zhang Y, Proenca R, Maffei M, Barone M, Leopold L, Friedman JM (1994): Positional cloning of the mouse obese gene and its human homologue. Nature $\underline{372(6505), 425-}$ 432

Zhao Y, Sun R, You L, Gao C, Tian Z (2003): Expression of leptin receptors and response to leptin stimulation of human natural killer cell lines. Biochem Biophys Res Commun $\underline{300}(2), 247-252$ 


\section{DANKSAGUNG}

Zunächst gilt mein Dank Herrn Prof. Dr. med. Gerd Hasenfuß für die Möglichkeit, in seiner Abteilung zu promovieren.

Mein besonderer Dank gilt Frau Prof. Dr. med. Katrin Schäfer für die Bereitstellung des Themas und die Möglichkeit, diese Arbeit in ihrer Arbeitsgruppe anzufertigen. Weiterhin danke ich ihr für ihre umfassende und kompetente Betreuung. Es war mir immer möglich, mit fachlichen und inhaltlichen Fragen auf sie zuzukommen.

Für die Betreuung während der Durchführung der Versuche und bei der Auswertung vor allem der Fluoreszenzzytometrie danke ich Herrn PD Dr. med. Marco Schroeter.

Für die Bereitstellung der humanen Präparate und Aufklärung der Patienten über die Entnahme während des geplanten Eingriffes danke ich Herrn Dr. med. Theodor Tirilomis aus der Klinik für Thorax-, Herz- und Gefäßchirurgie der Universitätsmedizin Göttingen.

Weiterhin danke ich Herrn Dr. med. Norman Eschholz ausdrücklich für die gute Kooperation und Zusammenarbeit im Rahmen unserer Experimente zur atherogenen Wirkung von Leptin.

Mein ausdrücklicher Dank gilt der gesamten Arbeitsgruppe, insbesondere unseren MTAs Sarah Barke und Anika Hunold, die mit ihrer unermüdlichen Unterstützung und Einarbeitung den Erfolg der Auswertungen und Versuche maßgeblich gewährleistet haben. Sie waren stets Ansprechpartner und Problemlöser und haben die vielen Präparate exzellent aufgearbeitet und somit die Grundlage für die Ergebnisse geschaffen. Ebenfalls danken möchte ich Frau Dr. med. Magdalena Beham, Dr. med. Hendrik Kuschicke sowie Markus Bernhardt für die ständige gegenseitige Motivation und konstruktive Vorschläge zur stetigen Verbesserung unserer wissenschaftlichen Arbeit. Ohne diese angenehmen und netten Stunden wäre die trockene Laborarbeit um einiges zäher und langweiliger gewesen.

Weiterhin gilt der Dank meiner Familie sowie meiner Freundin, die stets hinter mir standen und immer neue Motivation geleistet haben. Ohne sie wäre diese Dissertation nicht in dieser Form entstanden und wohlmöglich ewig unvollendet auf meinem MacBook verschollen. 